Aus der Klinik für Dermatologie, Venerologie und Allergologie

(Prof. Dr. med. M. P. Schön)

der Medizinischen Fakultät der Universität Göttingen

\title{
Funktionelle Defekte von dermalen innate lymphoid cells type 2 (dILC2) in RAG1-defizienten Mäusen
}

\author{
INAUGURAL-DISSERTATION \\ zur Erlangung des Doktorgrades \\ der Medizinischen Fakultät der \\ Georg-August-Universität zu Göttingen
}

vorgelegt von

\author{
Mohamed Mahde Saleh \\ aus \\ Bagdad, Irak
}

Göttingen 2020 
Dekan:

Referent/in

Ko-Referent/in:

Drittreferent/in:
Prof. Dr. med. W. Brück

Prof. Dr. med. T. Buhl

Datum der mündlichen Prüfung: 
Hiermit erkläre ich, die Dissertation mit dem Titel „Funktionelle Defekte von dermalen innate lymphoid cells type 2 (dILC2) in RAG1-defizienten Mäusen“ eigenständig angefertigt und keine anderen als die von mir angegebenen Quellen und Hilfsmittel verwendet zu haben.

Göttingen, den 


\section{Inhaltsverzeichnis}

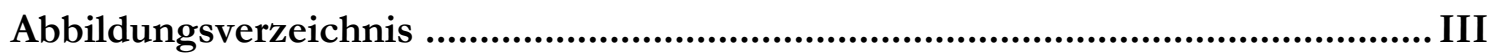

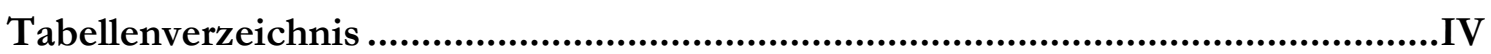

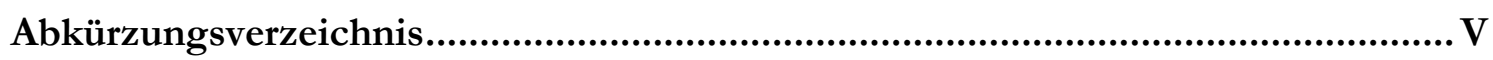

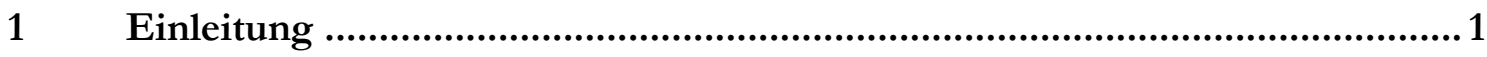

1.1 Die Dichotomie des menschlichen Immunsystems .................................................................

1.2 Nomenklatur und Klassifizierung von innate-like lymphoid cells ...................................................2

1.2.1 ILC beim Menschen und der Maus .....................................................................................

1.2.2 ILC2 - Auftreten und Funktion....................................................................................

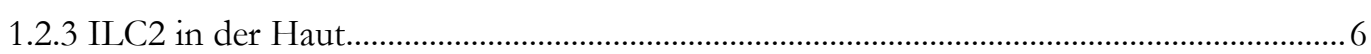

1.2.4 ILC2 - Mediatoren für entzündliche und allergische Hauterkrankungen ..........................7

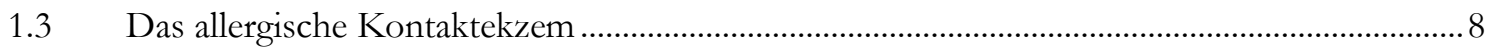

1.3.1 Die Sensibilisierungsphase ..............................................................................................

1.3.2 Die Entzündungs- und Regulationsphase.......................................................................... 10

1.3.3 Die Rolle von ILC2 beim allergischen Kontakekzem ...................................................11

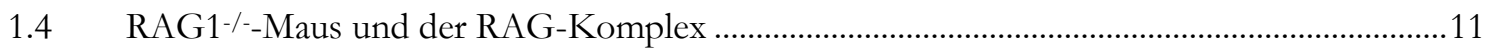

1.4.1 RAG1/RAG2 - traditionelle Funktion..........................................................................12

1.4.2 Die molekularen Mechanismen des RAG-Komplexes.......................................................13

1.4.3 Der RAG-Komplex stabilisiert das Lymphozyten-Genom ............................................14

1.4.4 Die Rolle von RAG in ILC .............................................................................................15

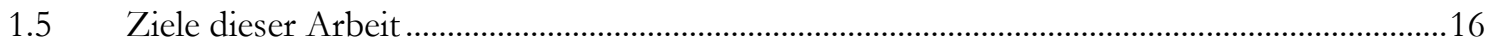

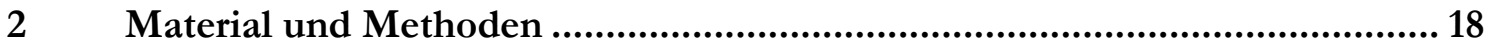

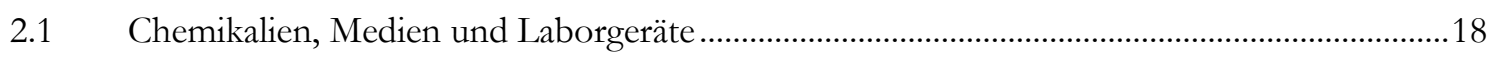

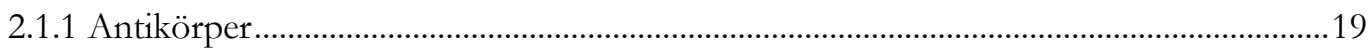

2.1.2 Verbrauchsmaterialien...............................................................................................2

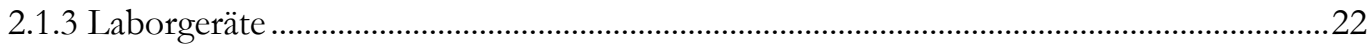

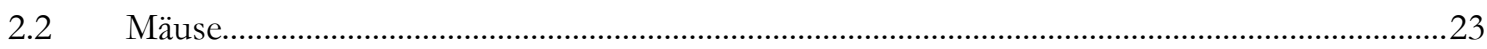

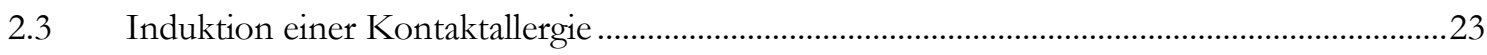

2.3.1 Induktion einer DNFB-Kontaktallergie.......................................................................24

2.3.2 Adoptiver Transfer von W'T-Lymphozyten in RAG1/--Mäuse.........................................25

$2.4 \quad$ Isolation von Zellen aus der Haut und Antikörperfärbung......................................................26

2.4.1 Färbung intrazellulärer Antigene ......................................................................................2

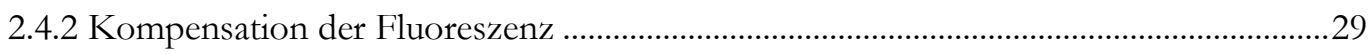

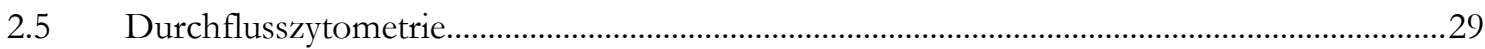


2.6 Apoptose-Assays mit Annexin-V- und Caspase-3/7-Färbung .............................................3

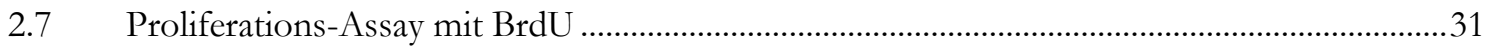

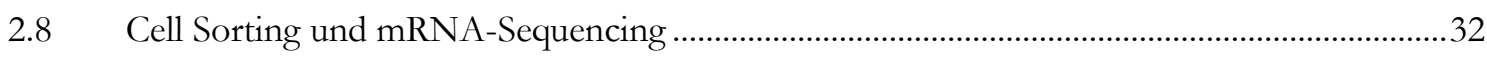

2.8.1 RNA Präparation, Qualitätskontrolle und Quantitätsmessung......................................32

2.8.2 Bioinformatische Analyse (mapping und normalization) ..................................................33

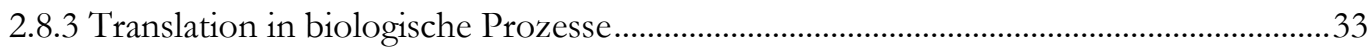

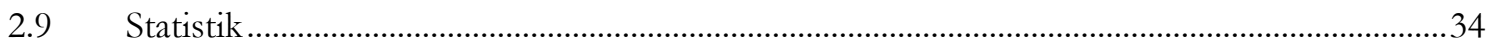

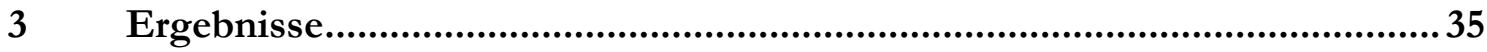

3.1 Identifikation und gating von dILC2 mittels FACS …...........................................................35

3.1.1 RAG1-/-Mäuse haben signifikant höhere absolute dILC2-Zahlen als WT-Mäuse .......36

3.1.2 RAG1-/--Mäuse zeigen auch relativ mehr dILC2 als WT-Mäuse....................................37

3.1.3 ICOS- und GATA3-Expression variiert nicht zwischen WT- und RAG1-defizienten

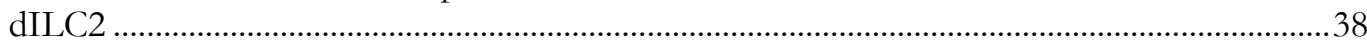

3.2 RNA-Sequenzierung zeigt zahlreiche unterschiedlich exprimierte Gene zwischen WTund RAG1-defizienten dILC2.

3.2.1 Die unterschiedlich regulierten Gene sind mit Signalwegen assoziiert, die verantwortlich sind für T-Zell-Immunantwort, Proliferation, viraler und parasitärer Abwehr und Autoimmun-Prozessen.......................................................................................41

3.2.2 Mehrere Zytokine und Zytokin-Rezeptoren werden unterschiedlich exprimiert..........43

3.3 Im DNFB-Kontaktallergie-Modell sinken die dILC2 in RAG1-/--Mäusen ...........................45

3.4 RAG1-defiziente dILC2 zeigen eine höhere Annexin-V-Expression sowie vermehrt Caspase-3/7-Spaltprodukte

3.5 RAG1-defiziente dILC2 zeigen eine höhere Proliferationsrate und einen höher exprimierten IL-7-Rezeptor....

$4 \quad$ Diskussion.................................................................................... 52

4.1 RAG1---Mäuse besitzen mehr dILC2 als WT-Mäuse............................................................52

4.1.1 Aktivierung und Differenzierung nach ICOS und GATA3 unterscheiden sich nicht.54

4.1.2 Schwierigkeiten mit der Definition und Nomenklatur von ILC2 in der Haut..... 55

4.2 Die unterschiedliche Dynamik der dILC2 im DNFB-Kontaktallergie-Modell in WT- und RAG1---Mäusen.

4.3 RNA-Sequenzierung zeigt ein stark verändertes Gen-Expressionsprofil in RAG1-

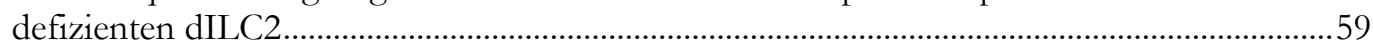

4.3.1 RAG1-defiziente dILC2 neigen zur Apoptose ............................................................62

4.3.2 Der IL-7-Rezeptor ist in RAG1-defizienten dILC2 höher exprimiert..........................63

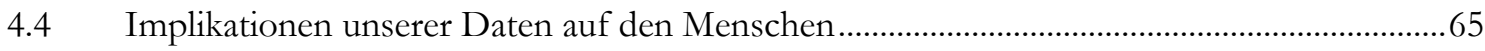

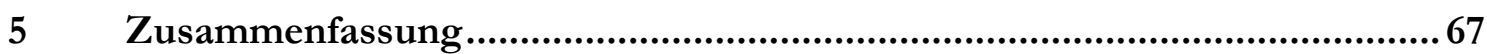

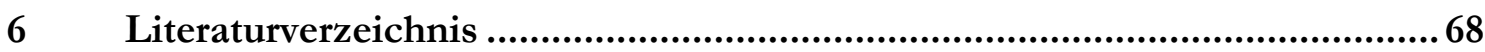




\section{Abbildungsverzeichnis}

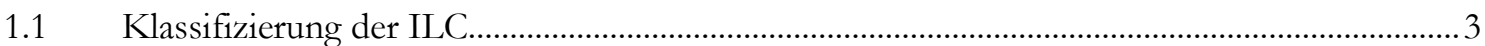

1.2 Pathogenese des allergischen Kontaktekzems ..........................................................................

1.3 Molekulare Strukturen und Ablauf der RAG-Spaltaktivität .........................................................13

1.4 Schicksal der Zelle nach RAG-induzierten DNA-Doppelstrangbrüchen.................................15

$1.5 \quad$ Illustration der Fragestellung dieser Dissertation....................................................................

2.1 Experimenteller Aufbau zur Induktion einer DNFB-CHS.......................................................24

2.2 Adoptiver Transfer von WT-Lymphozyten in RAG1--Mäuse .................................................25

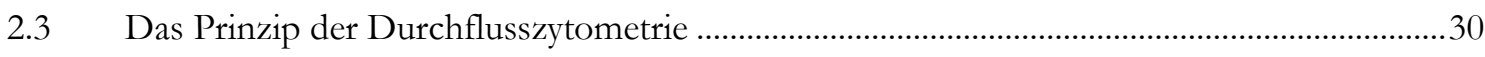

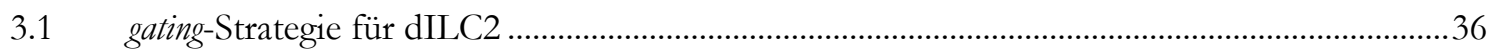

3.2 RAG1\%-Mäuse weisen absolut mehr dILC2 als WT-Mäuse auf ..................................................37

3.3 RAG1\%-Mäuse haben relativ mehr dILC2 als WT-Mäuse ...........................................................38

3.4 RAG1-defiziente dILC2 zeigen eine ähnliche GATA3- und ICOS-Expression ......................39

3.5 Über 2000 Gene sind in RAG1-defizienten dILC2 unterschiedlich reguliert ...........................40

3.6 Immunantwort, Proliferation sowie Autoimmun-Signalwege werden in RAG1-defizienten dILC2 unterschiedlich reguliert................................................................................................42

3.7 RAG1-defiziente dILC2 zeigen in den Sequenzierungs-Daten einen aktivierten Phänotyp.44

3.8 Im DNFB-Kontaktallergie-Modell zeigen WT- und RAG1-defiziente dILC2 eine

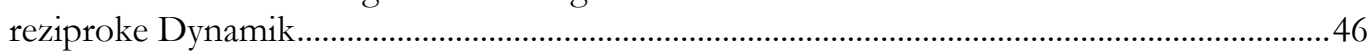

3.9 Der adoptive Transfer von WT-Lymphozyten kann die beobachtete dILC2-Dynamik

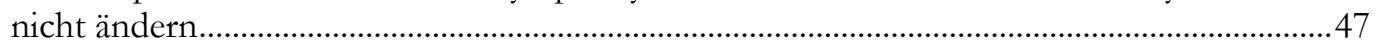

3.10 RAG1-defiziente dILC2 haben eine erhöhte Apoptose-Affinität in Ruhe...............................48

3.11 Eine erhöhte Caspase-3/7-Aktivität bedingt die erhöhte Apoptose-Affinität von RAG1-

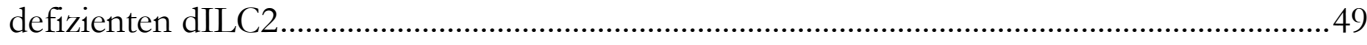

3.12 Der IL-7-Rezeptor ist in RAG1-defizienten dILC2 stärker exprimiert......................................50

3.13 RAG1-defiziente dILC2 haben eine erhöhte Proliferationsrate .................................................51

4.1 dILC2 zeigen in RAG1\%-Mäusen ein stark verändertes Gen-Expressionsprofil, wobei sowohl die Apoptose und die Proliferation als auch das allgemeine Zytokinprofil beeinflust werden 


\section{Tabellenverzeichnis}

2.1 Verwendete Chemikalien und Medien mit Firma und Standort...............................................18

2.2 Im Durchflusszytometer verwendete Antikörper mit zugehörigem Typ, dem UrsprungsOrganismus (bost), gebundenem Farbstoff, Klon sowie Firma und Standort .........................19

2.3 Oberflächenmarker sowie beschriebene Funktionen ................................................................20

2.4 Verbrauchsmaterialien mit Firma und Standort.......................................................................21

2.5 Verwendete Laborgeräte mit Firma und Standort .......................................................................22

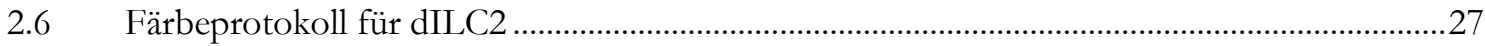




\section{Abkürzungsverzeichnis}

\begin{tabular}{|c|c|}
\hline 7-AAD & 7-Aminoactinomycin \\
\hline Areg & Amphiregulin \\
\hline APC & Allophycocyanin \\
\hline AT & Adoptiver Transfer \\
\hline CHS & contact hypersensitivity \\
\hline $\mathrm{CD}$ & cluster of differentiation \\
\hline DNFB & 1-Fluor-2,4-dinitrobenzol \\
\hline DSB & DNA-Doppelstrangbrüche \\
\hline FACS & fluorescence-activated cell sorting \\
\hline FITC & Fluoreszin-Isothiocyanat \\
\hline FMO & fluorescence minus one \\
\hline GATA3 & GATA-binding protein 3 \\
\hline GO & gene ontology \\
\hline ICOS & inducible T-cell costimulator \\
\hline IETC & intraepidermal T cells \\
\hline IFN & Interferon \\
\hline IL/IL-R & Interleukin/Interleukin-Rezeptor \\
\hline ILC & innate-like lymphoid cells \\
\hline dILC2 & dermal innate-like lymphoid cells type 2 \\
\hline iILC2 & inflammatory innate-like lymphoid cells type 2 \\
\hline nILC2 & natural innate-like lymphoid cells type 2 \\
\hline JAK3 & Janus-Kinase 3 \\
\hline KEGG & Kyoto Encyclopedia of Genes and Genomes \\
\hline MHC & major histocompatibility complex \\
\hline MFI & mean fluorescence intensity \\
\hline MyD88 & myeloid differentiation primary response 88 \\
\hline NIG & Network of Integrative Genomics \\
\hline NK-Zellen & Natürliche Killerzellen \\
\hline PBS & phosphate-buffered saline \\
\hline PE & Phycoerythin \\
\hline PerCP & Peridinin-Cholophyll \\
\hline $\mathrm{RAG} 1 / 2$ & recombination activation gene 1 and 2 \\
\hline RAR & retinoic acid receptor \\
\hline RNA/DNA & ribonucleic acid/deoxyribonucleic acid \\
\hline $\mathrm{ROR} \alpha / \gamma \mathrm{t}$ & $\mathrm{R} A \mathrm{R}$-related orphan receptor alpha/gamma-thymus \\
\hline SCID & severe combined immunodeficiency \\
\hline STAT & signal transducers and activators of transcription \\
\hline TCR & T cell receptor \\
\hline TH1/2/17 & T-Helfer-Zelle Тyр 1, Typ 2 oder Tyр 17 \\
\hline TNCB & 1-Chlor-2,3,4-trinitrobenzol \\
\hline TLR & toll-like receptor \\
\hline VDJ & variety, diversity, joining \\
\hline Veh & Vehikel \\
\hline WT & Wildtyp \\
\hline
\end{tabular}




\section{$1 \quad$ Einleitung}

\subsection{Die Dichotomie des menschlichen Immunsystems}

Das menschliche Immunsystem dient dem Schutz des menschlichen Organismus vor pathogenen Keimen und Substanzen. Zusätzliche Aufgaben sind die Aufrechterhaltung einer physiologischen Homöostase der residenten Bakterien-Flora sowie die Geweberegeneration und -reparation (Iwasaki und Medzhitov 2010).

Traditionell prägt eine strenge Dichotomie die Systematik des menschlichen Immunsystems: Es wird aufgeteilt in ein angeborenes und erworbenes bzw. unspezifisches und spezifisches, sowie ein zelluläres und humorales Immunsystem. Das angeborene Immunsystem ist fokussiert auf die breite Immunabwehr durch das Erkennen von pathogenen Mustern über pattern recognition receptors (PRR) (Janeway 1989). Verschiedene Zellen und Rezeptoren werden dem angeborenen Immunsystem zugerechnet, darunter Makrophagen, Granulozyten und Natürliche Killerzellen (NK-Zellen). Demgegenüber steht das spezifische, erworbene Immunsystem: Zellulär werden B- und T-Zellen unterschieden, die sich wiederum in B1- und B2-Zellen sowie T-Helfer-Zellen 1, 2 und $17\left(\mathrm{~T}_{\mathrm{H}} 1-, \mathrm{T}_{\mathrm{H}} 2\right.$ - und $\mathrm{T}_{\mathrm{H}} 17-$ Zellen$)$ aufteilen lassen. Über komplexe Mechanismen wird über einen Proteinkomplex aus recombination activation gene 1 und recombination activation gene 2 (RAG1 und RAG2) eine Rekombination bestimmter Gen-Segmente (sog. VDJ-Segmente, nach variety, diversity und joining) der Rezeptor der T-Zellen (t-cell receptor; TCR, T-Zell-Rezeptor) generiert, sodass eine enorme Diversität und Spezifität der Oberflächenerkennung möglich ist (Oettinger et al. 1990).

Diese Zweiteilung wurde über Jahrzehnte aufrechterhalten. Mittlerweile legen aber neue Erkenntnisse nahe, dass diese strenge Zweiteilung des Immunsystems nicht sinnvoll ist. Durch die Verbesserung laborexperimenteller Methoden werden regelmäßig neue Subtypen von Immunzellen identifiziert und immer mehr bzw. immer differenziertere Mechanismen der Kommunikation aufgeschlüsselt. Dadurch wird das bisherige Wissen beständig erweitert, wodurch ein völlig neues Verständnis des Immunsystems erforderlich wird. 


\subsection{Nomenklatur und Klassifizierung von innate-like lymphoid cells}

Innate-like lymphoid cells (ILC) sind eine Gruppe von angeborenen Immunzellen, die sich nicht eindeutig in die Dichotomie des angeborenen oder erworbenen Immunsystems einordnen lassen. Entwicklungsgeschichtlich werden sie einerseits zum angeborenen Immunsystem gerechnet, andererseits produzieren sie Zytokine und Transkriptionsfaktoren, die typisch für das erworbene Immunsystem sind. Die bisher am längsten bekannten ILC sind NK-Zellen und lymphoid-tissue inducer cells (LTi Zellen), die bereits seit mehreren Jahrzehnten bekannt und seither Gegenstand extensiver Forschung sind (Kiessling et al. 1975; Mebius et al. 1997). Allen ILC gemein ist das Fehlen von spezifischen Rezeptoren (wie z. B. des TCR), das Fehlen spezifischer Marker der myeloiden Zellreihe sowie ihr lymphoider Phänotyp einschließlich der Produktion von Lymphozyten-typischen Transkriptionsfaktoren und Zytokinen (Spits et al. 2013).

Eine große Schwierigkeit bei der Beschreibung der ILC ist die wechselhafte und uneinheitliche Klassifikation bzw. Nomenklatur. Spits et al. (2013) haben sich an einer einheitlichen Nomenklatur versucht, die die ILC in drei verschiedene Gruppen einteilt (ILC1, ILC2 und ILC3). Dabei handelt es sich meines Erachtens um eine wegen ihrer Einfachheit und Vollständigkeit hilfreiche Einteilung, die auch in dieser Dissertation weiterverwendet wird. Abb. 1.1 gibt einen Einblick in die Klassifizierung und Einteilung der ILC.

Die Entstehung aller ILC geht von einer gemeinsamen inbibitor of DNA-binding protein 2 positiven (ID2 ${ }^{+}$) ILC-Vorläuferzelle aus (Verykokakis et al. 2014). ILC1 zeichnen sich durch die Expression des Tbox transcription factors 21 (TBX21, oder auch T-bet) und die Produktion klassischer $\mathrm{T}_{\mathrm{H}} 1-Z y t o k i n e ~ w i e ~ I n t e r f e r o n$ gamma (IFN $\gamma$ ) oder den Tumor-Nekrose-Faktor alpha (TNF $\alpha$ ) aus (Daussy et al. 2014). Wenn zusätzlich Eoemesodermin (EOMES) exprimiert wird, dann entwickeln sich NK-Zellen, die anders als die ILC1 über zytotoxische Proteine verfügen, wie beispielsweise Granzyme und Perforine (Gordon et al. 2012). ILC2 exprimieren als Transkriptionsfaktoren das GATA-binding protein 3 (GATA3) und den RAR-related orphan receptor alpha $(\mathrm{ROR} \alpha)$ (Wong et al. 2012; Yagi et al. 2014). Sie produzieren $\mathrm{T}_{\mathrm{H}} 2$-polarisierende Zytokine wie die Interleukine 4, 5 oder 13 (IL-4, IL-5 oder IL-13, IL; Interleukin) (Fallon et al. 2006). Die Aktivierung von ILC2 erfolgt vor allem über die Stimulation durch IL-25, IL-33 sowie thymic stromal lymphopoitein (TSLP) (gell et al. 2001; Halim et al. 2012; Hurst et al. 2002; Kim et al. 2013). Als letzte Gruppe seien die ILC3 genannt, die der $T_{H} 17$-Gruppe entsprechen. Sie produzieren nach der Expression von $\mathrm{R}$ AR-related orphan receptor gamma-thymus (ROR $\gamma \mathrm{t}$ ) Zytokine wie IL-17 oder IL-22 (Eberl et al. 2004). 


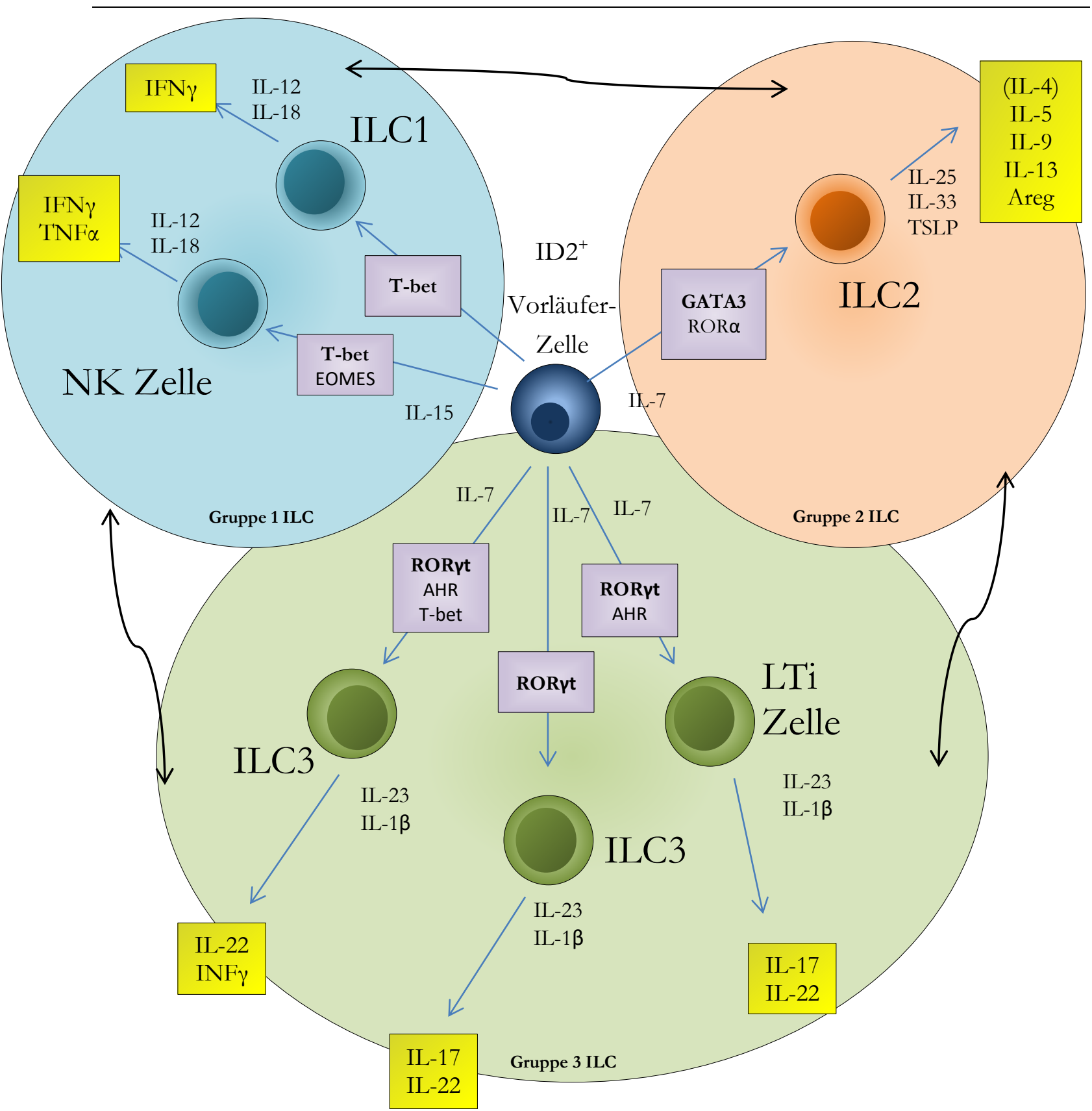

Abb. 1.1: Klassifizierung der ILC. Innate-like lymphoid cells können in drei verschiedene Gruppen eingeteilt werden: ILC1, ILC2 und ILC3. Interleukin-7 (IL-7), aber auch IL-15 stellen wichtige Überlebensund Differenzierungsfaktoren dar (Moro et al. 2010). Die Pfeile in der Abbildung kennzeichnen den jeweiligen Differenzierungsweg, die daneben aufgeführten Zytokine stellen Faktoren dar, die den jeweiligen Weg induzieren und triggern. Die violetten Rechtecke kennzeichnen die exprimierten Transkriptionsfaktoren. In den gelben Rechtecken stehen die von den jeweiligen Zellen produzierten Zytokine. Die schwarzen Pfeile zwischen den Gruppen beziehen sich darauf, dass die ILC der verschiedenen Gruppen ihr Transkriptions- und Polarisationsprofil ändern und dann den anderen Gruppen zugerechnet werden können. Diese interzelluläre Plastizität wird für alle Gruppen von ILC beschrieben (Abbildung modifiziert nach Artis und Spits 2015; Spits et al. 2013). 


\subsubsection{ILC beim Menschen und der Maus}

ILC wurden das erste Mal in der Maus entdeckt und beschrieben. Dennoch existieren zahlreiche Studien, die ILC im Menschen beschreiben und die Rolle bei der Gewebe-Homöostase und Pathologien herausstellen (Hazenberg und Spits 2014). Man hat festgestellt, dass humane ILC teilweise andere Marker exprimieren und anders als die murinen, also von der Maus stammenden, ILC zu identifizieren sind. Um den Unterschieden auf den Grund zu gehen, haben Simoni et al. (2017) das Transkriptom sowohl humaner als auch muriner ILC-Zellpopulationen durch aufwendiges single cell sequencing (Einzelzell-Sequenzierung) unter physiologischen und pathologischen Bedingungen untersucht. Nach diesen Studien wurde beim Menschen keine distinkte ILC1-Zellpopulation gefunden. Es wurden Zellen identifiziert, die den klassischen ILC1-Phänotyp aufweisen, aber andere Marker passten nicht in das Bild. Eine Erklärung bestehe darin, dass es sich bei den in der Literatur beschriebenen humanen ILC1 möglicherweise um Kontaminationen mit NK-Zellen oder anderen ILC handeln könnte. ILC2 und ILC3 konnten jedoch im Menschen nachgewiesen werden und passten größtenteils zu den murinen ILC2 und ILC3. Dennoch wurden bis dahin in der Literatur Subgruppen und Eigenschaften definiert, die in den von Simoni et al. (2017) durchgeführten Untersuchungen nicht aufzufinden waren. So wurden etwa Unterschiede in der Expression von Oberflächenantigenen festgestellt, wie z. B. des major histocompatibility complex II (MHC II), des inducible T-cell costimulator-ligand (ICOS-L) sowie des IL2R. Auch die Transkriptionsfaktoren GATA3 und T-bet waren unterschiedlich stark exprimiert. Die Regulation und Kommunikation mit anderen Zellreihen des Immunsystems sowie die interzelluläre Plastizität der ILC schienen ebenso unterschiedlich zu sein. Zusammenfassend ist davon auszugehen, dass sich die Daten, die zu murinen ILC existieren, nicht vollständig auf humane ILC übertragen lassen. In den Experimenten dieser Dissertation liegt der Fokus auf den murinen ILC2.

\subsubsection{ILC2 - Auftreten und Funktion}

Wie die anderen ILC benötigen auch die ILC2 den common gamma chain receptor ( $\gamma$ c-Rezeptor oder IL-2R $\gamma$ ), die Janus-Kinase 3-Signalwege (JAK3) sowie ID2 für ihre Entwicklung aus der gemeinsamen Vorläuferzelle (Moro et al. 2010; Robinette et al. 2018; Verykokakis et al. 2014). Zusätzlich exprimieren sie den IL-7-Rezeptor (CD127, CD: cluster of differentiation), der von zentraler Bedeutung für ihre Entwicklung, Differenzierung und Funktion ist (Vonarbourg und Diefenbach 2012). In IL-7R $\mathrm{R}^{-/}$-Mäusen kommt es zu einem beinahe vollständigen Fehlen vitaler 
ILC2 (Robinette et al. 2017). Die überlebenswichtigen exprimierten Transkriptionsfaktoren entsprechen denjenigen, die auch für die $\mathrm{T}_{\mathrm{H}} 2$-Differenzierung verantwortlich sind, nämlich GATA3 und ROR $\alpha$ (Yagi et al. 2014).

Als Antwort auf eine Stimulation mit IL-25, IL-33, TSLP oder TNF-like ligand 1 A (TL1A) produzieren sie $\mathrm{T}_{\mathrm{H}}$ 2-typische Zytokine wie IL-5, IL-9, IL-13 und in kleineren Mengen auch IL-4 und Amphiregulin (Areg). Nach der Aktivierung kommt es klassischerweise zu einer erhöhten Expression von killer cell lectin-like receptor subfamily G member 1 (KLRG1), ICOS und homing cell adhesion molecule (HCAM; CD44) (Huang et al. 2015, Nussbaum et al. 2013).

ILC2 interagieren mit verschiedenen Zellen des angeborenen und erworbenen Immunsystems. Einerseits ist eine Kommunikation mit $\mathrm{CD}^{+}{ }^{+}$T-Zellen über MHC-II:CD4-Proteinkomplexe bekannt, andererseits spielt eine Interaktion über ICOS:ICOS-L eine zentrale Rolle (Maazi et al. 2015; Oliphant et al. 2014).

Neuere Studien haben gezeigt, dass ILC2 in Abhängigkeit von umgebenden Zytokinen und Entzündungssignalen auch zu anderen ILC polarisiert werden können. Nach einer in vitro oder in vivo Gabe von IL-1 $\beta$ zeigen ILC2 eine Induktion von T-bet, eine Heraufregulation von IL12Rß2 (der Beta-2-Kette des Rezeptors) sowie eine Produktion von INFy (Ohne et al. 2016). Dies sind allerdings Merkmale, die ILC1 zugeschrieben werden. Weitere Arbeitsgruppen haben gezeigt, dass die ILC2 nach der Hinzugabe von IL-25 einen „,natürlichen“ und „,inflammatorischen“ Phänotyp annehmen, der auch als nILC2 und ilLC2 bezeichnet wird. Die iILC2 wiesen dabei eine niedrigere Expression von thymocyte antigene 1 (Thy1; CD90) und CD44 auf und haben große Mengen der für ILC3 typischen Zytokine wie IL-17 und IL-22 produziert (Huang et al. 2015). Diese Plastizität vergrößert weiterhin die immunologische Kapazität der ILC2 und unterstreicht ihre wichtige Rolle in der Regulation von komplexen Immunantworten.

ILC2 treten in vielen verschiedenen Organen wie der Haut, der Leber, dem Fettgewebe, den Lymphknoten, der Lunge sowie im Magen-Darm-Trakt auf. Initial wurden sie innerhalb der intestinalen Mukosa entdeckt. Dabei wurde gezeigt, dass nach systemischer Stimulation mit IL25 große Mengen IL-5 produziert werden und dies dort für eine Immunabwehr gegen Nippostrongylus brasiliensis sorgt, auch in RAG1\%-Mäusen, die keine B- und T-Zellen besitzen (Fallon et al. 2006; Hurst et al. 2002). Im weiteren Verlauf wurden auch in anderen Organen Zellen identifiziert, die nicht zu den T-Zellen gehörten, jedoch große Mengen an $\mathrm{T}_{\mathrm{H}} 2$-typischen Zytokinen produzierten. Ihre Bezeichnungen variierten zwischen natural helper cells, nuocytes sowie $I_{H} 2-$ cells (innate helper cells) (Moro et al. 2010; Neill et al. 2010; Price et al. 2010). Später konnten diese Beschreibungen einer gemeinsamen und distinkten Zellpopulation zugeordnet werden, nämlich 
den ILC2. Die ILC2 spielen jedoch nicht nur eine wichtige Rolle in der Immunabwehr, es gibt auch Indizien dafür, dass sie essentiell für die Transformation von weißem zu braunem Fettgewebe sind und somit auch in die Pathogenese der Adipositas involviert sein könnten (Lee et al. 2015).

Außerdem wird den ILC2 eine zentrale Rolle in der Pathogenese des allergischen Asthmas und der entzündlichen Hauterkrankungen wie z. B. der atopischen Dermatitis zugeschrieben (Bernink et al. 2014; Roediger et al. 2014).

\subsubsection{ILC2 in der Haut}

Es existieren bisher nur wenige Arbeiten, die sich näher mit der Relevanz der ILC2 in der Haut beschäftigt haben. Die ILC werden in der Regel durch eine sog. Negativ-Selektion definiert, also durch das Nicht-Vorhandensein bestimmter Antigene, die bei allen anderen Immunzellen auftreten. Wichtige Aktivatoren der ILC2 in der Haut sind IL-25, IL-33, TSLP, aber auch IL-2. Nach der Aktivierung nehmen die ILC2 in der Haut einen aktivierten Phänotyp an und exprimieren große Mengen ihrer Effektor-Zytokine IL-5, IL-13 und in kleinen Mengen IL-4. Außerdem existieren Berichte darüber, dass die ILC2 Areg produzieren, dem eine Schlüsselrolle bei der Proliferation und Apoptose von epithelialen Zellen zukommt (Salimi et al. 2013). ILC2 besitzen dementsprechend neben der Immunantwort auf ein Pathogen eine wichtige regulatorische Funktion bei der Gewebereparation und Wundheilung. ILC2 konnten in der Haut des Menschen und der Maus nachgewiesen werden, obwohl sie im Menschen einen anderen Phänotyp aufweisen. Daher wird davon ausgegangen, dass sich ILC2 in der menschlichen Haut anders verhalten als in der murinen Haut (Salimi et al. 2013).

Die ILC2 sind auch innerhalb der einzelnen Organen im jeweiligen Organismus unterschiedlich. Der Umstand, dass ILC2 der Haut einen anderen Phänotypen besitzen als ILC2 anderer Organe, unterstreicht die Tatsache, dass es sich um eine distinkte für die Haut spezifische Zellpopulation handelt, die auch spezifisch an die besonderen physiologischen Eigenschaften der Haut angepasst ist (Roediger et al. 2013; Sonnenberg et al. 2013). Zusätzlich verkomplizierend beschrieben unterschiedliche Autoren auch unterschiedliche Eigenschaften von der Haut residenten ILC2: Die von Kim et al. (2014) identifizierten ILC2 konnten mittels eines Anti-CD90Antikörpers depletiert werden (deplete: aufbrauchen, entfernen), während die von Roediger et al. (2013) definierten ILC2 diesem Effekt entgegenwirken konnten. Weiterhin exprimierten die von Roediger et al. (2013) identifizierten ILC2, die auch als dermale ILC oder dILC2 bezeichnet werden, das Oberflächenantigen CD103. Dabei handelt es sich um ein Integrin, das wichtig für 
Migration, Homing, aber auch die Immunabwehr ist. Es wird als das Integrin $\alpha E \beta 7$ bezeichnet und als ein Zell-Matrix-Adhäsionsmolekül charakterisiert, das seine Funktion durch die Bindung an E-Cadherin erfüllt (Hadley et al. 1997). CD103 wird außerdem von einer Reihe weiterer Immunzellen exprimiert, darunter epidermale dendritische Zellen oder auch regulatorische T-Zellen (Roediger et al. 2014; Schlickum et al. 2008). Die genaue Funktion der Expression von CD103 in dILC2 ist nicht bekannt und Gegenstand aktueller Forschung.

Es bleibt festzuhalten, dass ILC2 in verschiedenen Organen unterschiedliche Eigenschaften haben. Außerdem weisen auch die in der Haut beschriebenen ILC2 anhand verschiedener Forschungsergebnisse teilweise distinkte Unterschiede auf, die für eine weitere Diversität innerhalb Haut-residenter ILC2 sprechen.

\subsubsection{ILC2 - Mediatoren für entzündliche und allergische Hauterkrankungen}

Soweit bisher bekannt, sind die ILC2 zentral in die Pathogenese entzündlicher und allergischer Erkrankungen der Haut involviert. Eine wichtige Erkenntnis besteht darin, dass ILC2 in atopisch geschädigter Haut einerseits in erhöhter Zellzahl auftauchen und andererseits einen aktivierten Phänotyp haben (Kim 2015). Eine wichtige Rolle für die Pathogenese der atopischen Dermatitis spielen die Schlüssel-Zytokine der ILC2 und dabei vor allem IL-4, IL-5 und IL-13 (Bieber 2008). In einem murinen experimentellen Modell kann ein der atopischen Dermatitis ähnliches Krankheitsbild unter Zuhilfenahme des topischen Vitamin-D-Analogons MC903 induziert werden (Li et al. 2006). Eine topische MC903-Applikation führt im Verlauf zur Xerose, Akanthose und Spongiose der Haut, auch in $\mathrm{RAG}^{-1}$-Mäusen, die keine funktionierenden Bund T-Zellen besitzen. Den ILC2 kommt daher scheinbar eine wichtige Funktion bei der Induktion des Krankheitsbilds zu (Kim et al. 2013). Mechanistisch wurde gezeigt, dass die von ILC2 produzierten Zytokine zur Invasion eosinophiler Granulozyten, zur Aktivierung von TZellen, dendritischen Zellen und Makrophagen sowie zur Regulation basophiler Granulozyten und Mastzellen führen (Kim et al. 2013; Roediger et al. 2013; Salimi et al. 2013).

Auch bei allergischen Reaktionen der Haut spielen die ILC2 eine wichtige Rolle: Patienten mit einer Allergie gegen Hausstaubmilben wiesen im Unterschied zu gesunden Patienten erhöhte ILC2-Zahlen im Blut auf (Zhong et al. 2017). Außerdem wurde nachgewiesen, dass ILC2 bei Patienten mit chronischer Rhinosinusitis gehäuft aufzufinden sind (Mjosberg et al. 2011). 


\subsection{Das allergische Kontaktekzem}

Es wird zwischen einem irritativen und einem allergischen Kontaktekzem unterschieden. Das irritative Kontaktekzem entsteht durch die kumulative Applikation einer Substanz, die zu einer Schädigung der Keratinozyten und einer lokalen Inflammation führt. Demgegenüber steht das allergische Kontaktekzem (contact hypersensitivity; CHS, Kontakthypersensibilität), bei dem es zu einer zytotoxisch-allergischen Typ-4-Reaktion kommt (Martin 2012; Peiser et al. 2012). Da in dieser Dissertation aus Praktikabilitätsgründen das allergische Kontaktekzem experimentell induziert wurde, geht es im Folgenden nur noch um das allergische Kontaktekzem.

Die meisten Erkenntnisse zu den pathophysiologischen Grundlagen des allergischen Kontaktekzems stammen von Maus-Modellen. Der Pathophysiologie liegt eine Typ-4-Allergie nach der Klassifikation von Coombs und Gell zugrunde (Honda et al. 2013). Diese Form der Allergie wird auch als Spättyp-Reaktion bezeichnet, da es zu einer immunologischen Reaktion kommt, die sich im Unterschied zur Soforttyp-Reaktion erst über ein längeres Zeitintervall (meist Tage) ausbilden muss. Das allergische Kontaktekzem kann in eine Sensibilisierungs-, eine Entzündungs- und eine Regulationsphase eingeteilt werden. Während der Sensibilisierung kommt es zu einer systemischen Präsentation eines Allergens, das über die Haut aufgenommen wird. Die Entzündung kommt durch einen zweiten Kontakt mit demselben Allergen mehrere Tage nach dem Erstkontakt zustande. Die darauffolgende Regulationsphase dient dazu, das Ausmaß der Entzündungsreaktion im Rahmen zu halten (Peiser et al. 2012). 


\subsubsection{Die Sensibilisierungsphase}

\section{Sensibilisierung}

\section{Exzitation (challenge)}

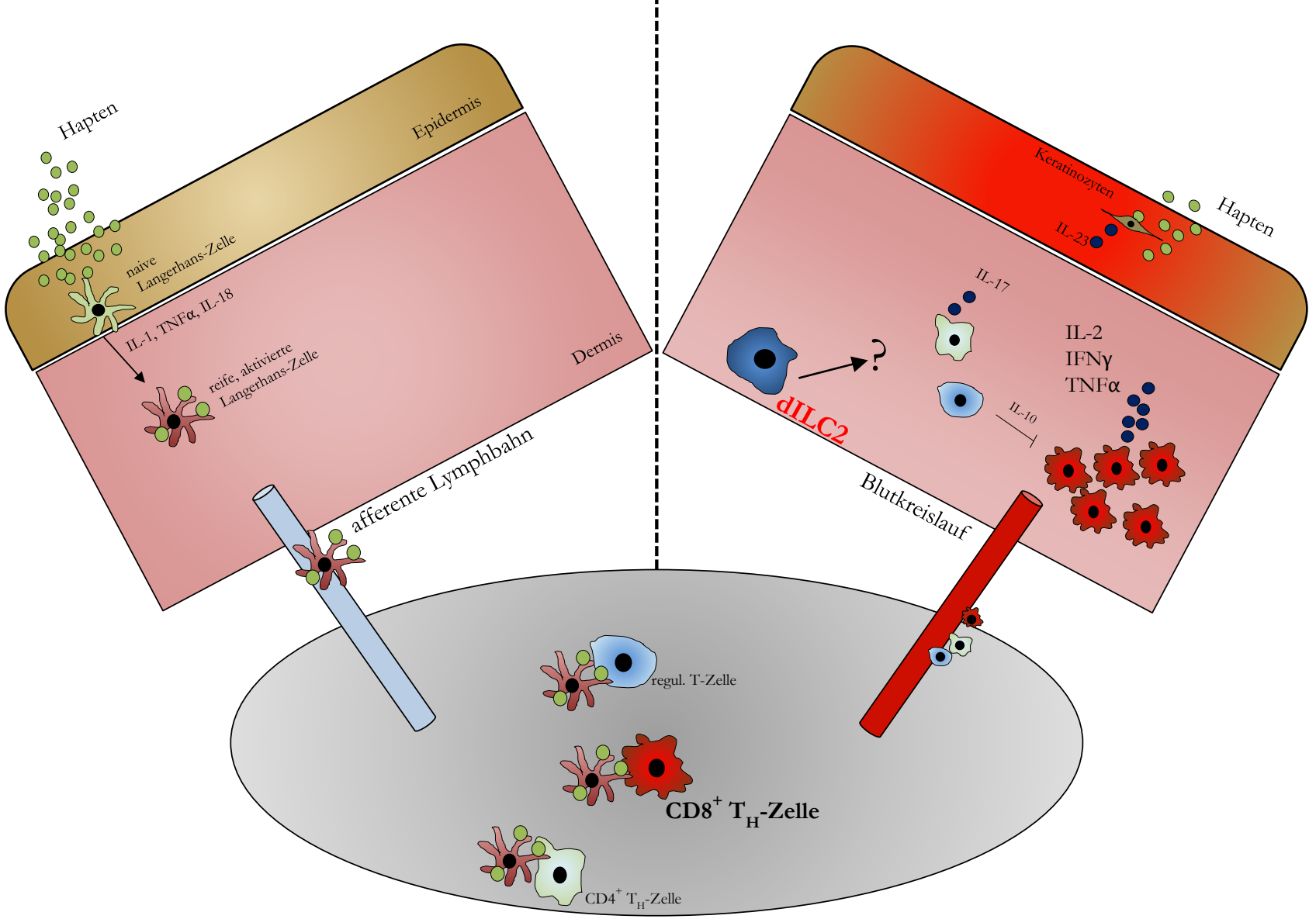

drainierender Lymphknoten

Abb. 1.2: Pathogenese des allergischen Kontaktekzems. Illustration der Pathogenese eines klassischen Kontaktekzems. Details zum Ablauf siehe Kap. 1.3. (Abbildung modifiziert nach Honda et al. 2013).

Die Sensibilisierung findet nach einem ein- oder mehrmaligen Kontakt der Haut mit einer allergenen (also einer potentiell eine Allergie stimulierenden) Substanz statt, die als Hapten bezeichnet wird. Die erste Bedingung für das Entstehen eines Kontaktekzems besteht darin, dass die potentiell allergene Substanz das Stratum corneum und die Keratinozyten durchdringt und in tiefere Schichten der Epidermis gelangt. Ein wichtiges Strukturprotein der Keratinozyten, nämlich das Fillagrin, verhindert diesen Prozess und sorgt für eine inter- und intrazelluläre Stabilität 
$\overline{\text { (Sandilands et al. 2009). Bei einem Defekt dieses Proteins, wie er bei vielen Patienten mit atopi- }}$ scher Dermatitis vorkommt, ist die natürliche Hautbarriere gestört, was ein leichteres Eindringen von Substanzen ermöglicht. Deshalb ist die Inzidenz von allergischen Kontaktekzemen bei Menschen mit atopischer Dermatitis erhöht (Visser et al. 2013).

Nicht jede Substanz hat ein allergenes Potential. In der Regel handelt es sich um kleine organische Partikel mit einer Molekulargröße < 500 Dalton. Sie müssen klein genug sein, um die Epidermis durchdringen zu können, und sollten nicht zu groß sein, um selbst immunogen wirken zu können. Das allergene Potential dieser Substanzen entsteht nämlich erst nach einer Formierung von stabilen Hapten-Protein-Komplexen durch physikalische, chemische oder biologische Einflüsse (Divkovic et al. 2005; Martin 2011).

Die gebildeten Hapten-Protein-Komplexe können von in der Epidermis befindlichen antigenpräsentierenden dendritischen Zellen (sog. naive Langerhans-Zellen) phagozytiert und prozessiert werden. Die Hapten-Protein-Komplexe werden internalisiert und auf MHC-I- und MHCII-Proteinen auf der Zelloberfläche präsentiert; sodass die dendritischen Zellen einen reifen und aktivierten Phänotyp annehmen (Aiba et al. 1997). Dieser Prozess wird durch die von den Keratinozyten ausgeschütteten Zytokine wie IL-1, IL-18 und TNF $\alpha$ verstärkt. Die maturierten dendritischen Zellen migrieren von der Epidermis in die drainierenden Lymphknoten und präsentieren dabei den prozessierten Hapten-Protein-Komplex auf ihrer Oberfläche (Moodycliffe et al. 2000; Nuriya et al. 1996; Zhou und Tedder 1995).

Im Lymphknoten treffen die aktivierten dendritischen Zellen auf T-Zellen, die das auf der Zelloberfläche präsentierte Hapten erkennen. Es kommt zur klonalen Expansion und Aktivierung zytotoxischer $\mathrm{CD}^{+}{ }^{+}$T-Zellen sowie zur Ausbildung regulatorischer T-Zellen (Tregs) und anderer $\mathrm{CD}^{+}{ }^{+} \mathrm{T}-$ Zellen. Diese migrieren aus dem Lymphknoten in die Blutbahn und sind dort nachzuweisen. Dieser Prozess dauert in der Regel einige Tage.

\subsubsection{Die Entzündungs- und Regulationsphase}

Wenn es nun zu einer erneuten Exposition mit demselben Hapten auf der Haut kommt, dann wird eine zellvermittelte Immunreaktion ausgelöst. Hierbei ist es nicht mehr entscheidend, an welcher Stelle auf der Haut dies geschieht, da sich die immunologische Reaktion im Vorfeld bereits systemisch ausgebreitet hat. Nach einem erneuten Kontakt kommt es in der Regel nach 12-72 Stunden zu einer allergischen Reaktion. Es kommt zur Aktivierung zytotoxischer CD8 ${ }^{+}$ T-Zellen (Vocanson et al. 2006). Sie scheinen für die Entstehung der Entzündung eine tragende Rolle zu spielen, da bei Tieren, bei denen die $\mathrm{CD} 8^{+} \mathrm{T}$-Zellen depletiert sind, keine Entzündung 
bei einem Wiederkontakt mit dem Hapten entsteht (Bour et al. 1995). Die zytotoxischen TZellen schütten verschiedene Interleukine aus, unter anderem IL-2, IFN $\gamma$ und TNF $\alpha$, die zu einer generalisierten Entzündungsreaktion mit Akanthose, Spongiose und Hyperkeratose der Haut führen. Als weiterer entzündungsstimulierender Faktor gelten die Keratinozyten, die bei Hapten-Kontakt IL-23 ausschütten und damit zur Bildung und Aktivierung von $\mathrm{T}_{\mathrm{H}} 17-$ Zellen führen (Larsen et al. 2009). Regulatorische T-Zellen supprimieren diese Immunantwort als physiologischer Gegenspieler (Cavani et al. 2003; Reduta et al. 2011). Zu den genauen zellulären und immunologischen Mechanismen besteht noch erheblicher Forschungsbedarf. Es kann als gesichert gelten, dass der Bildung von IL-10 eine entscheidende regulatorische Funktion zukommt (Ring et al. 2006).

Interessanterweise scheinen auch T-Zell-unabhängige Mechanismen eine Rolle bei der Entzündung zu spielen. Neuere Arbeiten haben gezeigt, dass es in RAG1 ${ }^{-/}$-Mäusen, die keine B- und T-Zellen ausbilden, ebenfalls zur Bildung eines immunogenen Gedächtnisses kommt, was durch die Bildung von in der Leber gespeicherten Gedächtnis-NK-Zellen erklärt wird (O'Leary et al. 2006).

\subsubsection{Die Rolle von ILC2 beim allergischen Kontaktekzem}

Arbeiten von Rafei-Shamsabadi et al. (2018) konzentrierten sich auf die Rolle von ILC2 beim allergischen Kontaktekzem, das in Mäusen durch TNCB (2,4,6-Trinitrochlorbenzol) ausgelöst wurde. In den Experimenten konnte gezeigt werden, dass die Mäuse nach effektiver ILC2Depletion eine stärkere Ohrschwellung als naive WT-Mäuse bei der TNCB-CHS aufweisen. Die ILC2 scheinen also einen regulatorischen und supprimierenden Effekt auf die $\mathrm{T}_{\mathrm{H}} 1$-gesteuerte TNCB-CHS auszuüben. Ob und wie sich diese Beobachtung auf andere Kontaktallergene übertragen lässt und durch welche Mechanismen sie vermittelt werden, bleibt zum jetzigen Zeitpunkt unklar.

\subsection{RAG1 ${ }^{-/}$-Maus und der RAG-Komplex}

Die Beschreibung und Entwicklung der RAG1//-Maus gelang erstmals 1992 durch den USamerikanischen Forscher Mombaerts. Der Thymus dieser defizienten Mäuse enthielt auffällig wenige Zellen (ca. 15-130-mal weniger als W'T-Mäuse). In der Milz und im Knochenmark waren keine Immunglobuline bzw. Immunglobulin-tragende Zellen nachweisbar, was auf ein vollständiges Fehlen von B-Zellen hinweist. Auffällig war weiterhin, dass die betroffenen Mäuse keine vollständig ausgebildeten Lymphknoten besitzen. In den jeweiligen Lymphknoten waren keine 
B- und T-Lymphozyten enthalten. Die fehlende Entwicklung der B- und T-Zellen wurde dem fehlenden V(D)J-Rearrangement durch das fehlende RAG1-Protein zugeschrieben und korrelierte damit. Mechanistisch entgingen die fehlerhaft gebildeten Lymphknoten nicht der physiologischen und natürlichen Selektion des Thymus, was zu einer Apoptose führte. Neben der Rolle im Rearrangement des TCR kommt den RAG-Proteinen demnach auch eine wichtige Rolle bei der Entwicklung der Lymphozyten zu. Außerdem ist bekannt, dass RAG1 im zentralen Nervensystem in großer Menge exprimiert wird. Interessanterweise wurden keine neuroanatomischen Auffälligkeiten und kein pathologisches Verhalten bei diesen Mäuse beschrieben (Mombaerts et al. 1992).

Wegen der fehlender B- und T-Lymphozyten in den $\mathrm{RAG}^{-/-}$-Mäusen werden sie häufig als Modell zur Untersuchung des angeborenen Immunsystems ohne einen Einfluss des erworbenen Immunsystems eingesetzt. Neuere Daten haben jedoch gezeigt, dass dies nicht ohne Einschränkungen möglich ist. So haben etwa Karo et al. (2014) nachgewiesen, dass auch NK-Zellen RAG1 zumindest teilweise während ihrer Entwicklung und unabhängig vom fehlenden TCR exprimieren können. NK-Zellen, die RAG1 durch einen knockout während ihrer Entwicklung nicht exprimieren, sind durch funktionelle Defekte wie eine eingeschränkte Fähigkeit zur viralen Abwehr bestimmt, was auf eine erniedrigte Expression DNA-reparierender Proteine zurückgeführt wurde. Dadurch kam es signifikant häufiger zu DNA-Doppelstrangbrüchen (DSB) als bei RAG-exprimierenden NK-Zellen. Neben den NK-Zellen haben auch 30-40\% der ILC2 und ILC3 eine RAG1-Expression während ihrer Entwicklung gezeigt (Karo et al. 2014; Karo und Sun 2015). Diese Beobachtungen legen nahe, dass RAG1 neben dem V(D)J Rearrangement auch vitale Prozesse der Physiologie in Immunzellen reguliert. Darauf wird in den nächsten Abschnitten weiter eingegangen.

\subsubsection{RAG1/RAG2 - traditionelle Funktion}

RAG1 und RAG2, die zusammen als RAG-Komplex bezeichnet werden, sind klassischerweise für die Restrukturierung und das Rearrangement von bestimmten genetischen Bereichen verantwortlich. Durch eine variable Verknüpfung von sog. V- für variable, D- für diversity und JSegmenten für joining kann eine Vielzahl unterschiedlicher Kombinationen entstehen, die wiederum zu einer Vielzahl verschiedener Rezeptoren führt, die die Segmente kodieren. Durch weitere Mechanismen wie die somatische Hypermutation und das alternative Splicen werden eine noch größere Diversität und Spezifität der jeweiligen Rezeptoren erreicht. Damit ist es 
möglich, bis zu $10^{11}$ verschiedene B-Zell-Rezeptoren und bis zu $10^{15}$ verschiedene T-Zell-Rezeptoren zu generieren (Nishana und Raghavan 2012). Dadurch kann eine auf den jeweiligen Krankheitserreger ideal zugeschnittene Immunantwort eingeleitet werden.

\subsubsection{Die molekularen Mechanismen des RAG-Komplexes}

Der RAG-Komplex wird als eine funktionelle Einheit aus RAG1 und RAG2 verstanden und bildet ein Hetero-Tetramer, in dem RAG1 die enzymatische Endonuklease-Aktivität besitzt, die aber ohne das Vorhandensein von RAG2 seine katalytische Funktion nicht ausüben kann (Kim et al. 1999; Landree et al. 1999; Oettinger et al. 1990). Abb. 1.3 illustriert die molekularen Mechanismen bei der Spaltaktivität des RAG-Komplexes (Karo und Sun 2015; Schatz und Ji 2011).
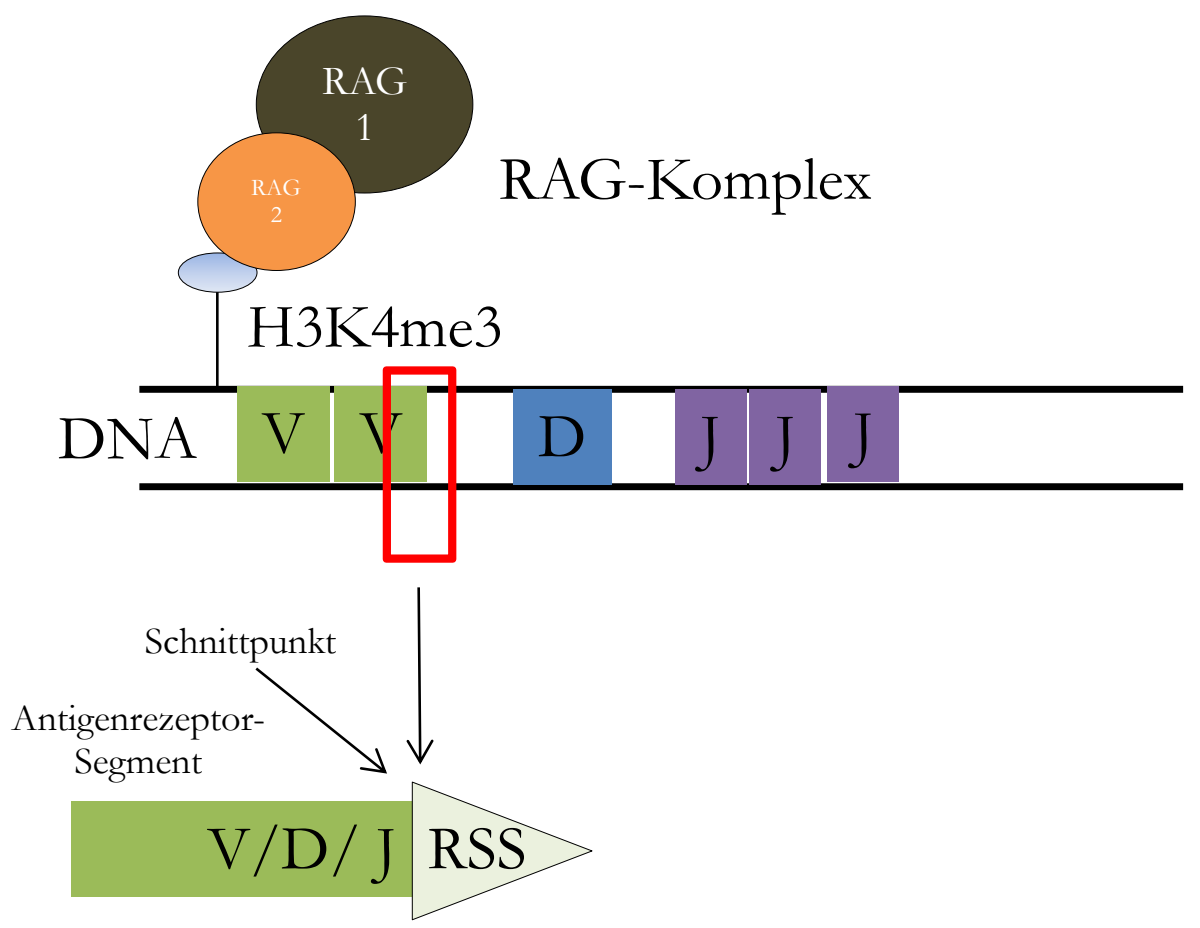

Abb. 1.3: Molekulare Strukturen und Ablauf der RAG-Spaltaktivität. Um die VDJ-Gensegmente in unterschiedlicher Art und Weise miteinander verbinden zu können, muss die DNA an bestimmten Stellen geschnitten und wieder zusammengefügt werden. Dies wird durch den RAG-Komplex, der aus RAG1 und RAG2 besteht, katalysiert. Um dem Komplex zu vermitteln, wo sich diese Gensegmente befinden, stellt die Zelle raffinierte Mechanismen bereit: RAG2 ist für die Bindung an die Histon-Bestandteile H3K4me3 verantwortlich (denotiert die Addition von drei Methylgruppen an die Aminosäure Lysin 4 im Histon H3 Protein), die sich in der Umgebung der VDJ-Segmente befinden (Early et al. 1980; Matthews et al. 2007; Sakano et al. 1979; Schatz und Spanopoulou 2005). Der eigentliche Ort des Geschehens ergibt sich durch die Bindung des RAG-Komplexes an sog. recombination signal sequences (RSS). Das Verbinden der DNA-Spaltprodukte geschieht durch eine nicht-homologe Endverknüpfung und die Aktivierung DNA-reparierender Enzyme (Gellert 2002). (Abbildung modifiziert nach Schatz und Ji 2011). 


\subsubsection{Der RAG-Komplex stabilisiert das Lymphozyten-Genom}

Abb. 1.3 illustriert die Bindungseigenschaften des RAG-Komplexes. Interessanterweise wurde gezeigt, dass die von RAG2 gebundenen H3K4me3 Histon-Segmente nicht nur in der Nähe von VDJ-Gensegmenten, sondern über das gesamte Genom verstreut aufzufinden sind (im Folgenden als „Nicht-VDJ-Segmente“ bezeichnet) (Ji et al. 2010). Außerdem häufen sich diese RAG-Komplexe an Stellen, an denen aktiv Transkription stattfindet. Es konnte gezeigt werden, dass diese Komplexe auch dort enzymatisch aktiv sind und die DNA dort spezifisch schneiden. Nach der enzymatischen Aktivität, also der Induktion von DSB durch den RAG-Komplex, kommt es zur Reparation dieser Brüche durch eine sog. nicht-homologe Endverknüpfung (NHEJ) (Gellert 2002). Nach dem DSB wird eine Vielzahl von Proteinen aktiviert, die für eine Reparation der DNA sorgen (Ciccia und Elledge 2010). Wenn die Reparation nicht gelingt, dann wird die Apoptose dieser Zellen eingeleitet (Zhou und Elledge 2000), wodurch sich ein dynamisches Gleichgewicht zwischen Reparation und Apoptose einstellt. Dadurch wird sichergestellt, dass der riskante Prozess der induzierten DSBs nicht zu einer Fehlfunktion oder Entartung der betroffenen Zelle führt (Abb. 1.4). Der RAG-Komplex scheint bei beiden Wegen eine funktional entscheidende Rolle zu spielen. 


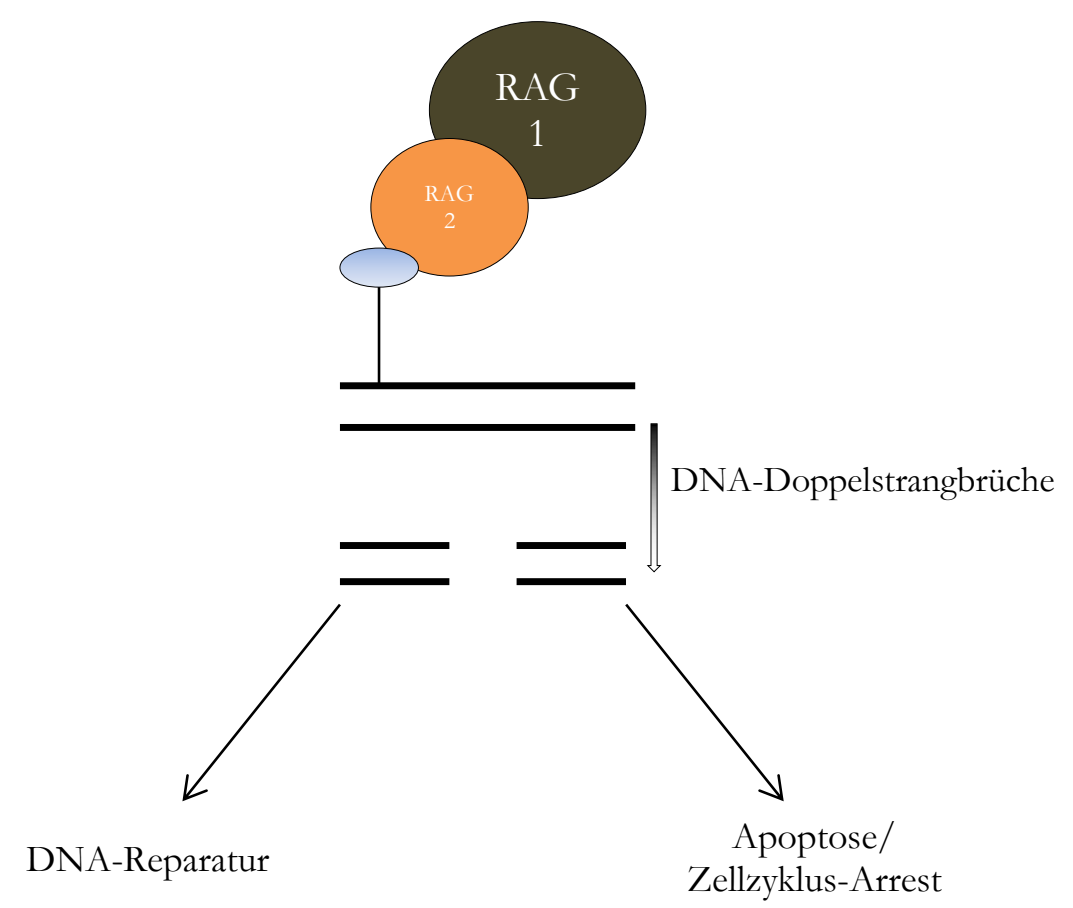

Abb. 1.4: Schicksal der Zelle nach RAG-induzierten DNA-Doppelstrangbrüchen. Die DSB sind einerseits die Grundbedingung für die VDJ-Rekombination, andererseits bilden sie auch eine Gefahr für die Integrität der DNA. Um dieser Gefahr entgegenzuwirken, werden bei der Induktion der DSB nun entweder Proteine für die DNA-Reparatur oder Proteine aktiviert, die für Apoptose und ZellzyklusArrest verantwortlich sind. So wird sichergestellt, dass das Genom der betroffenen Zellen vor Entartung geschützt bleibt. Die Regulation dieser beiden Prozesse ist noch wenig erforscht und Gegenstand aktueller Forschung.

\subsubsection{Die Rolle von RAG in ILC}

Wie bereits einleitend erwähnt wurde, spielt RAG nicht nur in den Zellen des adaptiven Immunsystems eine Rolle. Karo et al. (2014) konnten zeigen, dass RAG ebenso in 30-40 \% der peripheren ILC in der Entwicklung zumindest zeitweilig exprimiert wird. Dafür wurde eine Ragreporter Maus verwendet, die bei einer RAG-Expression der betroffenen Zellen einen Farbstoff exprimiert (GFP; green fluorescent protein), der dann in der entdifferenzierten Zelle nachgewiesen werden kann. Auf diese Weise konnte die vorhandene RAG-Expression in peripheren ILC nachgewiesen werden. Karo et al. (2014) führten weitergehende Experimente durch, die gezeigt haben, dass diejenigen NK-Zellen, die RAG in ihrer Entwicklung exprimieren, einen weniger aktivierten Phänotypen aufweisen und schlechter auf Entzündungsreize und Virusinfektionen reagieren als NK-Zellen, die kein RAG exprimieren. Außerdem schien diese Beobachtung nicht auf NK-Zellen begrenzt zu sein, sie ließ sich vielmehr auch auf andere Immunzellen erweitern, wie etwa auf die CD8 ${ }^{+}$T-Zellen. Wenn RAG1 nicht in NK-Zellen exprimiert werden konnte, 


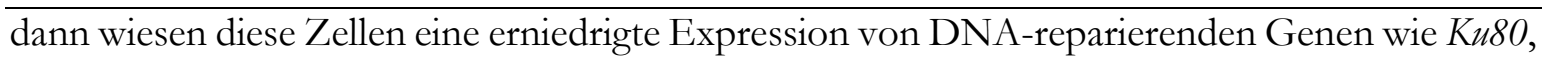
Chk22 sowie Atm auf. Dieser Effekt schien auch spezifisch mit der Endonuklease-Spaltaktivität des RAG1-Proteins verbunden zu sein, da RAG1-endonuclease-dead Mäuse, in denen spezifisch die Endonuklease-Aktivität des RAG1-Proteins ausgeknockt war, eine ähnliche genomische Instabilität mit einer erhöhten Apoptose und einer verminderten Proliferation zeigten (Karo et al. 2014; Karo und Sun 2015). Die genaue Rolle von RAG in anderen ILC wie den ILC2 bleibt unklar.

\subsection{Ziele dieser Arbeit}

ILC2 sind seit etwa einem Jahrzehnt ein wichtiges immunologisches Forschungsthema, da zur Funktion dieser Zellen wenig bekannt war. Mittlerweile entsteht ein immer breiter werdendes Verständnis zur Physiologie dieser einzigartigen Zellgruppe. ILC2 sind zahlenmäßig deutlich seltener ist als andere Immunzellen, weshalb die Untersuchung dieser Zellen stets mit einem hohen experimentellen Aufwand verbunden, ist insbesondere bei schwer zu untersuchenden Organen wie der Haut.

Die einzigartige Eigenschaft von RAG1/\%-Mäusen, keine B- und T-Zellen zu besitzen, macht sie in der Theorie zu einem praktikablen Maus-Modell, die Funktion der ILC2 unabhängig von den Einflüssen des adaptiven Immunsystems zu untersuchen. So besitzen RAG1 ${ }^{-/}$-Mäuse aus bisher unbekannten Gründen in absoluten Zahlen sogar mehr dILC2 als W'T-Mäuse, was sie zu einem noch besseren Untersuchungs-Modell macht.

ILC2 besitzen keinen spezifischen Antigen-Rezeptor, doch RAG1 scheint auch hier eine wichtige Rolle in der Entwicklung zu spielen, wahrscheinlich durch eine Stabilisierung des Genoms. Verschiedene Beobachtungen stützen die Ansicht, dass RAG1 nicht nur die Entwicklung von Zellen des adaptiven Immunsystems gewährleistet, sondern sich ebenfalls auf die ILC2 auswirkt. Aktuelle Forschungsergebnisse haben gezeigt, dass sich die Untersuchungen an RAG1-defizienten ILC2 nicht direkt auf WT-ILC2 übertragen lassen. RAG1 spielt anscheinend eine zentrale Rolle in der Entwicklung und Funktion dieser Zellen und scheint dort Funktionen unabhängig vom Rearrangement des TCR auszuführen.

Mein erstes Ziel bestand darin, die ILC2 in der Haut zu identifizieren und in verschiedenen knockout-Mäusen zu quantifizieren. Außerdem habe ich erstmals die ILC2-Dynamik während einer DNFB-induzierten CHS geprüft und untersucht. 
$\overline{\text { Das weitergehende Ziel bezog sich darauf, bezugnehmend auf die Forschungsergebnisse von }}$ Karo et al. (2014) die ILC2 in der RAG1 ${ }^{-}$-Maus funktionell zu untersuchen. Hierzu habe ich die beiden Zellpopulationen systematisch sowohl auf molekularer als auch auf funktioneller Ebene miteinander verglichen und die Unterschiede sowie Gemeinsamkeiten herausgearbeitet (Abb. 1.5).

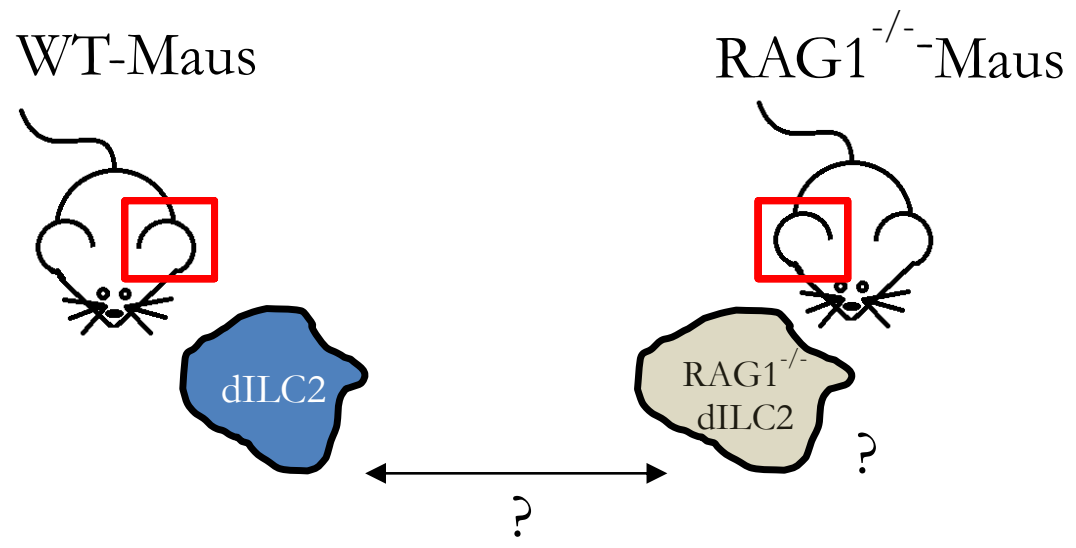

Abb. 1.5: Illustration der Fragestellung dieser Dissertation. 


\section{$2 \quad$ Material und Methoden}

\subsection{Chemikalien, Medien und Laborgeräte}

Tabelle 2.1: Verwendete Chemikalien und Medien mit Firma und Standort.

\begin{tabular}{|c|c|}
\hline Chemikalien und Medien & Firma, Ort \\
\hline Liberase & Roche, Grenzach-Wyhlen, Deutschland \\
\hline DNAse & Roche, Grenzach-Wyhlen, Deutschland \\
\hline Caspase-3/7-Staining Kit & ThermoFisher, Karlsruhe, Deutschland \\
\hline $\begin{array}{l}\text { 7-Aminoactinomycin (7-AAD) Viability Stain- } \\
\text { ing Solution }\end{array}$ & BioLegend, Koblenz, Deutschland \\
\hline Annexin-V-Staining Kit & eBioscience, Frankfurt am Main, Deutschland \\
\hline Bromdesoxyuridin (BrdU) -Staining Kit & BD Pharmingen, Heidelberg, Deutschland \\
\hline Phosphate-buffered saline (PBS) & Sigma, Taufkirchen, Deutschland \\
\hline 1-Fluor-2,4-dinitrobenzol (DNFB) & Sigma, Taufkirchen, Deutschland \\
\hline Mouse Foxp3 Buffer Set & BD Pharmingen, Heidelberg, Deutschland \\
\hline $\begin{array}{l}\text { Roswell Park Memorial Institute (RPMI-1640) } \\
\text { Medium }\end{array}$ & Lonza, Köln, Deutschland \\
\hline Zombie Fixable Viability Kit & BioLegend, Koblenz, Deutschland \\
\hline
\end{tabular}




\begin{tabular}{|l|l|}
\hline Chemikalien und Medien & Firma, Ort \\
\hline Trypan Blau 0,4\% & Sigma, Taufkirchen, Deutschland \\
\hline Fetal calf serum (FCS) Superior & Biochrom, Berlin, Deutschland \\
\hline Trizol & Sigma, Taufkirchen, Deutschland \\
\hline Aceton & Roth, Karlsruhe, Deutschland \\
\hline & \\
\hline Isofluran & abbvie, Wiesbaden, Deutschland \\
\hline & \\
\hline
\end{tabular}

\subsubsection{Antikörper}

Tabelle 2.2: Im Durchflusszytometer verwendete Antikörper mit zugehörigem Typ, dem Ursprungs-Organismus (host), gebundenem Farbstoff, Klon sowie Firma und Standort.

\begin{tabular}{|l|l|l|l|l|}
\hline $\begin{array}{l}\text { Oberflächenmar- } \\
\text { ker }\end{array}$ & Isotyp und host & Farbstoff & Klon & Firma, Ort \\
\hline CD2 & IgG2b $\lambda$, Ratte & FITC & RM2-5 & $\begin{array}{l}\text { BioLegend, Koblenz, } \\
\text { Deutschland }\end{array}$ \\
\hline CD2 & IgG2b $\lambda$, Ratte & APC & RM2-5 & $\begin{array}{l}\text { BioLegend, Koblenz, } \\
\text { Deutschland }\end{array}$ \\
\hline CD3 & IgG2a, Ratte & FITC & KT3 & $\begin{array}{l}\text { AbDSerotec, Puch- } \\
\text { heim, Deutschland }\end{array}$ \\
\hline CD3 & IgG2a, $x$, Ratte & FITC & 17 A2 & $\begin{array}{l}\text { BioLegend, Koblenz, } \\
\text { Deutschland }\end{array}$ \\
\hline
\end{tabular}




\begin{tabular}{|c|c|c|c|c|}
\hline $\begin{array}{l}\text { Oberflächenmar- } \\
\text { ker }\end{array}$ & Isotyp und host & Farbstoff & Klon & Firma, Ort \\
\hline CD44 & IgG2b $x$, Ratte & BV 510 & IM7 & $\begin{array}{l}\text { BioLegend, Koblenz, } \\
\text { Deutschland }\end{array}$ \\
\hline CD45 & IgG2b $x$, Ratte & Pacific Blue & 30-F11 & $\begin{array}{l}\text { ThermoFisher, Karls- } \\
\text { ruhe, Deutschland }\end{array}$ \\
\hline CD90 & IgG1 $\lambda$, Ratte & PerCP & $53-2.1$ & $\begin{array}{l}\text { BioLegend, Koblenz, } \\
\text { Deutschland }\end{array}$ \\
\hline CD278 & $\begin{array}{l}\text { IgG, arm. Hams- } \\
\text { ter }\end{array}$ & APC & C398.4A & $\begin{array}{l}\text { BioLegend Koblenz, } \\
\text { Deutschland }\end{array}$ \\
\hline CD127 & IgG2a $x$, Ratte & APC & A7R34 & $\begin{array}{l}\text { eBioscience, Frankfurt } \\
\text { am Main, Deutschland }\end{array}$ \\
\hline GATA3 & IgG2b x, Maus & APC & 16E10A23 & $\begin{array}{l}\text { BioLegend Koblenz, } \\
\text { Deutschland }\end{array}$ \\
\hline Fc-Block & / & / & / & $\begin{array}{l}\text { BioLegend Koblenz, } \\
\text { Deutschland }\end{array}$ \\
\hline
\end{tabular}

Tabelle 2.3: Oberflächenmarker sowie beschriebene Funktionen. Informationen von Lai et al. (1998).

\begin{tabular}{|l|l|}
\hline Oberflächenmarker & Funktionen \\
\hline $\begin{array}{l}\text { CD2 (T-Zell-Oberflä- } \\
\text { chenantigen) }\end{array}$ & Adhäsion, T-Zell-Aktivierung \\
\hline
\end{tabular}




\begin{tabular}{|c|c|}
\hline Oberflächenmarker & Funktionen \\
\hline CD3 (TCR) & TCR Untereinheit, Signaltransduktion \\
\hline $\begin{array}{l}\text { CD44 (Hyaluronsäure- } \\
\text { Rezeptor) }\end{array}$ & $\begin{array}{l}\text { bindet Hyaluronsäure, Leukozytenadhäsion und -homing, T- } \\
\text { Zell-Aktivierung, Tumormetastasierung }\end{array}$ \\
\hline $\begin{array}{l}\text { CD45 (Pan-Leukozyten- } \\
\text { Antigen) }\end{array}$ & $\begin{array}{l}\text { Tyrosin-Phosphatase, Leukozyten-Differenzierung und Aktivie- } \\
\text { rung, Pan-Leukozyten-Marker }\end{array}$ \\
\hline CD90 (Thy1) & Signaltransduktion, T-Zell- Aktivierung \\
\hline CD278 (ICOS) & T-Zell-Ko-Stimulation, B7-H2 Rezeptor, Zytokin-Produktion \\
\hline CD127 (IL-7R $\alpha)$ & $\begin{array}{l}\text { IL-7R Alpha-Kette, in Assoziation mit CD132 hohe Affinität } \\
\text { von IL-7 }\end{array}$ \\
\hline
\end{tabular}

\subsubsection{Verbrauchsmaterialien}

Tabelle. 2.4: Verbrauchsmaterialien mit Firma und Standort.

\begin{tabular}{|l|l|}
\hline Vorrats-, Arbeits- und Kulturgefäße & Firma, Ort \\
\hline $50 \mu$ Filter & BD Pharmingen, Heidelberg, Deutschland \\
\hline & \\
\hline Eppendorf Varipetten & Eppendorf, Hamburg, Deutschland \\
\hline Pipetten-Spitzen & StarLab Group, Hamburg, Deutschland \\
\hline Inject-F Spritze $1 \mathrm{ml}$ & \\
\hline
\end{tabular}




\subsubsection{Laborgeräte}

Tabelle 2.5: Verwendete Laborgeräte mit Firma und Standort.

\begin{tabular}{|c|c|}
\hline Geräte und Laborinstallation & Firma, Ort \\
\hline Mikroskop & Zeiss, Oberkochen, Deutschland \\
\hline BD FACSCanto II & BD Pharmingen, Heidelberg, Deutschland \\
\hline BD FACSAria & BD Pharmingen, Heidelberg, Deutschland \\
\hline Brutschränke & $\begin{array}{l}\text { Thermofisher-unitymedia, Braunschweig, } \\
\text { Deutschland }\end{array}$ \\
\hline Zentrifugen & $\begin{array}{l}\text { Thermofisher-unitymedia, Braunschweig, } \\
\text { Deutschland }\end{array}$ \\
\hline Kühlschränke & Liebherr, Ethingen (Donau), Deutschland \\
\hline Tiefkühlschränke & Liebherr, Ethingen (Donau), Deutschland \\
\hline Ohr-Dicken-Messgerät C220T & Kroeplin, Schlüchtern, Deutschland \\
\hline Isofluran-Anlage & VisualSonic, Canada \\
\hline Rasierer & Panasonic, Deutschland \\
\hline Homogenisator & $\begin{array}{l}\text { Thermofisher-unitymedia, Braunschweig, } \\
\text { Deutschland }\end{array}$ \\
\hline
\end{tabular}




\section{$2.2 \quad$ Mäuse}

In dieser Studie stammten sämtliche Mäuse aus dem C57BL/6 Hintergrund. Unsere Versuchstiere wurden im hauseigenen Tierstall der Universitätsmedizin Göttingen (UMG) unter speziellen und pathogen-freien Bedingungen und im 12-Stunden Tag-Nacht-Zyklus gezüchtet und aufgezogen. Die C57BL/6 Wildtyp (WT), RAG1 $1^{-/}, \mathrm{TLR}^{-/-}$und TLR3/MyD88 ${ }^{-/-}$-Mäuse wurden vom Jackson Laboratory, Bar Harbor, ME erworben (MyD88; Myeloid differentiation primary response 88, TLR3; toll-like receptor 3). Alle Mäuse eines Experiments waren alters- und geschlechtsangepasst (Alter zwischen 8-13 Wochen). Sämtliche Experimente wurden unter ethischer Genehmigung durch die lokalen Versuchstierschutzbehörden und die zuständigen Autoritäten mit bestem Gewissen durchgeführt.

\subsection{Induktion einer Kontaktallergie}

Um eine CHS zu induzieren, sind zwei verschiedene Phasen notwendig, nämlich eine Sensibilisierungs- und eine Exzitationsphase bzw. Regulationsphase.

In der Sensibilisierungsphase werden dem Organismus potente Allergene auf der Hautoberfläche präsentiert. Die dadurch entstehende immunologische Reaktion führt zu einer immunologischen (Hyper-)Reagibilität auf diese Substanz, die dann bei einem erneuten, einige Tage später auftretenden Kontakt (Exzitationsphase) eine kontaktallergische Reaktion auslöst. Zum Ausschluss einer lokalen Reaktion sollte die Exzitation (oder: challenge) an einem anderen Ort als die Sensibilisierung stattfinden. Außerdem sollte sichergestellt werden, dass die Substanz keine akut-toxische oder irritative Reaktion bewirkt 


\subsubsection{Induktion einer DNFB-Kontaktallergie}

In meinen Experimenten erfolgte die Induktion der CHS mit DNFB, einem etablierten und potenten Kontaktallergen (Ablauf siehe Abb. 2.1) (Bour et al. 1995).

\begin{tabular}{cccc}
$\mathrm{d} 0$ & $\mathrm{~d} 1$ & $\mathrm{~d} 5$ & $\mathrm{~d} 6$ \\
\hline $0,5 \%$ & $0,5 \%$ & $0,25 \%$ & Ohrschwellung + \\
DNFB & DNFB & DNFB & Isolation
\end{tabular}

Abb. 2.1: Experimenteller Aufbau zur Induktion einer DNFB-CHS. Vorgehensweise bei der Induktion einer DNFB-CHS in der Maus. Klein d kennzeichnet die Tage, zwischen den Tagen liegen jeweils exakt 24 Stunden. Unter dem Pfeil ist die jeweilige DNFB-Konzentration angegeben, die auf die Haut aufgetragen wurde. An d6 wurden sowohl die Ohrschwellung gemessen als auch die Zellen isoliert und analysiert.

Die zu behandelnden Mäuse wurden durch die Verwendung einer Isofluran-Anlage in eine Kurzzeitnarkose versetzt. Mit einem handelsüblichen Rasierer wurde der Rücken der Tiere sauber rasiert, um damit die Resorptionsoberfläche zur Auftragung der Substanzen zu optimieren. Für die Sensibilisierung erfolgte die Applikation von $20 \mu \mathrm{l}$ 0,5\%iger DNFB-Lösung (gelöst in

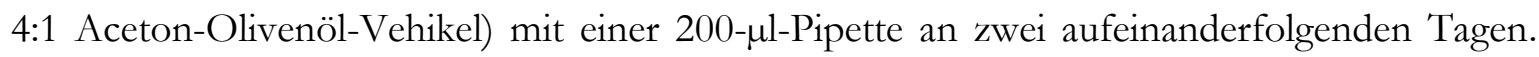
Fünf Tage später erfolgte die challenge mit $20 \mu \mathrm{l}$ 0,25\% iger DNFB-Lösung am rechten Ohr sowie als Kontrolle die Applikation von $20 \mu \mathrm{l}$ des reinen Vehikels am linken Ohr. Die Ohr-Dicken wurden sowohl vor als auch nach der Applikation der Substanzen gemessen. Um die Mäuse identifizieren zu können, wurde der Schwanz mit einem wasserunlöslichen Stift farblich markiert. Die relative Ohr-Dicken-Schwellung wurde mit der folgenden Formel berechnet:

[(Dicke des DNFB-behandelten Ohrs nach challenge) - (Dicke des DNFB-behandelten Ohrs vor challenge) ] - [(Dicke des Vehikel-behandelten Ohrs nach challenge) - (Dicke des Vehikel-behandelten Ohrs vor challenge)].

( $\Delta$ Dicke des DNFB-behandelten Ohrs) - ( $\Delta$ Dicke des Vehikel-behandelten Ohrs). 


\subsubsection{Adoptiver Transfer von WT-Lymphozyten in RAG1 ${ }^{-/-}$-Mäuse}

Die Versuchsdurchführung der adoptiven Transfer-Experimente (AT: adoptiver Transfer) wird zur Verdeutlichung in Abb. 2.2 schematisch dargestellt.

WT-Maus

DNFB d5

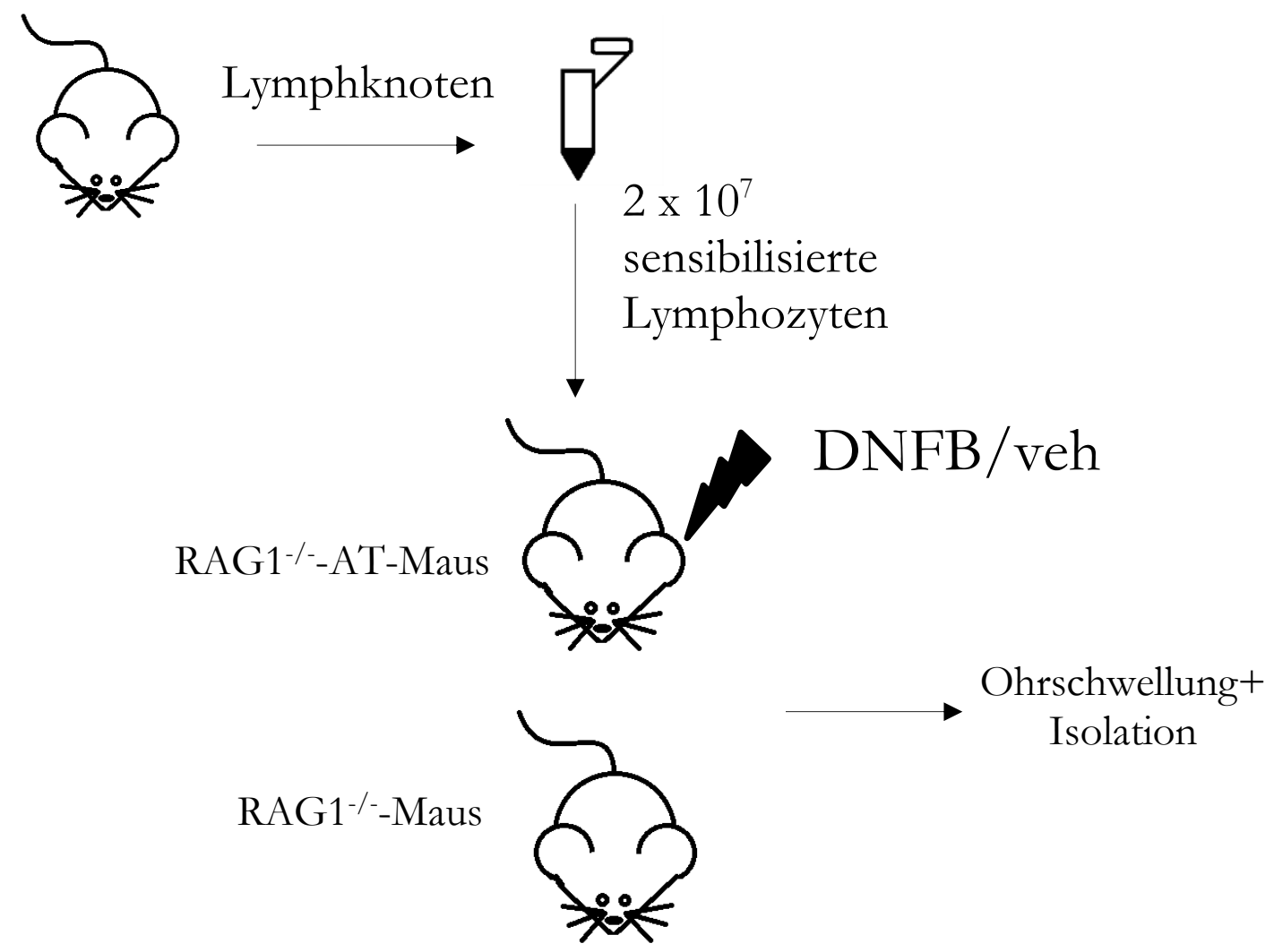

Abb. 2.2: Adoptiver Transfer von WT-Lymphozyten in RAG1\%--Mäuse. Die RAG1/--Mäuse, die die WT-Lymphozyten erhalten haben, werden als adoptive Transfer-Mäuse (AT-Mäuse) bezeichnet. Kontrolltiere (regelrecht sensibilisierte RAG1\%-Mäuse) erhielten statt der WT-Lymphozyten eine äquivoluminöse Menge PBS. Die challenge erfolgte bei beiden Tieren mit DNFB bzw. einem Vehikel.

Für die AT-Experimente wurden die WT-Mäuse mit DNFB sensibilisiert. Am Tag 5 wurden die Tiere getötet und die axillären, inguinalen und zervikalen Lymphknoten wurden präpariert. Dazu wurden die Lymphknoten in einen Eppendorf-Cup transferiert und in $1 \mathrm{ml}$ PBS (phosphatebuffered saline) gelöst. Mit einer Pipetten-Spitze und einem Homogenisator wurden die Lymphknoten manuell gepresst, um die enthaltenden Zellen besser herauszulösen. Anschließend wurde die Suspension über einen 50- $\mu$ l-Filter filtriert. Zur Quantifizierung wurden die Lymphozyten mit Trypan-Blau gefärbt und unter dem Mikroskop ausgezählt. Es wurden jeweils 2x10 ${ }^{7}$ 
Zellen in 100-200 $\mu$ l PBS gelöst, in einer 1-ml-Spritze aufgezogen und intravenös in eine naive Empfänger-RAG1 ${ }^{-/}$-Maus injiziert (diese Maus wird fortan als AT-Maus bezeichnet). Kontrolltiere, die der üblichen DNFB-Sensibilisierung unterzogen worden waren und sich ebenfalls an d4 befanden, erhielten als Kontrolle PBS intravenös appliziert. 24 oder 48 Stunden später wurden die Tiere nach dem üblichen Protokoll mit DNFB behandelt. Die Ohr-Dicken-Messung erfolgte jeweils vor sowie nach der challenge. Die weitere Aufarbeitung der Haut erfolgte 24 oder 48 Stunden später.

\subsection{Isolation von Zellen aus der Haut und Antikörperfärbung}

Die Haut ist ein Organ mit einem hohen Anteil an Kollagen und Bindegewebe, weshalb mehrere Prozeduren notwendig sind, um die zu untersuchenden Zellen zu isolieren.

Für meine Experimente wurden die unbehaarten Ohren von den jeweiligen Mäusen aufgearbeitet. Die Ohren wurden durch die Verwendung von scharfen Pinzetten in eine dorsale und eine ventrale Seite aufgespalten und getrennt voneinander weiterverarbeitet. Die jeweiligen Seiten wurden in eine 16-Well-Platte in eine Lösung mit 0,33 $\mathrm{ml}$ Liberase $(1,5 \mathrm{mg} / \mathrm{ml}$ PBS), 0,05 ml 0,1\% iger DNAse (1 \% in Aqua dest.) sowie $600 \mu \mathrm{l}$ RPMI Medium ohne Zusatzstoffe überführt und separat mittels einer Schere weiter zerkleinert, um die Gesamtoberfläche zu vergrößern. Daraufhin erfolgte die Verdauung des Gewebes für 90 Minuten bei $37^{\circ} \mathrm{C}$ in einem Brutschrank. Nach dem Abschluss der Verdauung erfolgte die Hinzugabe von $50 \mu$ FCS, um die Verdauung zu beenden. Um die Zellen für die Filtrierung vorzubereiten, wurde die Suspension über repetitives Auf- und Absaugen mit einer abgeschnittenen Pipetten-Spitze weiter gelöst. Um eine Einzel-Zell-Suspension zu erhalten, wurden die dadurch aufgelösten Zellverbände über einen 50- $\mu$ l-Filter filtriert und in ein 10-ml-Falcon-Tube überführt. Danach erfolgte die Zentrifugation bei $1300 \mathrm{rpm}$ (rounds per minute) für 7 Minuten bei Raumtemperatur. Der Überstand wurde abgesaugt und die Zellsuspension wurde in $1 \mathrm{ml}$ PBS gelöst. Um die Zellen quantifizieren zu können, wurden $10 \mu \mathrm{l}$ Zellsuspension mit $10 \mu \mathrm{l}$ Trypan-Blau vermischt und die Zellen wurden dann unter dem Mikroskop gezählt.

Es erfolgte der Transfer einer vorher bestimmten Zellzahl in FACS-Tubes. Für die Experimente wurden je nach Fragestellung Zellzahlen von 500.000 bis 1.000.000 Zellen verwendet. Nach der Überführung der Zellen in die FACS-Tubes erfolgte die Standard-Färbung zur Detektion von dILC2 nach dem unten aufgeführten Protokoll (Tab. 2.1). Die dILC2 wurden nach der von Roediger et al. (2013) etablierten Methode gefärbt und als CD45 ${ }^{+}$D $90^{\text {hi }} \mathrm{CD} 3$ CD2-Zellen definiert. 


\begin{tabular}{|c|c|c|c|c|c|c|}
\hline \multicolumn{7}{|c|}{$\begin{array}{l}\text { FACS } \\
\text { Tubes }\end{array}$} \\
\hline & $\begin{array}{l}\text { unstained } \\
\text { (ungefärbt) }\end{array}$ & $\begin{array}{l}\mathrm{FMO} \\
\mathrm{CD} 2 / 3\end{array}$ & $\begin{array}{l}\text { FMO } \\
\text { CD45 }\end{array}$ & $\begin{array}{l}\text { FMO } \\
\text { CD90 }\end{array}$ & $\begin{array}{l}\text { FMO } \\
\text { Zombie }\end{array}$ & Maus X \\
\hline $\begin{array}{l}\text { CD2 } \\
\text { (FITC) }\end{array}$ & - & - & + & + & + & + \\
\hline $\begin{array}{l}\text { CD3 } \\
\text { (FITC) }\end{array}$ & - & Isotyp FITC & + & + & + & + \\
\hline $\begin{array}{l}\text { CD45 (Pa- } \\
\text { cific-Blue) }\end{array}$ & - & + & $\begin{array}{l}\text { Isotyp } \mathrm{Pa}- \\
\text { cificBlue }\end{array}$ & + & + & + \\
\hline $\begin{array}{l}\text { CD90 } \\
\text { (PerCP- } \\
\text { Cy5) }\end{array}$ & - & + & + & $\begin{array}{l}\text { Isotyp } \\
\text { PerCP- } \\
\text { Cy5 }\end{array}$ & + & + \\
\hline $\begin{array}{l}\text { Zombie } \\
\text { (APC- } \\
\text { Cy7) }\end{array}$ & - & + & + & + & $\begin{array}{l}\text { Isotyp } \\
\text { APC-Cy7 }\end{array}$ & + \\
\hline
\end{tabular}

Tabelle 2.6: Färbeprotokoll für dILC2. Ein „, “ repräsentiert die Zugabe des jeweiligen Antikörpers, ein „„“' repräsentiert das Weglassen einer Zugabe. „Maus X“ stellt eine beliebige Maus-Probe dar.

Die Zellsuspension wurde ausgezählt und danach wurde eine je nach der Konzentration des Antikörpers ausgerechnete und ausreichende Menge an Antikörper zu der Zellsuspension gegeben. Die Mengen, die für eine bestimmte Zellzahl benötigt wurden, wurden den Angaben des Herstellers entnommen und im Forschungslabor der Dermatologie etabliert. Bei den an die Antikörper konjugierten Farbstoffen handelte es sich um PE (Phycoerythin), FITC (FluoreszinIsothiocyanat), PerCP (Peridinin-Chlorophyll), PacificBlue (Firmenname für 3-Carboxy-6,8- 
difluor-7-hydroxycumarin) und APC (Allophycocyanin). Um lebende und tote Zellen unterscheiden zu können, wurde der Vitalfarbstoff Zombie eingesetzt.

Um eine unspezifische ,verkehrte“ Bindung von Antikörpern an $F_{c}$-Rezeptoren zu vermeiden, erhielten alle Antikörper-enthaltenden Proben standardgemäß auch ein $\mathrm{F}_{\mathrm{c}}$-Block-Agens nach genauen Vorgaben des Herstellers. Alle Proben, außer der unstained-Probe (ungefärbt), haben einen $\mathrm{F}_{\mathrm{c}}$-Block erhalten. In jedem Experiment wurde eine unstained-Probe und mehrere FMO (fluorescence minus one) -Kontrollen mitgeführt. Die unstained-Probe dient zur Korrektur unspezifischer Eigenfluoreszenzen von Zellen. Die FMO-Kontrollen dienen als Kontrolle für den jeweils verwendeten Fluoreszenzfarbstoff. Sie erhalten statt des spezifischen Farbstoff-konjugierten Antikörpers einen unspezifischen Antikörper des gleichen Isotyps, der die Zelle jedoch nicht bindet. Somit wird ausgeschlossen, dass ein Farbstoff-tragender, aber nicht-bindender Antikörper das Ergebnis verfälscht. Außerdem wird durch die FMO-Kontrollen der Negativ-cut-off für die jeweils verwendete Farbe definiert: Alle Farbsignale, die stärker als die verwendete FMOKontrolle sind, werden als „positiv“ betrachtet.

Nach Hinzugabe der Antikörper wurden die Zellsuspensionen für 30 Minuten bei $4{ }^{\circ} \mathrm{C}$ im Dunkeln inkubiert. Schließlich wurden zum Waschen $1 \mathrm{ml}$ PBS in jede FACS-Tube hinzugefügt und die Proben wurden dann bei 1300 rpm für 7 Minuten zentrifugiert. Nach der Zentrifugation wurde das überstehende PBS abgesaugt und ein Restvolumen von $500 \mu$ l belassen.

\subsubsection{Färbung intrazellulärer Antigene}

Um intrazelluläre Antigene anzufärben, ist eine vorherige Fixierung sowie Permeabilisierung der Zellen notwendig. Im vorliegenden Fall sollte der $\mathrm{T}_{\mathrm{H}} 2$-Transkriptionsfaktor GATA3 angefärbt werden (Details siehe Kap. 2.9.1). Nach der Färbung der extrazellulären Zielstrukturen der Zellen erfolgt nun statt der Messung im FACS die weitere Behandlung der Zellen mit den Mouse Foxp3 Buffer Sets nach den genauen Angaben des Herstellers. Danach erfolgt die Messung der Zellen im FACS wie im Protokoll beschrieben.

\subsubsection{Kompensation der Fluoreszenz}

Die verschiedenen, an die Antikörper gebundenen Farbstoffe haben ein spezifisches Emissionsspektrum, das sich teilweise zwischen den verwendeten Farbstoffen überschneidet. Um unspezifische „Überschneidungen“ der Farbspektren zu verhindern und falsche Signale zu vermeiden, bedarf es einer „Kompensation“, die im Nachhinein manuell mit der BD FACSDivaSoftware durchgeführt wurde (BD Pharmingen, Heidelberg, Deutschland). 


\subsection{Durchflusszytometrie}

Die Durchflusszytometrie (FACS; fluorescence activated cell sorting) ist ein standardisiertes Verfahren, das mittels Laseremission und -absorption die Morphologie einer Zelle sowie die gebundenen fluoreszierenden Antikörper qualitativ und quantitativ physikalisch erfassen kann.

Jede Zelle besitzt eine bestimmte Größe und Granularität. Außerdem können Zellen mit fluoreszierenden Antikörpern beladen werden. Diese Antikörper sind an Fluoreszenz-Farbstoffe (z. B FITC, PE, APC usw.) gekoppelt, die wiederum ein spezifisches Emissionsmaximum besitzen. So hat beispielsweise APC sein maximales Emissionsspektrum im blauen Bereich des sichtbaren Lichts. Wenn nun ein mit APC beladener Antikörper an ein Zielantigen einer Zelle bindet, dann kann der blau fluoreszierende Farbstoff in den Fluoreszenz-Detektionslasern erfasst werden. Abb. 2.3 illustriert die Funktionsweise des FACS. 


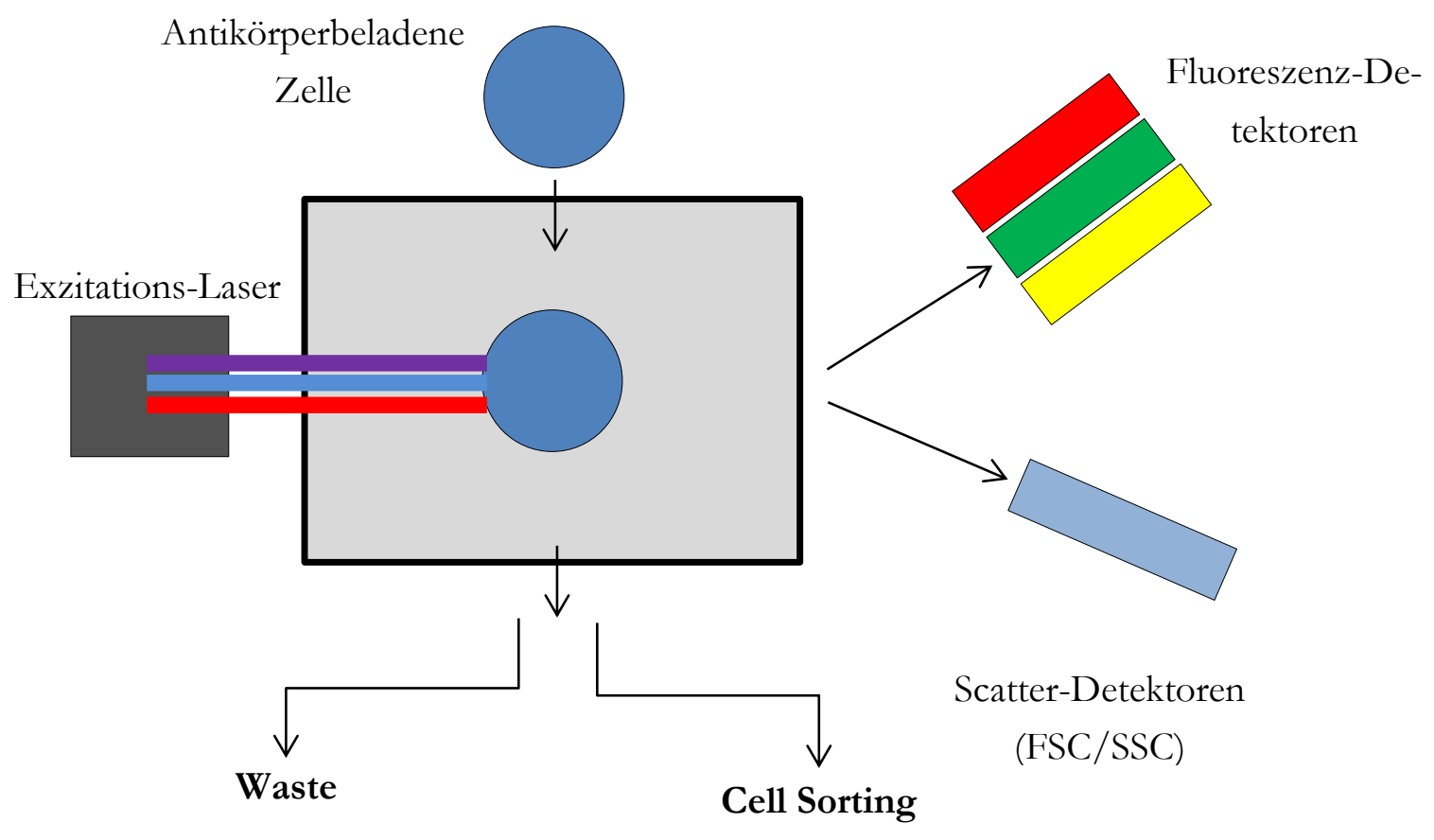

Abb. 2.3: Das Prinzip der Durchflusszytometrie. Diese Abbildung wurde selbst erstellt.

Eine zu untersuchende Zelle wird durch ein vorgefertigtes System in eine separate Kammer gezogen. In dieser separaten Kammer wird diese Zelle nun mit verschiedenen Exzitationslasern bestrahlt (violetter, blauer, roter Laser). Die physikalischen Reaktionen führen nun einerseits zu einer Streuung und andererseits zu einer Absorption bzw. Emission des Lichtes. Analog dazu wird zum einen die entstehende Streuung durch Scatter-Detektoren und zum anderen wird das elektromagnetische Farbspektrum der durchgeschossenen Laserstrahlen durch FluoreszenzDetektoren analysiert. Die Streuung wird durch einen sog. forward und sideward scatter (FSC, SSC) angegeben und graphisch aufgetragen. Der FSC ist direkt abhängig von der Größe, der SSC direkt abhängig von der Granularität der zu untersuchenden Zelle. Die Emissionswellen wiederum gelangen zu den Farbdetektoren. Sie können die elektromagnetischen Wellen messen und ebenfalls graphisch auftragen. Auf diese Weise können die Zellen durch die beschriebenen physikalischen Prozesse sowohl morphologisch und quantitativ (Größe und Granularität) als auch qualitativ (Antikörperbindung) charakterisiert werden. Die Zelle kann dann in Folge entweder verworfen (,Waste $\left.e^{6}\right)$ oder aber im Sinne eines Cell-Sorting-Mechanismus (siehe unten) für weitere Aufarbeitungs-Zwecke isoliert werden. 


\subsection{Apoptose-Assays mit Annexin-V- und Caspase-3/7-Färbung}

Zur Detektion einer frühen Apoptose wurden die Mäuse wie oben beschrieben mit DNFB sensibilisiert und behandelt. Nach der Behandlung mit DNFB wurden die Mäuse getötet. Die Zellisolation fand jedoch nicht 24 Stunden, sondern schon 2 Stunden später statt, um die frühen Phasen der Apoptose erfassen zu können.

Im Rahmen einer Apoptose finden verschiedene Reaktionen innerhalb einer Zelle statt. Eine davon ist die Veränderung der Phospholipid-Oberfläche der Zellmembran. Bestimmte Phospholipide, darunter das Phosphatidylserin (PS), werden von der intrazellulären zur extrazellulären Seite verlagert (Naito et al. 1997; Segawa und Nagata 2015). Annexine können Calciumabhängig dieses Phosphatidylserin binden und dadurch detektieren. Annexin-V kann an fluoreszierende Farbstoffe gebunden und seine Bindung kann dann mittels FACS gemessen werden. Zur Detektion wurde das Annexin-V-Staining Kit gemäß Herstelleranweisung verwendet.

Als weiterer Apoptose-Assay wurde auf die Färbung zellulärer dann zurückgegriffen, die durch die Aktivierung bestimmter Caspasen möglich ist. Caspasen sind eine Familie von Cystein-abhängigen Proteasen, die bestimmte Proteine spalten und dadurch eine Apoptose entweder initiieren oder amplifizieren können. Beispielhaft zu nennen sind die Caspase 3, die das apoptotische Potenzial von Caspase 8 potenzieren kann und zu verschiedenen zellulären Veränderungen durch die Spaltung von poly(ADP-ribose) polymerase (PARP), DNA-abhängige Proteinkinasen, Proteinkinase C $\delta$, und Aktin führt (Ow et al. 2008). Um nun eine Caspase-Aktivität in der Zelle zu bestimmen wurde das Caspase-3/7-Staining Kit eingesetzt. Es enthält ein Oligo-Peptid, das an einen DNA-bindenden Farbstoff gekoppelt ist. Dieser Farbstoff kann aufgrund des OligoPeptids die DNA nicht binden. Beim Vorhandensein aktivierter Caspase-3/7-Proteine können sie das Oligo-Peptid vom DNA-bindenden Farbstoff abspalten und freisetzen. Der freigesetzte DNA-bindende Farbstoff kann dann die zellulären Nukleinsäuren binden und ist dadurch ein indirekter Hinweis auf das Vorhandensein von aktivierten Caspase-3/7-Proteinen. Als Lebend/Tot-Farbstoff nutzte ich hier statt des in den meisten Experimenten verwendeten Zombie-Markers das 7-AAD, da dies vom Hersteller empfohlen wurde.

\subsection{Proliferations-Assay mit BrdU}

Zur Detektion der Proliferation führte ich die Färbung von intranukleär-gebundenem BrdU durch. Im Rahmen des Zellzyklus kommt es zur Neusynthese und Verdopplung des genetischen Materials einer Zelle. Hierfür werden die Nukleotide als Grundbaustein der DNA benötigt. 


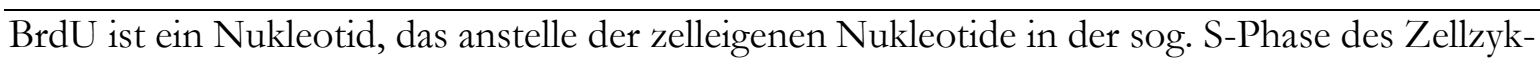
lus eingebaut werden kann. Das gebundene BrdU unterbricht damit den Zellzyklus und proliferierende, BrdU-einbauende Zellen arretieren. Im darauffolgenden Schritt kann durch intranukleäre Antikörperfärbungen das gebundene BrdU detektiert und damit durchflusszytometrisch messbar gemacht werden (Gratzner 1982).

Den Mäusen wurden drei Tage in Folge 1-2 mg BrdU in 100-150 $\mu$ l PBS gelöst intraperitoneal in 24-Stunden-Zeitabständen injiziert. Am vierten Tag erfolgten die Euthanisierung und die Aufarbeitung, Isolierung und Färbung der Zellen, wie es in 2.4 beschrieben wurde. Der zusätzliche Schritt der intranukleären Färbung des gebundenen BrdU erfolgte durch die Verwendung des BrdU-Staining Kits nach den genauen Anweisungen und Vorgaben des Herstellers.

\subsection{Cell Sorting und mRNA-Sequencing}

Für die RNA-Sequenzierung mussten die dILC2 zuvor isoliert werden. Dies wurde mit dem Cell Sorter BD FACSAria durchgeführt. Es wurden sämtliche dILC2 von $30 \mathrm{WTT}$ sowie 16 $\mathrm{RAG}^{-/}$-Mäusen sortiert, gereinigt und in $1 \mathrm{ml}$ Trizol sortiert., wobei man Zellzahlen von 15.000-20.000 dILC2 pro Gruppe erhielt.

Die RNA Isolierung erfolgte in der Core Unit für NGS-Integrative Genomics (NIG) der Universitätsmedizin Göttingen (UMG).

Mein eigener Anteil an der Methodik bestand in der Präparation und Sortierung der Zellen sowie im späteren Auswerten der Ergebnisse nach der Sequenzierung und dabei insbesondere der Translation auf biologische Prozesse. Die speziellen methodischen Details der Sequenzierung und Bioinformatik (Kap. 2.8.1-2.8.3) wurden unabhängig von mir im NIG-Labor durchgeführt und werden hier nur der Vollständigkeit halber aufgeführt. Die jeweiligen Materialien und verwendeten Software-Applikationen mit Hersteller und Herstellungsort beziehungsweise Software-Versionen werden in diesem speziellen Teil in den Text eingefügt.

\subsubsection{RNA Präparation, Qualitätskontrolle und Quantitätsmessung}

Die Sequenzierung der RNA erfolgte nach einem von Illumina bereitgestellten Protokoll für sehr geringe Mengen an RNA-Material (unter 10 ng). Nach der Präparation der RNA erfolgte das Umschreiben in eine cDNA-Library. Die RNA wird in DNA umgeschrieben, da DNA stabiler und leichter zu amplifizieren ist. Hierfür wurde das TruSeq RNA Library Preperation Kit v2, Set A verwendet (Illumina, München, Deutschland). Das Protokoll wurde durch verschiedene 
Schritte effizienter gestaltet: Erstens wurde das Detektieren und „Fangen“ der RNA durch ein optimales Verhältnis von RNA und Oligo dT Beads verbessert. Zweitens wurde durch eine Anpassung der Konzentration der jeweiligen Adapter die Ligation verbessert (Ligations-Effizienz: > 94 \%). Zuletzt wurde bei der Amplifizierung die Zahl der repetitiven PCR-Zyklen erhöht (normalerweise 10, hier erhöht auf ca. 15), um eine geeignete Menge an cDNA zu erhalten.

Die Qualität und Integrität der RNA wurde vor der Generation der cDNA-Library nicht überprüft, da ohnehin sehr geringe Mengen an RNA vorhanden waren $(<10 \mathrm{ng})$. Nach der Generation der cDNA-Library wurde zur Quantifizierung ein fluorometrisch-basiertes System, nämlich das QuantiFluor dsDNA System (Promega, Mannheim, Deutschland) verwendet. Nach der Quantifizierung erfolgte die Sequenzierung unter Verwendung vom Illumina HiSeq 4000 Kit (Illumina, München, Deutschland).

\subsubsection{Bioinformatische Analyse (mapping und normalization)}

Für die bioinformatische Analyse mussten die Daten der Sequenzierung mittels der Software „BaseCaller“ (Illumina, München, Deutschland) in BCL-Dateien umgeschrieben werden. AuBerdem erfolgte ein Umschreiben in fastq-Dateien unter Verwendung der Software „bcl2fastq“ (v2.17.1.14). Die Qualitätskontrolle erfolgte mit der frei verfügbaren Software FastQC (version 0.11.5, www.bioinformaticsbabraham.ac.uk/projects/fastqc).

Die Sequenzen wurden unter Verwendung der „STAR“-Software (version 2) neben dem Referenzgenom von Mus musculus aufgetragen, die zwei Mismatches je 50 Basenpaare erlaubt (Dobin et al. 2013). Daraufhin wurden die Kopien bzw. Lesezahlen für jedes einzelne Gen von Mus musculus gezählt, was durch die „featureCounts“-Software (version 1.5.0-p1) erfolgte (Liao et al. 2014). Die Analyse der Kopien wurde durch das Programm R durchgeführt (version 3.2.0, www.bioconductor.org). Der cut-off für die Kandidaten-Gene wurde bei einem absoluten $\log 2$ fold $>1$ und FDR-korrigierten $\mathrm{p}$-Werten $<0,05$ gesetzt. Dabei steht $\log 2$ fold $>1$ für eine mindestens 2-fach unterschiedliche Expression, FDR steht für false discovery rate und bezeichnet ein zusätzliches statistisches Verfahren, das routinemäßig bei der Analyse großer Sequenzierungs-Dateien zum Einsatz kommt.

\subsubsection{Translation in biologische Prozesse}

Zelluläre Prozesse sind hochkomplex und durch ein Zusammenspiel zahlreicher Proteine bestimmt, die wiederum von verschiedenen Genen exprimiert werden. Deshalb lohnt sich eine breite Betrachtungsweise der Daten, um ggf. „Muster“ in den gemessenen Unterschieden zu 
erkennen. Oft sind mehrere Gene hoch- bzw. herunterreguliert, die aber alle einem bestimmten zellulären Prozess oder Signalweg zuzuordnen sind (z. B. Proliferation, Zytokin-induzierte Aktivierung, oder Jak-STAT-Signalweg). Diese Prozesse und Signalwege lassen sich nun anhand größerer Datenbanken hierarchisch identifizieren und auf kleinere Unterfunktionen herunterbrechen. Sollte es eine bestimmte Anzahl an Genen geben, die sehr stark innerhalb eines spezifischen Prozesses verändert werden, dann verweist das auf eine biologische Relevanz. Um die Sequenzierungs-Daten zu analysieren, verwendet man standardmäßig zwei verschiedene Datensätze, nämlich zum einen der genontologischen Untersuchung (sog. GO-Term-Analyse, term: Begriff) und zum anderen der Untersuchung sog. KEGG-pathways (Kyoto Encyclopedia of Genes and Genomes, pathway: Signalweg). Die GO-Term-Analyse identifiziert zelluläre Prozesse und gliedert sie hierarchisch auf, die KEGG-pathways verläuft ähnlich, nur ohne eine hierarchisch-ontologische Gliederung. Für beide Analysen gibt es geeignete und frei zugängliche Software, die zur Analyse der Daten verwendet wurde. Für die GO-Term-Analyse wurde das Online-Programm Gorilla eingesetzt (Eden et al. 2009), für die KEGG-pathways das Online-Programm „David Functional Annotations“ (Huang et al. 2009).

\subsection{Statistik}

Die statistische Analyse der RNA-Sequenzierungs-Daten erfolgte anhand der oben aufgeführten Softwares durch das NIG. Für die statistische Analyse aller anderen Experimente und zur Anfertigung der Graphen wurde Graph Pad Prism verwendet. Die statistischen Unterschiede zwischen den Gruppen wurden im Falle einer Normalverteilung mittels t-test ermittelt. Eine statistische Signifikanz $\left(,{ }^{* \bullet}\right)$ wurde als p $<0,05$ interpretiert. Eine höhere Signifikanz $\left(,{ }^{* * \circ}\right)$ wurde definiert als $\mathrm{p}<0,01$ und die höchste Signifikanz (, $\left.{ }^{* * * \curvearrowleft}\right)$ mit $\mathrm{p}<0,001$. 


\section{$3 \quad$ Ergebnisse}

\subsection{Identifikation und gating von dILC2 mittels FACS}

Die ILC2 der Haut können auf verschiedene Art und Weise definiert und identifiziert werden. In dieser Sektion wird beschrieben, welche Schritte notwendig waren, um dILC2 in der Haut mittels FACS zu gaten. Gating bezeichnet das anglisierte Wort für das Selektieren einer spezifischen Zellpopulation im FACS (gate: Tor/Schloss). Es gibt verschiedene Möglichkeiten, die in der Literatur beschrieben und angewendet werden. Die zwei gängigsten und bekanntesten sind von Kim et al. (2013), Roediger et al. (2013) sowie Salimi et al. (2013) etabliert worden. In dieser Arbeit wurde die Methode von Roediger et al. (2013) gewählt, die die dILC2 als $\mathrm{CD} 45^{+} \mathrm{CD} 90^{\mathrm{hi}} \mathrm{CD} 3 \mathrm{CD} 2^{-}$-Zellen definiert. Diese Färbe-Strategie lieferte unter den verwendeten Versuchsbedingungen gut reproduzierbare Ergebnisse. Die dILC2-Zellpopulation ließ sich damit gut von den anderen Zellpopulationen abgrenzen (Abb. 3.1). 

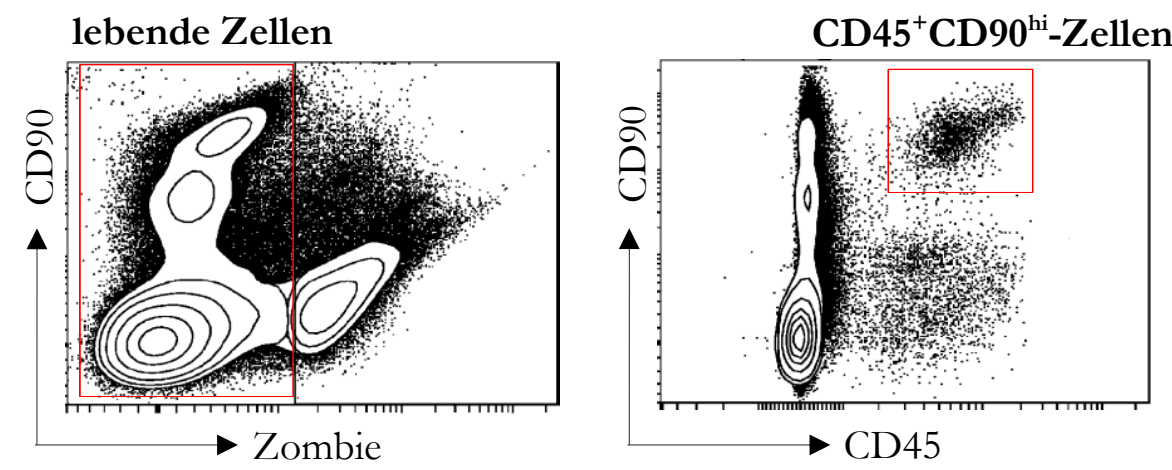

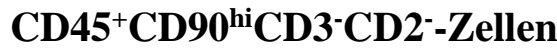

\section{(dILC2)}

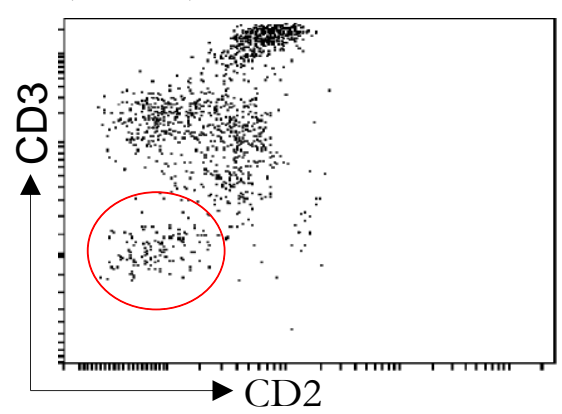

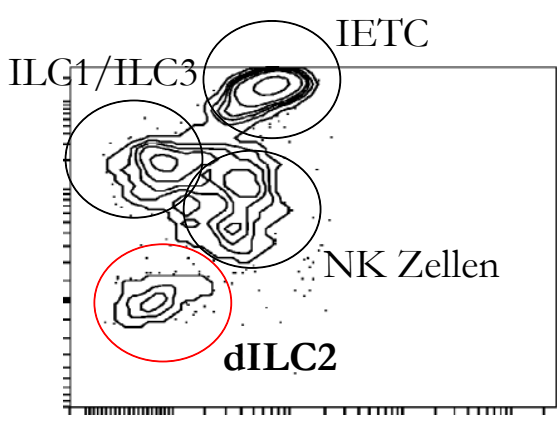

Abb. 3.1: Gating-Strategie für dILC2. Vier repräsentative FACS-Plots (plot: Fenster) für die verwendete gating-Strategie von Roediger et al. (2013). Oben links wurden mit dem Vitalfarbstoff Zombie-Zellen isoliert, die als „lebende Zellen“ bezeichnet werden, da sie negativ auf den Zombie-Farbstoff reagiert haben. Oben rechts wurden aus diesen lebenden Zellen die $\mathrm{CD} 45^{+} \mathrm{CD} 90$ hi (hi; high) -Zellen gegatet. Aus ihnen wurden die CD2-CD3-Zellen gegatet (untere Reihe, roter Kreis), die als dILC2 bezeichnet werden. In den unteren Reihen sieht man beispielhaft die verschiedenen Zellpopulationen aus dem $\mathrm{CD} 45^{+} \mathrm{CD} 90^{\text {hi }}$-gate aufgetragen. Unten links sieht man die Darstellung im DotPlot, unten rechts im ConcentrationPlot. Die übrigen Zellpopulationen sind unten rechts beschriftet als: NK Zellen, ILC1 und ILC3 sowie intraepidermale T-Zellen (IETCs).

\subsubsection{RAG1 ${ }^{-/}$-Mäuse haben signifikant höhere absolute dILC2-Zahlen als WT- Mäuse}

Nach der erfolgreichen Identifikation der dILC2 wurden zuerst die Zellzahlen in den verschiedenen knockout-Mäusen miteinander verglichen. Die Ergebnisse zeigen, dass der knockout von TLR3, MyD88 und der Doppel-knockout von TLR3 und MyD88 zu keinen signifikanten Änderungen der dILC2-Zellzahl im Vergleich mit den WT-Mäusen geführt haben (ungefähr 2000 dILC2 pro Ohr). Die RAG1 ${ }^{-}$-Mäuse wiesen jedoch mit 3813 dILC2 pro Ohr im Mittel bis zu 2-3mal mehr dILC2 auf als WT-Mäuse, was zu vorherigen Veröffentlichungen passt (Abb. 3.2) (Roediger et al. 2013). Bei der Gesamt-Leukozyten-Zahl (CD45+-Zellen) gab es keine signifikanten Unterschiede zwischen WT- und RAG1//-Mäusen (Daten nicht gezeigt). 


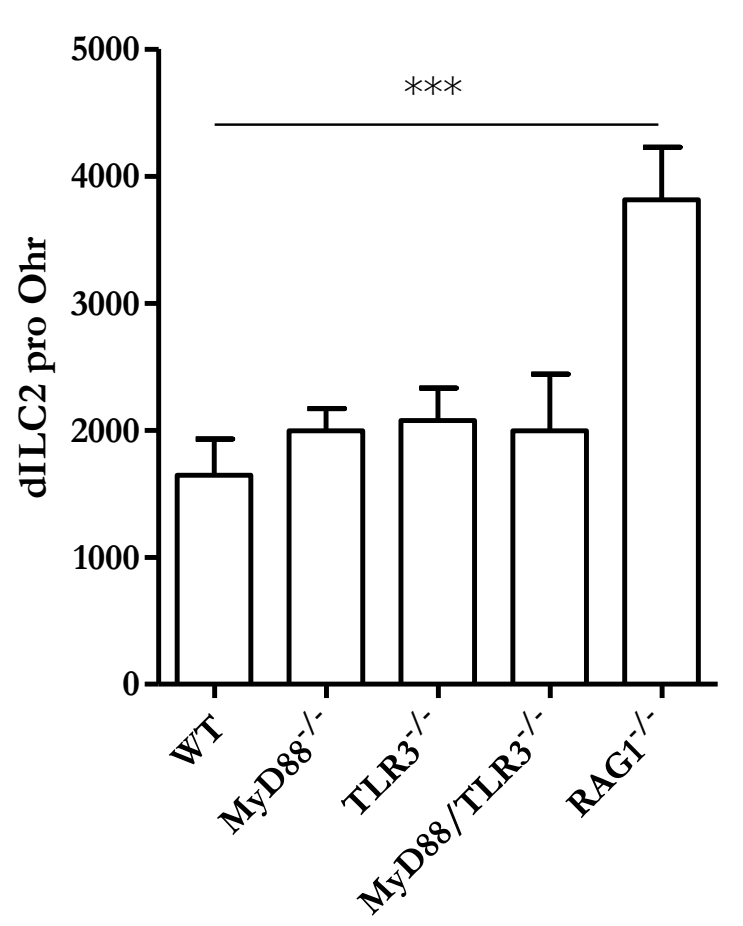

Abb. 3.2: RAG1-/--Mäuse weisen absolut mehr dILC2 als WT-Mäuse auf. Abgebildet ist ein Säulendiagramm, in dem die dILC2 als absolute Zellzahlen von WT-Mäusen und den verschiedenen knockout-Mäusen (MyD88-/, TLR3-/-, MyD88/TLR3-/-, RAG1/-) abzulesen sind. Die dILC2-Zellzahlen wurden auf ein einzelnes Mausohr hochgerechnet. Die Daten für WT- und RAG1-/--Mäuse sind gepoolt aus nicht aufgeführten Zellkultur-Experimenten und nativen Mausohren. Signifikanzniveau: *** p < 0,001, $\mathrm{n}=3-13$ pro Gruppe, \pm Standardfehler.

\subsubsection{RAG1 $^{-/-}$-Mäuse zeigen auch relativ mehr dILC2 als WT-Mäuse}

Neben den dILC2 waren mithilfe der gating-Strategie von Roediger et al. (2013) auch andere Zellpopulationen abzugrenzen, nämlich NK-Zellen, ILC1 und ILC3 sowie IETC (Abb. 3.1). Im nächsten Schritt wurde daher untersucht, ob dILC2 auch relativ zur CD $45^{+} \mathrm{CD} 90^{+}$-Zellpopulation in der RAG1 $1^{-/}$-Maus häufiger anzutreffen waren. Dabei ist zu erkennen, dass die dILC2Zellpopulation in den WT-Zellen im Mittel 11,15\% betrug, während sie in der RAG1 ${ }^{-1}$-Maus im Mittel 81,1\% ausmachte (Abb. 3.3). Deshalb haben $\mathrm{RAG}^{-1}$-Mäuse neben einem absolut höheren Wert von dILC2 auch relativ zur $\mathrm{CD} 45^{+} \mathrm{CD} 90^{+}$-Zellpopulation höhere Zellzahlen von dILC2. 
a
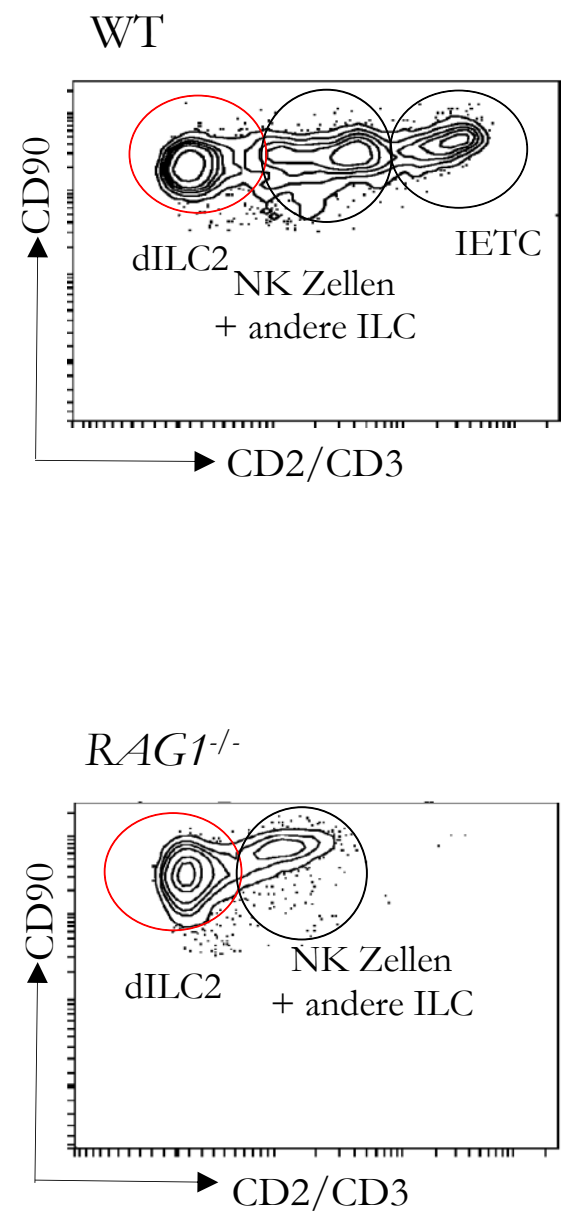

b
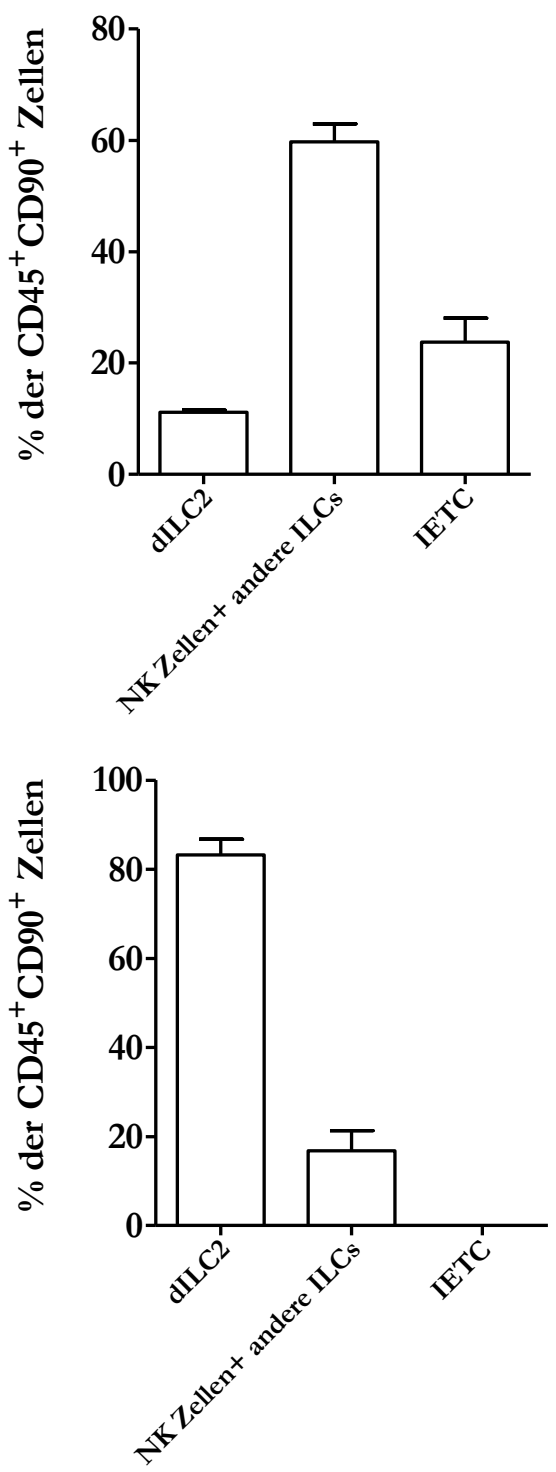

Abb. 3.3: RAG1-/-Mäuse haben relativ mehr dILC2 als WT-Mäuse. Zwei repräsentative FACSPlots, gegatet auf $\mathrm{CD} 45^{+} \mathrm{CD} 90^{+}$-Zellen. Die Kreise separieren die verschiedenen Zellpopulationen, namentlich dILC2 (roter Kreis), NK-Zellen und andere ILC sowie IETC (schwarze Kreise). Links oben repräsentativ für WT-Mäuse, links unten für RAG1\%-Mäuse. Letztere zeigen aufgrund des RAG1-knockouts keine IETC. Rechts zu sehen sind die statistischen Auswertungen, wie viel Prozent der jeweiligen Zellpopulation von den gesamten $\mathrm{CD} 45^{+} \mathrm{CD} 90^{+}$-Zellen ausmachen, die erste Zeile für WT-Mäuse, die zweite Zeile für RAG1 $\%$-Mäuse $(\mathrm{n}=4, \pm$ Standardfehler).

\subsubsection{ICOS- und GATA3-Expression variiert nicht zwischen WT- und RAG1- defizienten dILC2}

Um zu überprüfen, ob die absolut und relativ häufiger vorkommenden dILC2 in der RAG1 ${ }^{-1-}$ Maus phänotypische Unterschiede aufweisen, wurde eine Färbung eines wichtigen Aktivierungsmarkers und des zentralen Transkriptionsfaktors durchgeführt. dILC2 zeichnen sich 
durch die Expression des Aktivierungsfaktors ICOS sowie des Transkriptionsfaktors GATA3 aus (Spits 2013). Da es sich bei GATA3 um ein intrazellulär vorkommendes Protein handelt, ist eine vorherige Permeabilisierung der zu färbenden Zellen notwendig. Die technischen Voraussetzungen und Vorgehensweisen werden in Kap. 2.4.1 beschrieben.

Weder bei GATA3 noch bei ICOS ergab sich ein signifikanter Unterschied zwischen WT- und RAG1-defizienten dILC2. Unterschiede traten weder bei der Anzahl der positiven Zellen noch in der mean fluorescence intensity (MFI) auf, die die „Expressionsstärke“ beschreibt (Abb. 3.4 und Daten nicht gezeigt). Dies weist darauf hin, dass die RAG1-defizienten dILC2 im Vergleich zu WT-dILC2 nicht klassischerweise verschieden differenziert oder aktiviert sind.

- FMO-Kontrolle

WT-dILC2

RAG1\%-dILC2

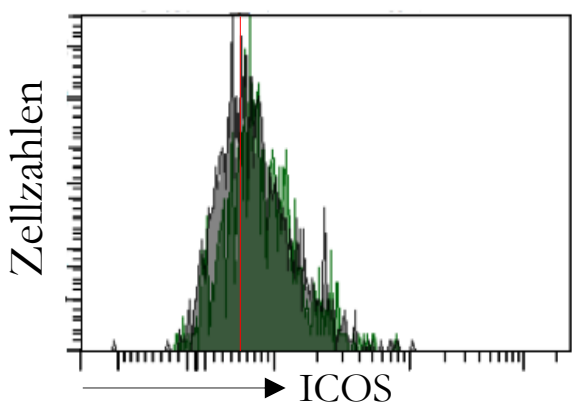

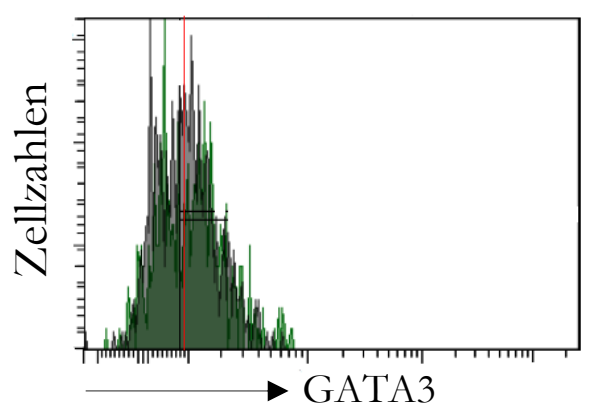

Abb. 3.4: RAG1-defiziente dILC2 zeigen eine ähnliche GATA3- und ICOS-Expression. Links ist ein repräsentativer FACS-Plot für die ICOS-Expression, rechts für die GATA3-Expression abgebildet. Die grüne Fläche zeigt die Expression der W'T-dILC2, die dahinter gelegte graue Fläche die der RAG1defizienten dILC2 und die rote Linie illustriert den cut-off der FMO-Kontrolle ( $\mathrm{n}=2-4)$. 


\subsection{RNA-Sequenzierung zeigt zahlreiche unterschiedlich exprimierte Gene zwischen WT- und RAG1-defizienten dILC2}

$\mathrm{RAG}^{-1-}$-Mäuse werden von vielen Arbeitsgruppen als Modell zur Untersuchung von ILC2 verwendet, da ILC2 in dieser Mauslinie zahlenmäßig häufiger vorkommen als in WT-Mäusen. AuBerdem erleichtert das Fehlen von Lymphozyten in diesen Mäusen erheblich die Aufreinigung und Isolation. Es konnte in der vorliegenden Untersuchung gezeigt werden, dass RAG1 ${ }^{1-}$ Mäuse sowohl absolut als auch relativ mehr dILC2 unter physiologischen Bedingungen in der Haut aufweisen als W'T-Mäuse. Neuere Studien fanden heraus, dass RAG1 einen Einfluss auf die Entwicklung von ILC2 hat (Karo et al. 2014). Deshalb ist es denkbar, dass RAG1-defiziente dILC2 trotz ähnlicher ICOS- und GATA3-Expression Unterschiede im Gen-Expressionsprofil aufweisen. Um dieser Fragestellung nachzugehen, wurde eine RNA-Sequenzierung von WTund RAG1-defizienten dILC2 mit Unterstützung des NIG der Universität Göttingen durchgeführt. Interessanterweise zeigte sich hier, dass insgesamt 2374 Gene mindestens um den Faktor 2 unterschiedlich reguliert waren (Gesamtbetrachtung von positiver und negativer Regulation). Von diesen waren 1160 hochreguliert und 1214 herunterreguliert (Abb. 3.5).

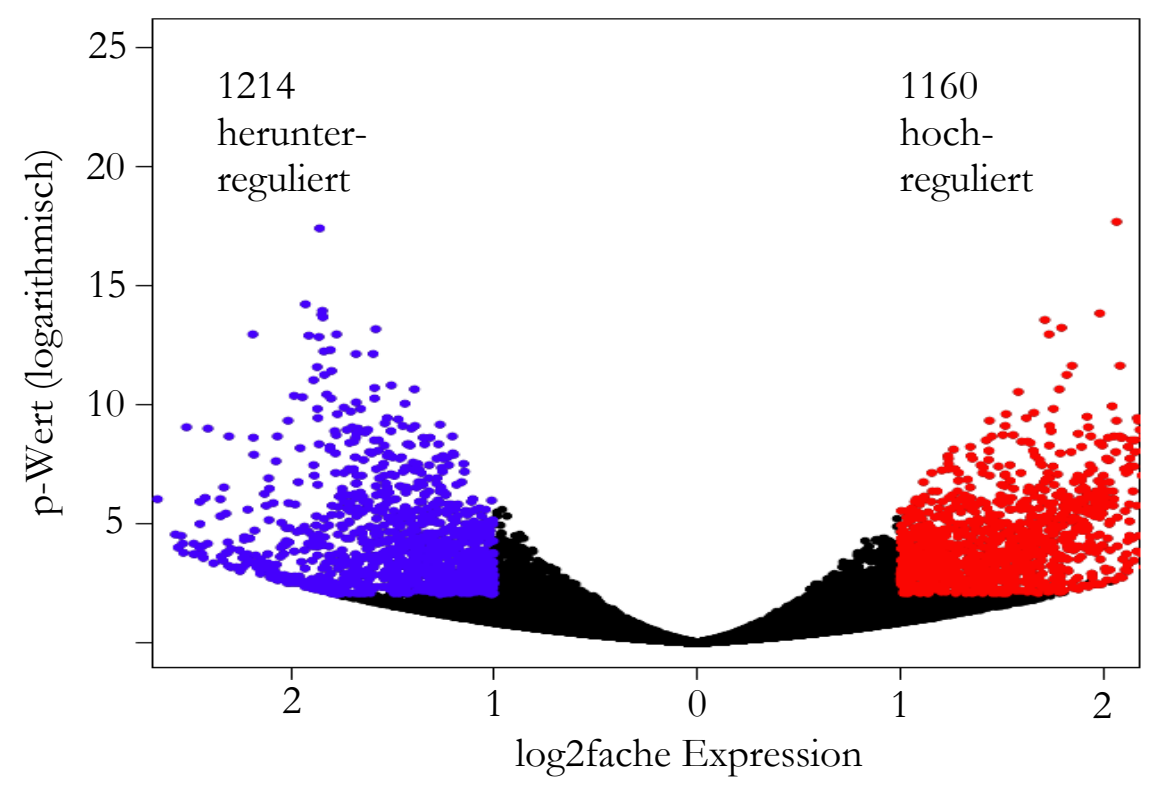

Abb. 3.5: Über 2000 Gene sind in RAG1-defizienten dILC2 unterschiedlich reguliert. VolcanoPlot aus den gewonnenen RNA-Sequenzierungs-Daten. Ein einzelner Punkt repräsentiert ein Gen. Die Abszisse trägt den Logarithmus zur Basis 2 als Maß für die Veränderung der Expression auf. Beispiel: Gene, die sich bei „1“ auf der Abszisse befinden, sind zweifach unterschiedlich reguliert (entweder hoch- oder herunterreguliert). Die roten Flächen zeigen signifikant hochregulierte, die blauen Flächen signifikant herunterregulierte Gene. Die Daten für die RNA-Sequenzierung wurden gewonnen aus gepoolten dILC2 aus 16 RAG1-/-Mäusen sowie 30 W'T-Mäusen. Der p-Wert ist angegeben als Logarithmus. 


\subsubsection{Die unterschiedlich regulierten Gene sind mit Signalwegen assoziiert, die verantwortlich sind für T-Zell-Immunantwort, Proliferation, viraler und parasitärer Abwehr und Autoimmun- Prozessen}

Für einen Überblick über die funktionelle Bedeutung der gemessenen Unterschiede wurde einerseits eine genontologische Analyse der betroffenen Gene (GO-Term-Analyse) und andererseits eine Untersuchung von KEGG-pathways (Kyoto Encyclopedia of Genes and Genomes) durchgeführt (für Näheres siehe Kap. 2.8.3). Besonders signifikante Treffer in der GO-TermAnalyse waren neben der Regulation der Zellproliferation Prozesse der Regulation der T-ZellImmunantwort sowie der T-Zell-Zytotoxizität (Abb. 3.6).

Die Analyse der KEGG-pathways ergab signifikante Veränderungen in verschiedenen immunologischen Prozessen, darunter bei den Zytokin-Zytokin-Rezeptor-Interaktionen sowie bei zytotoxischen Zell-Mechanismen. Zu den zellulären Signalwegen, die am signifikantesten betroffen waren, gehörte u. a. der Jak-STAT-Signalweg. Interessanterweise zeigten sich auch Beteiligungen bei Autoimmun-Prozessen und dabei insbesondere bei chronisch-entzündlichen Darmerkrankungen. Weiterhin zeigten sich Veränderungen bei Prozessen mikrobieller und besonders viraler und parasitärer (also $\mathrm{T}_{\mathrm{H}} 2$-dominierter) Immunabwehr (wie Masern und Leishmaniose) (Abb. 3.6 und Daten nicht gezeigt). 


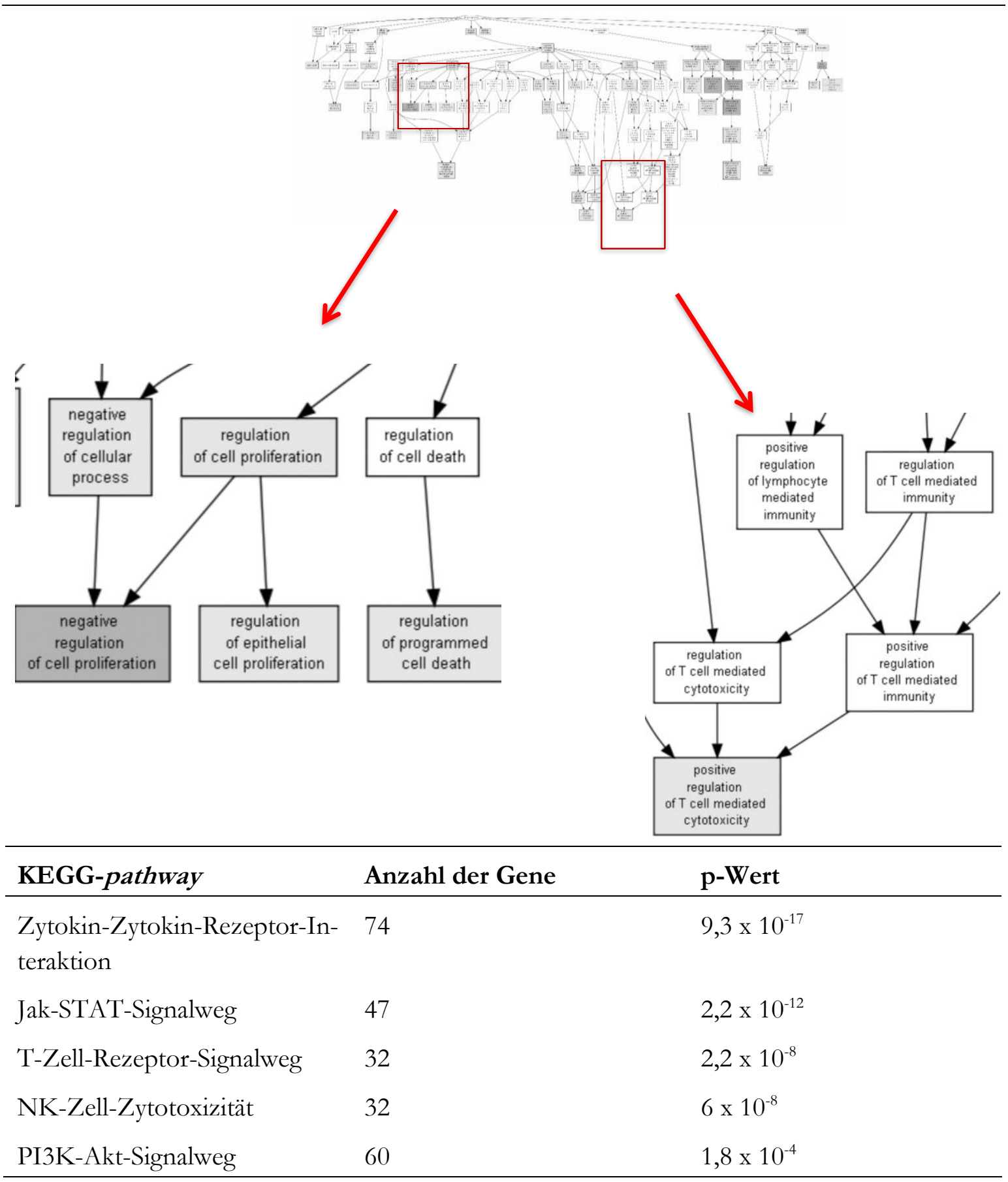

Abb. 3.6: Immunantwort, Proliferation sowie Autoimmun-Signalwege werden in RAG1-defizienten dILC2 unterschiedlich reguliert. Oben abgebildet ist ein mit der Software GOrilla entwickelter genontologischer Stammbaum der veränderten Funktionen. In roten Rechtecken hervorgehoben sind Funktionen, die für die Analyse und Fragestellung von besonderem Interesse waren, sie sind exemplarisch vergrößert und werden in englischer Sprache gezeigt. Unten abgebildet ist eine Tabelle mit den betroffenen KEGG-pathways (mit David Functional Annotations ermittelt), der Anzahl der veränderten Gene, sowie der errechnete p-Wert. Die fünf gezeigten Einträge gehören zu den zehn (von 94) am stärksten veränderten KEGG-pathways, wobei die Zytokin-Zytokin-Rezeptor-Interaktion die am signifikantesten veränderte war. 


\subsubsection{Mehrere Zytokine und Zytokin-Rezeptoren werden unterschiedlich exprimiert}

Eine detaillierte Analyse der betroffenen Gene der Zytokin-Zytokin-Rezeptor-Interaktion ergab, dass viele ILC2-typische Zytokine und Zytokin-Rezeptoren hochreguliert waren (Abb. 3.7a). Hierzu zählen Il5, Il13, Il2ra, Il2rb, Il2rg, Il4ra und Crfl2. Dies sind Hinweise auf einen aktivierten Phänotyp der RAG1-defizienten dILC2. Dabei sollte man darauf hinweisen, dass andere typische Rezeptoren wie Il13ra1 herunterreguliert waren, was auf eine Gegenkompensation hindeuten könnte. Interessanterweise waren nicht nur $\mathrm{T}_{\mathrm{H}} 2$-typische Zytokine und ZytokinRezeptoren unterschiedlich exprimiert, sondern auch typische $\mathrm{T}_{\mathrm{H}} 1$ - (Ifng, Il12rb) und $\mathrm{T}_{\mathrm{H}} 17-\mathrm{Gene}$ (Il17f, Il23r, Ifng, Il17a, Il12rb1, Tgfb1, Il10ra). Außerdem waren Transkriptionsfaktoren, die zu den relevanten Transkriptionsfaktoren von ILC1 gerechnet werden, höher exprimiert (Eomes, Tbx21) (Abb. 3.7b). Diese Gene sind jedoch auch charakteristisch für aktivierte ILC2, da sie unter bestimmten Bedingungen einen ILC1- bzw. ILC3-typischen Phänotypen annehmen können (Huang et al. 2015; Ohne et al. 2016). Allerdings zeigte sich kein Unterschied in der Gata3 bzw. Roryt-Expression, weder auf der Ebene der mRNA noch auf der Protein-Ebene. Dies deutet darauf hin, dass es sich mit großer Wahrscheinlichkeit nicht um eine Kontamination mit anderen ILC im gate der RAG1-defizienten dILC2 handelte, sondern dass die betroffenen ILC2 neben ihren klassischen Transkriptionsfaktoren zusätzlich noch weitere exprimierten.

Besonders relevante oder auffällige Ergebnisse der RNA-Sequenzierungs-Analysen wurden auf der Protein-Ebene verifiziert. So zeigten die RAG1-defizienten dILC2 zwar einen aktivierten Phänotyp in den Sequenzierung-Daten, bei den klassischen Aktivierungsmarkern wie ICOS, KLRG1 und CD44 ergaben sich jedoch keine signifikanten Unterschiede in der Expression gegenüber den W'T-dILC2 (Abb. 3.4 und Daten nicht gezeigt). Anders als in den Sequenzierungs-Daten war kein Nachweis einer unterschiedlichen Expression von intrazellulärem IL-5 und IL-13 möglich (Daten nicht gezeigt). Für weitere auffällige Befunde ließen sich die Veränderungen aber konsistent auch auf der Protein-Ebene zeigen: So wurde beispielsweise eine verstärkte Expression des IL-7R nachgewiesen (Abb. 3.7c). 


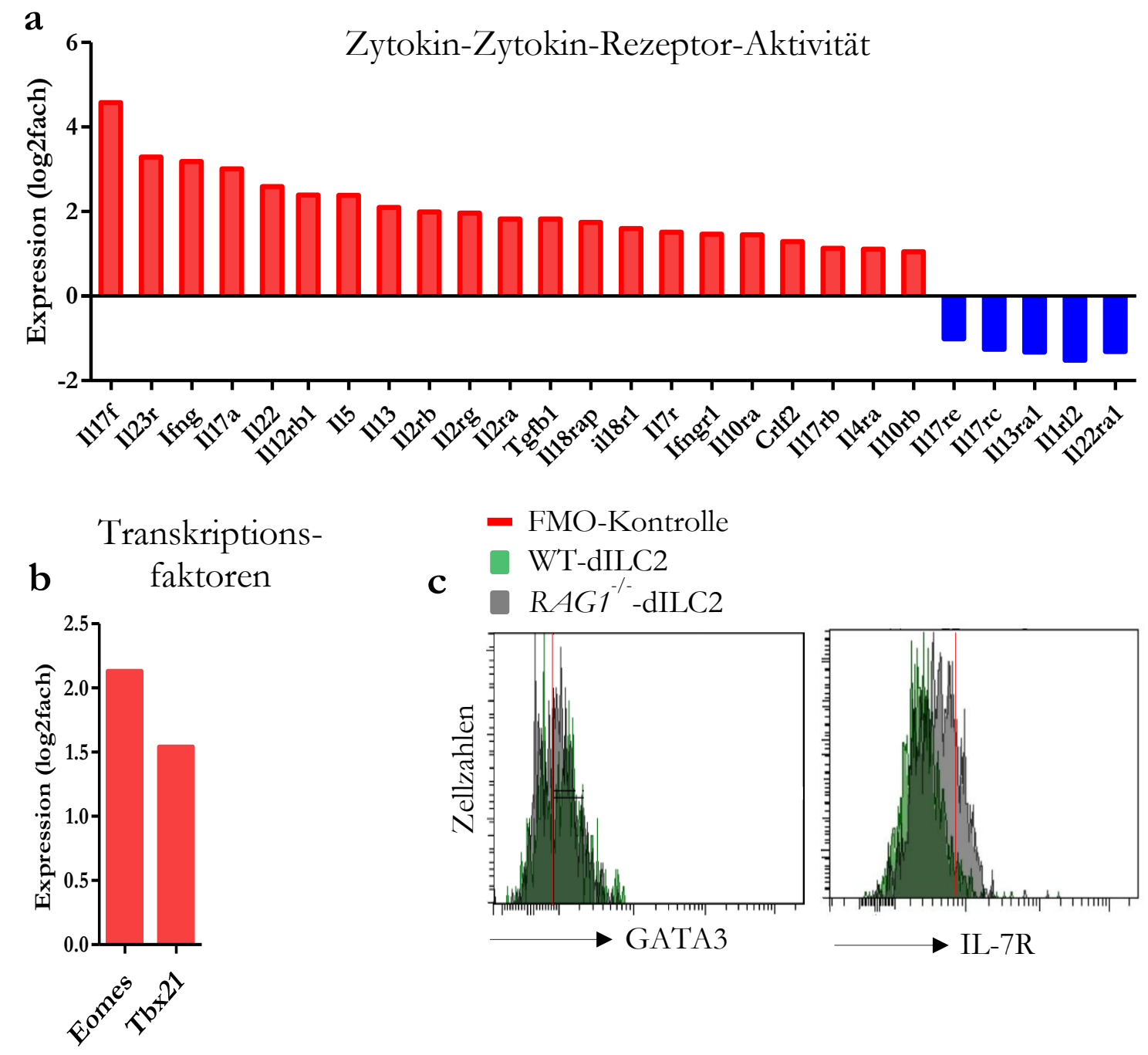

Abb. 3.7: RAG1-defiziente dILC2 zeigen in den Sequenzierungs-Daten einen aktivierten Phänotyp. (a) zeigt die Expression verschiedener Gene der Übergruppe Zytokin-Zytokin-Rezeptor-Aktivität in RAG1-defizienten dILC2. Die roten Balken stellen eine höhere Expression dar, die blauen Balken eine niedrigere Expression in RAG1-defizienten dILC2. Die jeweiligen Gene sind unter der Abszisse aufgetragen. (b) zeigt die Expression von ILC1-typischen Transkriptionsfaktoren, die Gen-Namen sind unter der Abszisse aufgetragen. (c) zeigt eine repräsentative Darstellung der GATA3 (links) sowie IL7R- (rechts) Expression von WT-dILC2 (grüne Fläche) sowie RAG1-defizienten dILC2 (hinter gelegte graue Fläche). Die rote Linie illustriert die Grenzen der FMO-Kontrolle ( $\mathrm{n}=2-4)$.

Zusammenfassend lässt sich festhalten, dass sich RAG1-defiziente dILC2 wesentlich im GenExpressionsprofil gegenüber W'T-dILC2 unterscheiden. Die vorliegenden Daten weisen darauf hin, dass die Immunantwort und die allgemeine Biologie der dILC2 erheblich verändert sein könnten, was sich vermutlich im Sinne eines überaktivierten Phänotyps interpretieren lässt. 


\subsection{Im DNFB-Kontaktallergie-Modell sinken die dILC2 in RAG1 ${ }^{-/-}$ Mäusen}

Es erschien möglich, dass durch die unterschiedliche genetische Regulation auch physiologische Funktionen der dILC2 in RAG1 ${ }^{-/}$-Mäusen variiert sein könnten. Um die funktionelle Relevanz der gezeigten Expressions-Veränderungen zu untersuchen, wurde durch DNFB-Behandlung ein CHS-Modell konzipiert und untersucht. Es ist bekannt, dass dILC2 eine wichtige regulatorische Funktion bei einer TNCB-CHS übernehmen (Rafei-Shamsabadi et al. 2018). Daher sollte geprüft werden, ob sich die allergische Immunantwort zwischen $\mathrm{RAG}^{-1}$-Mäusen und WTMäusen unterscheidet und wie sich die dILC2 in diesem Allergie-Modell verhalten. Dabei wurden sowohl die Ohrschwellungen als auch die Veränderungen der dILC2-Zellzahl analysiert.

Zwei Punkte waren bei der Analyse der Ohrschwellung auffällig. Zum einen war die Induktion der CHS durch DNFB möglich, obwohl keine T-Zellen vorhanden waren. Dies wurde auch in vorherigen wissenschaftlichen Arbeiten bereits gezeigt und durch eine Beteiligung von Gedächtnis-NK-Zellen interpretiert (O'Leary et al. 2006). Zum anderen war bei den RAG1 ${ }^{1 /-}$-Mäusen die Ohrschwellung im CHS-Modell geringer ausgeprägt als bei den WT-Mäusen $\left(8,4 \times 10^{-2} \mathrm{~cm}\right.$ bei den WT-Mäusen versus 3,8 x $10^{-2} \mathrm{~cm}$ bei den RAG1/--Mäusen, Zahlen als Mittelwerte) (Abb. 3.8). Da zumindest nach einer aktuell publizierten Arbeit den dILC2 eine eher regulatorische Rolle bei einer CHS zugeschrieben wird, ist davon auszugehen, dass die wesentliche immunologische Funktion der fehlregulierten RAG1-defizienten dILC2 erhalten geblieben ist (RafeiShambasadi et al. 2018).

In Bezug auf die Zellzahl fiel auf, dass die dILC2-Zellzahl in den WT-Mäusen im mit DNFB behandelten Ohr anstieg (207 auf 512 pro 200.000 gezählte Events, Zahlen als Mittelwerte), während sie in den RAG1//-Mäusen im behandelten Ohr absank (654 auf 442 pro 200.000 gezählte Events, Zahlen als Mittelwerte); es zeigte sich also eine reziproke Dynamik (Abb. 3.8). 

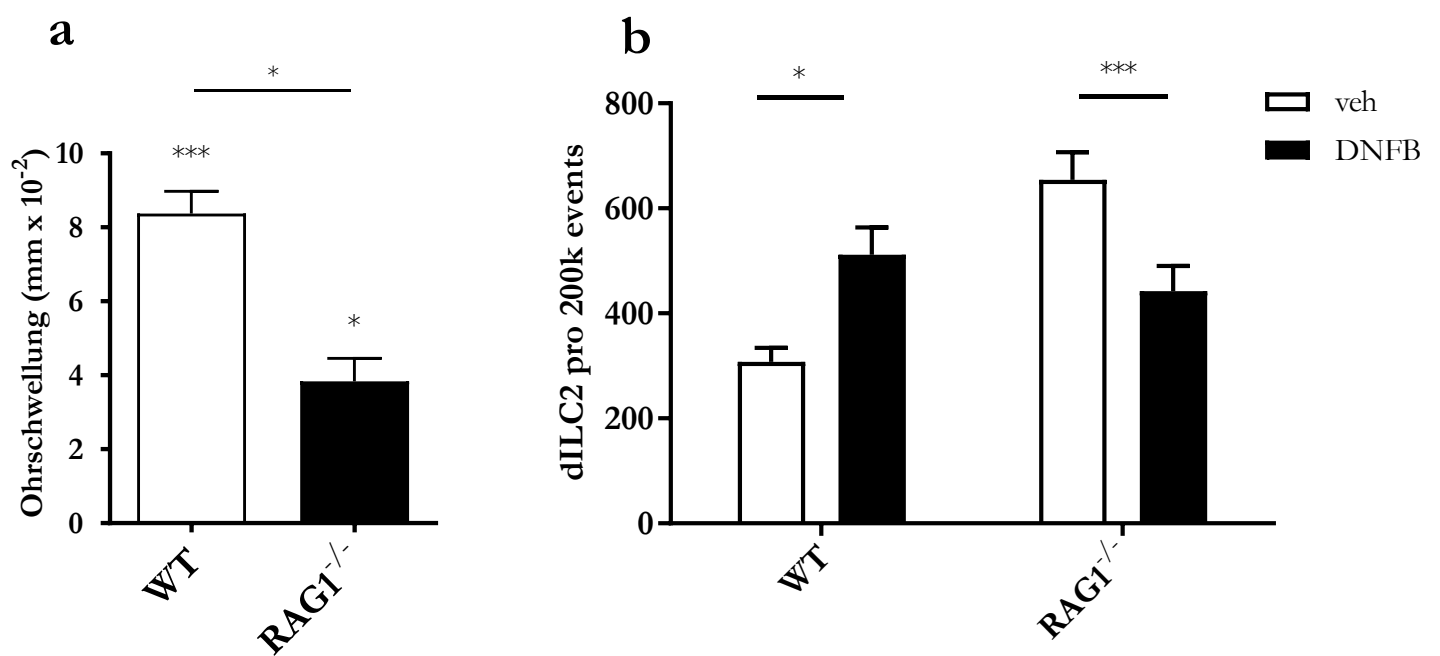

Abb. 3.8: Im DNFB-Kontaktallergie-Modell zeigen WT- und RAG1-defiziente dILC2 eine reziproke Dynamik. (a) zeigt die graphische Auftragung der Ohr-Dicken nach DNFB-challenge in WTund RAG1\%-Mäusen ( $\mathrm{n}=6-8$, gemessen in mehr als 2 verschiedenen Experimenten). Zur Erinnerung: challenge bezeichnet die Exzitation entweder des Vehikels (veh) oder des Allergens (DNFB) (siehe Kap. 2.3). Für die Berechnung der Signifikanz siehe den entsprechenden Absatz Kap. 2.3.1. (b) zeigt die dILC2-Zellzahl pro 200.000 gemessene Events; die weißen Säulen zeigen das Vehikel-behandelte Ohr, die schwarzen Säulen das DNFB-behandelte $\mathrm{Ohr}(\mathrm{n}=7-11$, gemessen in mehr als 3 verschiedenen Experimenten). Signifikanzniveaus: $* \mathrm{p}<0,01 ; * * *<0,001 ; \pm$ Standardfehler.

Um zu überprüfen, ob die in der RAG1/-Maus fehlenden Lymphozyten für die reziproke Dynamik der dILC2 im DNFB-CHS-Modell verantwortlich waren, wurden adoptive Transfer (AT) Experimente durchgeführt (siehe Kap. 2.3.2.). Die Ohrschwellung fiel in den AT-Mäusen vergleichbar aus. Auch der beobachtete Abfall der dILC2-Zellzahl ließ sich nicht durch den AT verändern (729 auf 511 in AT-Mäusen und 664 auf 334 pro 200.000 gezählte Events in naiven $\mathrm{RAG1}^{-/}$-Kontroll-Mäusen, Zahlen als Mittelwerte) (Abb. 3.9). Daraus ergab sich, dass die fehlenden Lymphozyten zumindest nicht der einzige Grund für die Reduktion der dILC2 nach der DNFB-CHS sind. Es ist daher wahrscheinlich, dass die dILC2 unabhängig vom Vorhandensein von B- und T-Zellen eine veränderte Biologie und Immunantwort aufweisen. 
a

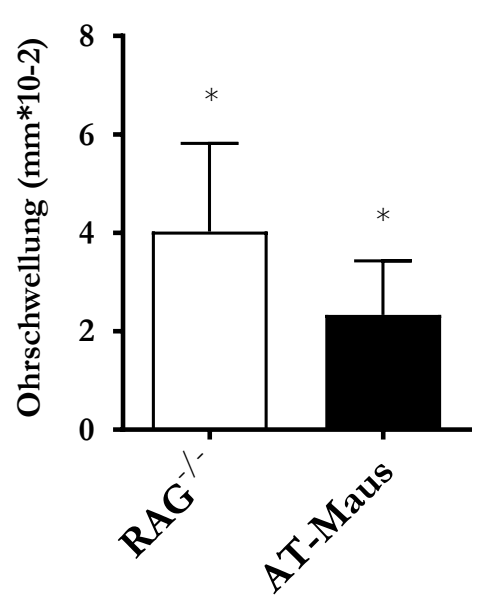

b

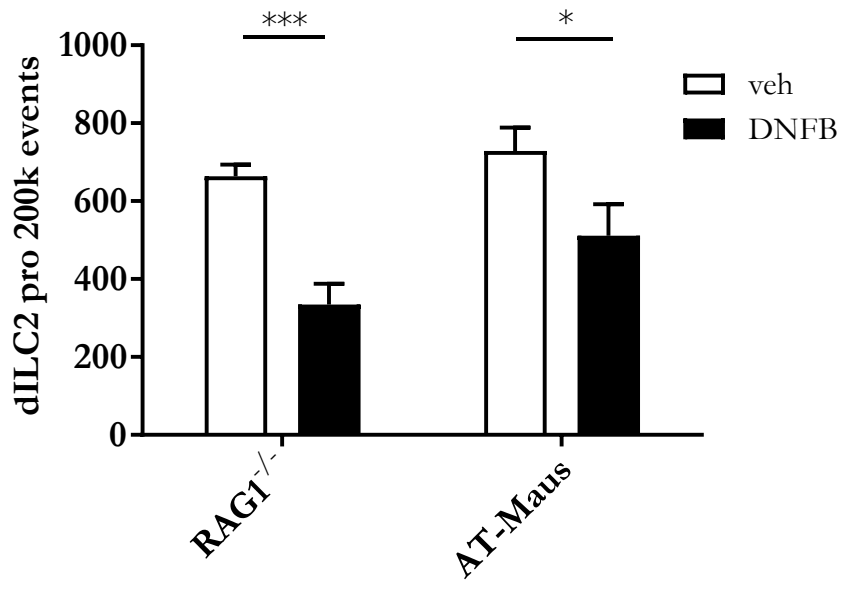

Abb. 3.9: Der adoptive Transfer von WT-Lymphozyten kann die beobachtete dILC2-Dynamik nicht ändern. (a) zeigt die graphische Auftragung der Ohr-Dicken nach DNFB-challenge in den Mäusen mit adoptivem Transfer (AT-Mäuse: adoptive-Transfer-Mäuse, schwarz) sowie die jeweiligen KontrollMäuse, die PBS erhielten (weiß). Für die Berechnung der Signifikanz siehe den entsprechenden Absatz Kap. 2.3.1. (b) zeigt die dILC2-Zellzahl pro 200.000 gemessene Events; die weißen Säulen zeigen das Vehikel-behandelte Ohr, die schwarzen Säulen das DNFB-behandelte Ohr ( $\mathrm{n}=7-8$, mindestens 2 unabhängige Experimente). Signifikanzniveaus: ${ }^{*} \mathrm{p}<0,05 ;{ }^{* * *} \mathrm{p}<0,001, \pm$ Standardfehler.

\subsection{RAG1-defiziente dILC2 zeigen eine höhere Annexin-V-Expression sowie vermehrt Caspase-3/7-Spaltprodukte}

Im DNFB-CHS-Modell fiel die dILC2-Zellzahl in den RAG1 ${ }^{-/}-$Mäusen ab, während sie in den WT-Mäusen anstieg. Die Sequenzierungs-Daten zeigten, dass RAG1-defiziente dILC2 zahlreiche Apoptose-assoziierte Gene gegenüber den WT-dILC2 mit signifikanten Veränderungen exprimierten (Daten nicht gezeigt). Um die funktionelle Relevanz der auf der genetischen Ebene gemessenen Unterschiede zu untersuchen und sie auf die Protein-Ebene zu übertragen, wurde ein Apoptose-Assay mit Annexin-V durchgeführt (Abb. 3.10). 


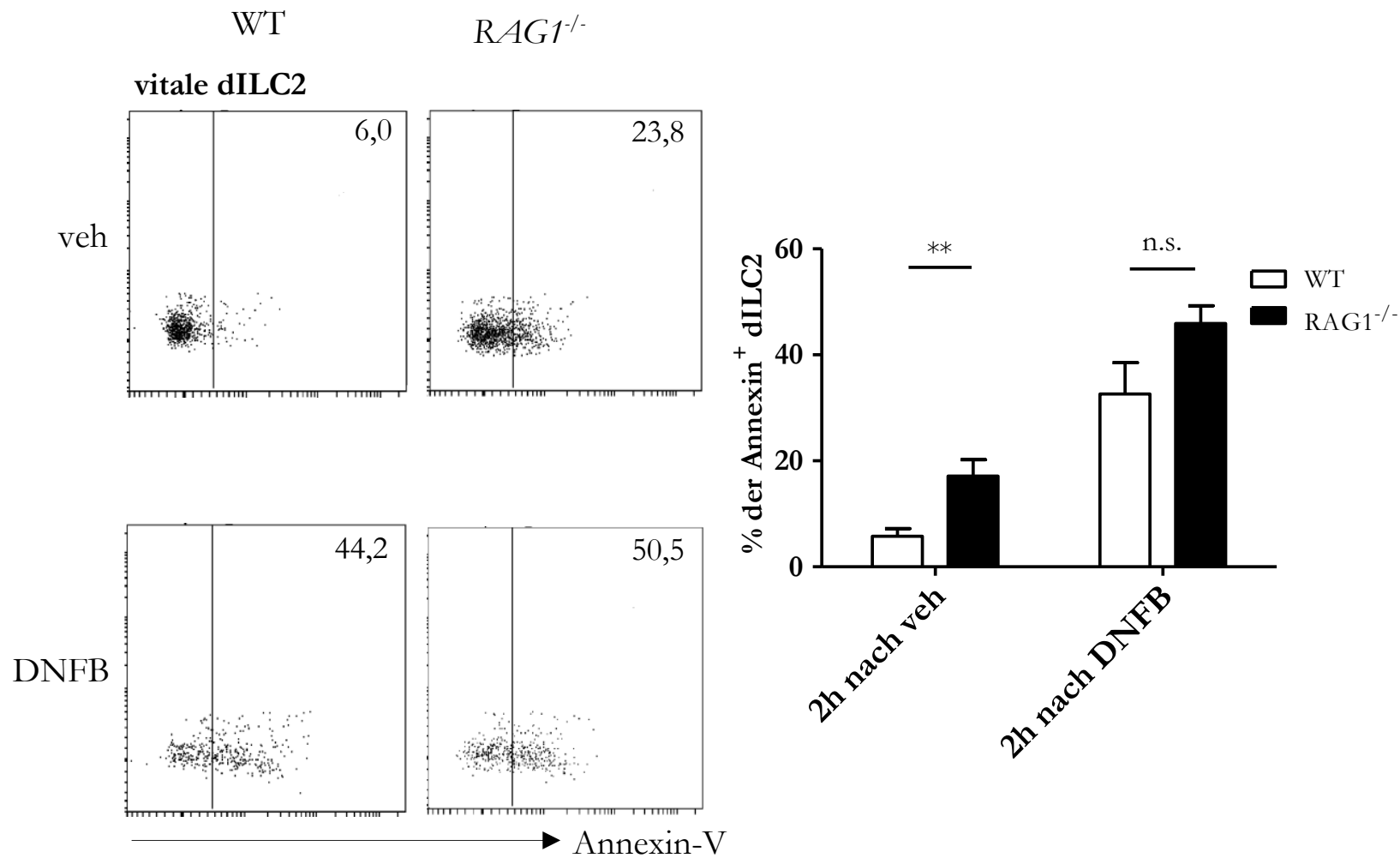

Abb. 3.10: RAG1-defiziente dILC2 haben eine erhöhte Apoptose-Affinität in Ruhe. (a) zeigt vier repräsentative FACS-Plots mit der Annexin-V-Expression von vitalen dILC2 in W'T- (erste Spalte) und RAG1\%-Mäusen (zweite Spalte), jeweils $2 \mathrm{~h}$ nach der challenge im Vehikel-behandelten (erste Zeile) und DNFB-behandelten (zweite Zeile) Ohr. Die Prozentzahlen für die dargestellten FACS-Plots sind beispielhaft angegeben. Die statistische Auswertung zeigt das Säulendiagramm rechts, wobei die weißen Säulen WT- und die schwarzen RAG1-/-Mäuse kennzeichnen ( $\mathrm{n}=9-10$ in mehr als 3 unabhängigen Experimenten). Signifikanzniveaus: ${ }^{* *} \mathrm{p}<0,01 ;$ n. s.: nicht signifikant, \pm Standardfehler.

Hierbei zeigten sich im Vehikel-Ohr von RAG1 ${ }^{-/}$-Mäusen signifikant mehr Annexin ${ }^{+}$-dILC2 als bei WT-Mäusen (17,8 \% gegenüber 5,8 \%, Zahlen als Mittelwerte). Im DNFB-behandelten Ohr stieg die Apoptose-Rate der dILC2 in beiden Mauslinien erheblich an; durch diesen Anstieg wurde der unter physiologischen Bedingungen beobachtete Effekt zwischen den beiden Tierstämmen knapp nicht mehr signifikant (Abb. 3.10). Dies wies darauf hin, dass RAG1defiziente dILC2 in Analogie zu den Sequenzierungs-Daten eine erhöhte Apoptose-Rate im Ruhe-Zustand hatten. Dieser Effekt wurde bei verstärkter Apoptose-Rate im CHS-Modell maskiert. 
Zur genaueren Untersuchung der erhöhten Apoptose-Rate wurde ein Caspase-3/7-Assay durchgeführt. Dabei konnte eine erhöhte MFI in den Caspase-3/7-Spaltprodukten identifiziert werden, was die Annahme stützte, dass die erhöhte Apoptose zumindest partiell auch durch eine erhöhte Caspase-3/7-Aktivität bedingt wurde (Abb. 3.11). Diese Ergebnisse passten auch zu den Sequenzierungs-Daten, in denen sich Veränderungen im klassischen Apoptose-Weg unter Beteiligung der Fas/Fas-Ligand-Interaktion sowie des anti-apoptotischen Proteins bcl-2 zeigten (Daten nicht gezeigt).
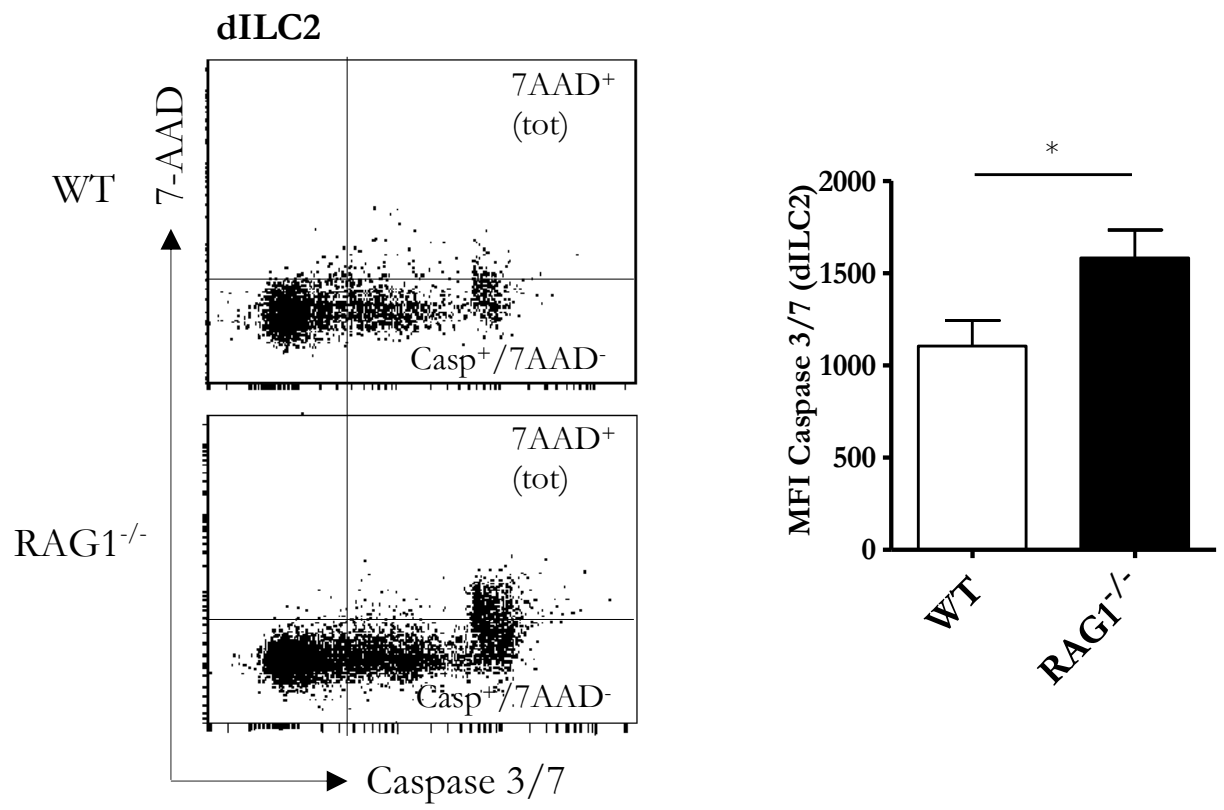

Abb. 3.11: Eine erhöhte Caspase-3/7-Aktivität bedingt die erhöhte Apoptose-Affinität von RAG1-defizienten dILC2. Abgebildet sind zwei repräsentative FACS-Plots von WT- (links oben) und RAG1-defizienten dILC2 (links unten). Die dILC2-Zellpopulation ist in 4 Bereiche aufgeteilt: 7AAD /Caspase- (vital, unten links), Caspase ${ }^{+} / 7 \mathrm{AAD}^{-}$Bereich (apoptotisch, unten rechts), Caspase ${ }^{+} / 7 \mathrm{AAD}^{+}$ (tot, oben rechts) sowie Caspase- $/ 7 \mathrm{AAD}^{+}$(tot, oben links). Die Abbildung rechts zeigt die statistische Auswertung der MFI der Caspase-3/7-Aktivität der dILC2 in WT- (weiß) und RAG1/--Mäusen (schwarz) $(\mathrm{n}=7-8)$. Signifikanzniveau: $* \mathrm{p}<0,05, \pm$ Standardfehler.

\subsection{RAG1-defiziente dILC2 zeigen eine höhere Proliferationsrate und einen höher exprimierten IL-7-Rezeptor}

Interessanterweise hatten $\mathrm{RAG}^{-/}$-Mäuse trotz einer erhöhten Apoptose-Neigung durch eine gesteigerte Caspase-3/7-Aktivität auch erhöhte dILC2-Zellzahlen in Ruhe. Außerdem wiesen die Sequenzierungs-Daten auf eine erhöhte Aktivität des proliferativen Jak-STAT-Signalweges hin, der downstream (downstream: abwärts; intrazelluläre Signaltransduktion) zum IL-7R-Signalweg 
eine Rolle spielt (Mackall et al. 2011) (Abb. 3.12a). IL-7 ist einer der wichtigsten Überlebensund Entwicklungsfaktoren für ILC2 (Robinette et al. 2015). Die Ergebnisse zeigten, dass RAG1-defiziente dILC2 im FACS eine signifikant höhere Expression des IL-7R in Ruhe als WT-dILC2 aufwiesen (Abb. 3.12b). Dies könnte als Grund für die erhöhten Zellzahlen in Ruhe angesehen werden. Andere Autoren vermuten ebenfalls eine Rolle von IL-7 in der Regulation der dILC2-Zellzahl (Roediger et al. 2013).

Initiale Experimente führten zu keiner Zunahme der dILC2-Zellzahlen nach dreitägiger subkutaner Injektion von IL-7 (Daten nicht gezeigt). Hierzu bedarf es weiterer Experimenten und weiterer Etablierung

a

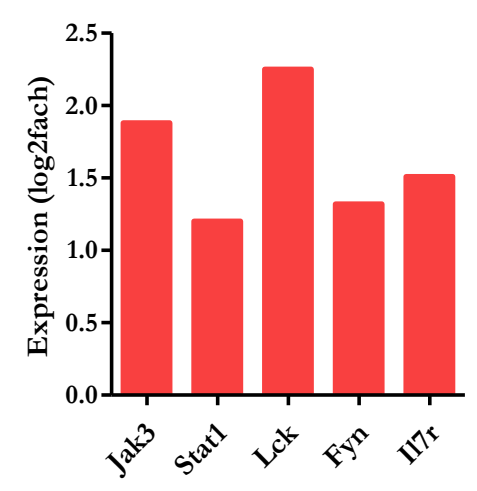

b

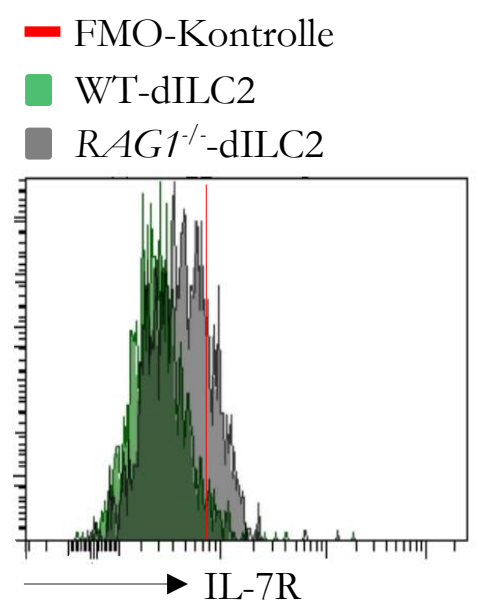

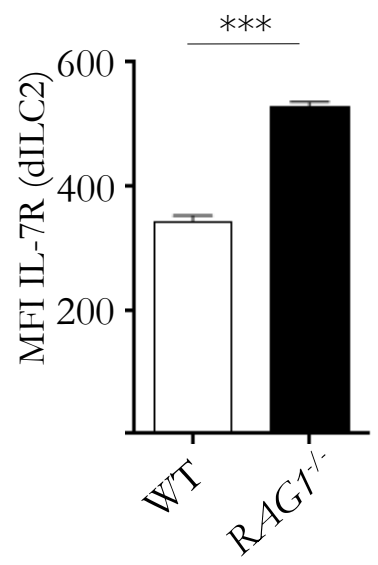

Abb. 3.12: Der IL-7-Rezeptor ist in RAG1-defizienten dILC2 stärker exprimiert. (a) zeigt die erhöhte Expression von verschiedenen Genen aus dem IL-7R-Signalweg. Die Daten stammen aus den eigenen Sequenzierungs-Daten. Die Gen-Namen sind unter der Abszisse aufgetragen. (b) zeigt einen repräsentativen FACS Plot für die IL-7R-Expression von W'T- (grüne Fläche) und RAG1-defizienten dILC2 (dahinter gelegte graue Fläche); die rote Linie kennzeichnet die FMO-Kontrolle. Rechts wird die statistische Auswertung der MFI der IL-7R- Expression von WTT- (weiß) sowie RAG1-defizienten dILC2 (schwarz) dargestellt $(\mathrm{n}=4)$. Signifikanzniveau: ${ }^{* * *} \mathrm{p}<0,001, \pm$ Standardfehler. 
$\overline{\text { Durch die erhöhte Expression des IL-7R lag es nahe, dass RAG1-defiziente dILC2 eine erhöhte }}$ Proliferationsaktivität besitzen. Um diese Hypothese zu überprüfen, wurde eine in vivo BrdUFärbung durchgeführt. RAG1-defiziente dILC2 wiesen gegenüber WT-dILC2 eine signifikant gesteigerte BrdU-Inkorporation auf (Abb. 3.13). Dies bestätigte die Vermutung, dass RAG1defiziente dILC2 eine gesteigerte Proliferationsaktivität besitzen. Somit konnte gezeigt werden, dass RAG1-defiziente dILC2 sich sowohl durch eine erhöhte Apoptose-Affinität als auch gleichzeitig durch eine gesteigerte Proliferationsaktivität bei höher exprimiertem IL-7R auszeichnen.
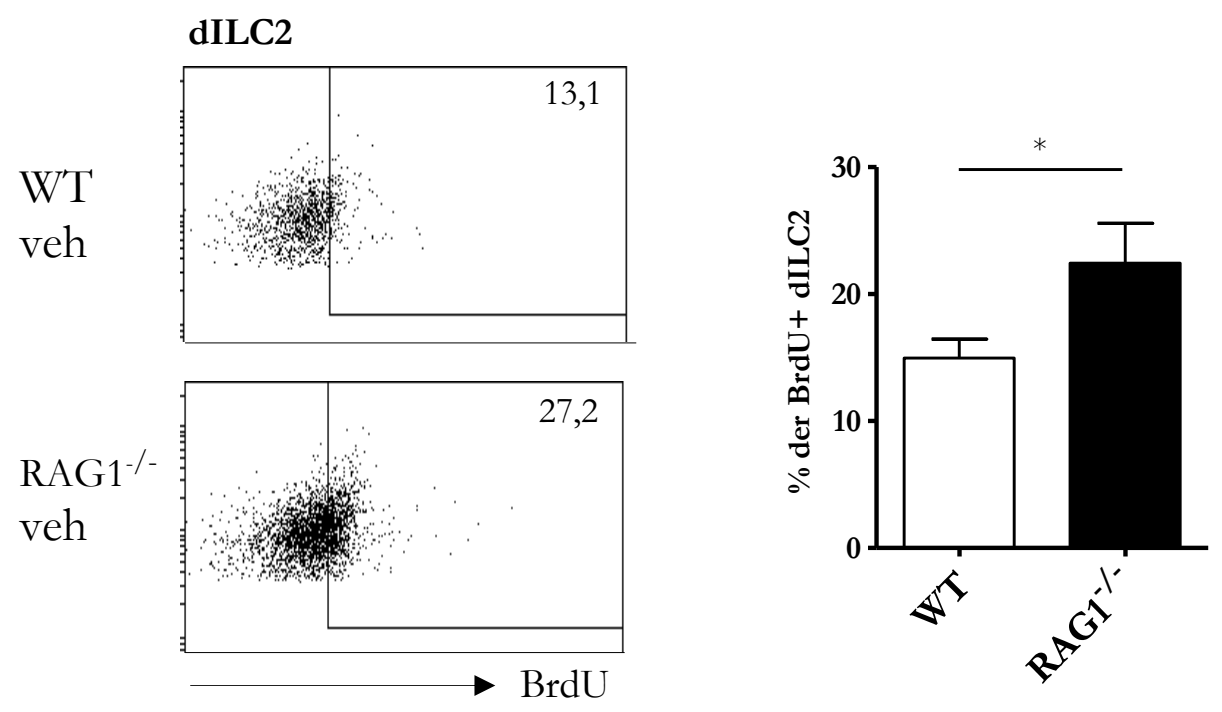

Abb. 3.13: RAG1-defiziente dILC2 haben eine erhöhte Proliferationsrate. Links abgebildet sind zwei repräsentative FACS-Plots bei WT- (oben) und RAG1-defizienten dILC2 (unten). Die Prozentzahlen für die Plots sind beispielhaft angegeben. Rechts ist die statistische Auswertung abgebildet; in weiß sind die Prozentzahlen der BrdU+ ${ }^{+}$dILC2 in WT, in schwarz die für RAG1 $\%$-Mäuse dargestellt $(\mathrm{n}=9$, drei unabhängige Experimente). Signifikanzniveau: $* p<0,05, \pm$ Standardfehler. 


\section{$4 \quad$ Diskussion}

\subsection{RAG1 ${ }^{-/-}$-Mäuse besitzen mehr dILC2 als WT-Mäuse}

Die erste wichtige Beobachtung der vorliegenden Studie bestand darin, dass RAG1 ${ }^{-/}$-Mäuse im Unterschied zu anderen untersuchten knockout-Mäusen (TLR3, MyD88, TLR3/MyD88) signifikant höhere Zahlen an dILC2 als WT-Mäuse aufwiesen. Erwähnenswert ist, dass die RAG1 ${ }^{-1}$ Mäuse keine insgesamt erhöhte Gesamt-Leukozyten-Zahl aufwiesen und andere ILC-Zellpopulationen, wie NK-Zellen, nicht signifikant höher als in WT-Mäusen ausfielen. Dies bedeutet, dass die dILC2-Zellpopulation unter den untersuchten Zellpopulationen selektiv erhöht war. Grundsätzlich kann es drei verschiedene Mechanismen geben, warum dILC2 in RAG1--Mäusen zahlenmäßig häufiger vorkamen: Erhöhte Produktion, verminderter Abbau oder verminderte Migration aus der Haut heraus.

Für eine höhere Produktion existieren diverse Hinweise: Die Tatsache, dass RAG1 ${ }^{-/}$-Mäuse mehr dILC2 als WT-Mäuse besitzen, wurde bereits von Roediger et al. (2013) beschrieben. Die Wissenschaftler mutmaßten, dass dies auf ein Überangebot an IL-7 in RAG1 ${ }^{-/-}$-Mäusen durch die fehlenden B- und T-Zellen zurückzuführen sein könnte. Dies führe zu einem Nischen-Effekt mit einem Überangebot an IL-7 und einer dadurch erhöhten Proliferation, die sich wiederum in höheren Zellzahlen manifestiere. Spekulativ könne es sich dabei um eine biologische Kompensation handeln, sodass bei der Abwesenheit von B- und T-Zellen eine immer noch ausreichende Immunantwort des Organismus sichergestellt werden kann. Demzufolge wären die erhöhten dILC2-Zahlen nicht auf das Fehlen von RAG1 in den dILC2 selbst, sondern auf „extrinsische“ Faktoren zurückzuführen (Roediger et al. 2013). Wenn man von einer gemeinsamen Vorläuferzelle der ILC2 ausgeht, dann müssten dementsprechend auch ILC2 anderer Organe vermehrt aufzufinden sein. In der Tat gibt es Untersuchungen, dass auch ILC2 der Lunge in $\mathrm{RAG1}^{-/}$-Mäusen häufiger vorkommen als in WT-Mäusen (Huang et al. 2015). Eine generell erhöhte Produktion erscheint also wahrscheinlich.

Die Überlegung, RAG1 ${ }^{/-}$-Mäuse hätten mehr freies IL-7, das dann auch von den dILC2 gebunden werden würde, bewegt sich jedoch im rein spekulativen Bereich, weil es keine Daten gibt, die diese These ausreichend stützen würden. Außerdem ist sogar bekannt, dass es bei hohen verfügbaren Mengen an IL-7 zu einer kompensatorischen Herunterregulation vom IL-7R kommt (Park et al. 2004). Die dILC2 in den vorliegenden Experimenten zeigten hingegen eine stärkere Expression vom IL-7R, was gegen diese Beobachtung spricht. Es ist also denkbar, dass nicht die vermehrten IL-7-Mengen zu einer erhöhten Proliferation führen, sondern die Zellen 
selbst effektiver auf das vorhandene IL-7 reagieren können, wodurch es dann zu einer erhöhten Proliferation kommt (weitere Ausführung siehe Kap. 4.3.2).

Das proliferative IL-7R-Signal kann anhand der eigenen Daten noch nicht als alleiniger Grund für die erhöhten Zellzahlen angenommen werden. Methodisch zeigte die erhöhte Inkorporation von BrdU zwar eine erhöhten DNA-Synthese, was allerdings noch keine Erklärung für einen genauen Mechanismus liefert. Um die These beweisen zu können, dass das gesteigerte IL-7Signal zu diesen Veränderungen führt, wären weitere Experimente notwendig. Beispielsweise haben von mir durchgeführte initiale Experimente gezeigt, dass sich die dILC2-Zellzahl nach dreitägiger subkutaner IL-7-Applikation bei der adulten Maus nicht wesentlich verändert. Es ist daher denkbar, dass IL-7 schon zu einem früheren Zeitpunkt der dILC2-Entwicklung eine Rolle spielt und eine IL-7-Stimulation im entdifferenzierten Zustand daher keine wesentliche Änderung mehr bewirkt. Hier stehen weitere Untersuchungen aus. Ein geeignetes Experiment, um diese These zu überprüfen, wäre einerseits die Depletion von IL-7 zu verschiedenen Entwicklungsstadien in der Maus mit einer darauffolgenden Messung der dILC2-Zellzahl. Denkbar wäre auch die Blockade des IL-7R mit einer darauffolgenden Analyse der Zellzahlen.

Mäuse mit einem Knock-out von TLR3, MyD88 oder beiden knockouts gleichzeitig (TLR3/MyD88) haben keine veränderten absoluten dILC2-Zahlen gezeigt. TLR3 gehört zu der Gruppe der toll-like receptors, die eine Gruppe von Rezeptoren bilden, die wichtig für die angeborene Immunabwehr sind. Es ist bekannt, dass humane ILC2 TLR1, TLR4 und TLR6 exprimierten und nach einer Stimulation eine erhöhte Produktion von IL-5 und IL-13 gezeigt haben (Maggi et al. 2017). Es scheint also, dass sich knockouts, die die Funktion des angeborenen Immunsystems betreffen, nicht auf die Zellzahlen der dILC2 auswirken. Anders verhält sich dies bei einem Ausfall des RAG1-Proteins, das sich auf das erworbene Immunsystem bezieht. Dies kann als weiterer Hinweis interpretiert werden, dass es sich bei den Zellzahl-Änderungen in den $\mathrm{RAG1}^{-/-}$-Mäusen um einen RAG1-spezifischen ,intrinsischen“ Effekt handelte, was anhand der vorliegenden Daten jedoch nicht mit abschließender Sicherheit gesagt werden kann. Die folgenden Interpretationen und Veränderungen beziehen sich also nur auf eine Beobachtung von dILC2 in RAG1 ${ }^{-1}$-Mäusen und lassen sich mit den vorliegenden Experimenten nicht spezifisch durch das alleinige Fehlen der RAG1-Expression der dILC2 erklären. 


\subsubsection{Aktivierung und Differenzierung nach ICOS und GATA3 unterscheiden sich nicht}

RAG1-defiziente dILC2 besaßen im FACS eine vergleichbare GATA3- und ICOS-Expression. Es ist bekannt, dass ILC2 bei einer Aktivierung bestimmte Oberflächenmarker, wie etwa ICOS, höher exprimierten als naive ILC2 (Paclik et al. 2015). Dies legt nahe, dass die erhöhten Zahlen nicht durch eine klassische Aktivierung dieser Zellen zustande kamen. Überraschenderweise zeigte sich jedoch in den Sequenzierungs-Daten, dass sowohl die Aktivierung als auch die Differenzierung der RAG1-defizienten dILC2 grundlegend unterschiedlich sein könnten. Einerseits zeigte sich in den Sequenzierungs-Daten eine erhöhte Expression typischer ILC2-Zytokine wie Il5 und I113. Andererseits fiel eine Erhöhung klassischer ILC1- und ILC3-stimulierender Zytokine wie Ifng, Il17a, Il17f und Il22 auf. Nicht nur die Zytokine selbst, sondern auch eine Reihe von Zytokin-Rezeptoren zeigten eine erhöhte Expression, darunter waren Il4ra, Ifngrl, $I l 17 r b$, Il23r, Il2rb, Il2rg sowie Il2ra. Zusammenfassend war auffällig, dass die RAG1-defizienten dILC2 ein differentes und für ILC2 atypisches Zytokin-Expressionsprofil aufwiesen, das eher einem ILC3-Typ bzw. ILC1-Typ entsprach.

Bei einem so überraschenden Ergebnis ist auszuschließen, dass es sich bei der untersuchten und sequenzierten RAG1-defizienten dILC2-Zellpopulation um eine andere ILC-Gruppe gehandelt hat, die auch im gleichen gate aufzufinden war. Die identische GATA3-Expression im FACS legt nahe, dass es sich wirklich um dILC2 und nicht um eine Kontamination mit anderen ILC handelte. Für den gegenüber ILC3- bzw. ILC1-ähnlichen Phänotyp kann es also unterschiedliche Gründe geben: ILC2 können im aktivierten Status einen Phänotyp annehmen, der dem von ILC3- bzw. ILC1 ähnelt und dabei auch ein ähnliches Zytokin-Expressionsprofil aufweist (Huang et al. 2015; Zhang et al. 2017). ILC2, die mit IL-25 stimuliert wurden, konnten $\mathrm{T}_{\mathrm{H}} 17$ ähnliche Zytokine produzieren und wurden als inflammatorische ILC2 (iILC2) bezeichnet. AuBerdem fand sich ebenfalls eine leicht erhöhte Expression des Transkriptionsfaktors ROR $\gamma t$, der eher für ILC3 typisch ist (Huang et al. 2015). Weiterhin konnten US-amerikanische Wissenschaftler zeigen, dass IL-1 $\beta$ bei ILC2 zu einer Transformation in der Richtung von ILC1 führen kann; sie produzierten dann messbare Mengen von INF $\gamma$ und exprimierten die $\beta$-Kette des IL12R (Ohne et al. 2016). Die gesteigerte Aktivierung von RAG1-defizienten dILC2 könnte ebenfalls neben dem IL-7R-Signal die erhöhte proliferative Aktivität erklären, da sich aktivierte Zellen oft in einem proliferativen Zustand befinden. Woher aber kommt die Aktivierung? Roediger et al. (2013) konnten einen enormen Anstieg der dILC2-Zellzahl sowie eine starke Aktivierung der dILC2 nach einer systemischen Administration von IL-2 beobachten. IL-2 scheint demnach einen starken proliferativen und aktivierenden Reiz auf die dILC2 auszuüben. Hierzu passend 
zeigten die eigenen Sequenzierungs-Daten beispielsweise auch eine erhöhte Expression von Genen des IL-2R.

Die genaue Ursache für die vermeintlich gesteigerte Aktivierung in den RAG1 $1^{-/-}$-Mäusen konnte jedoch in meinen Daten nicht abschließend gefunden werden. Es ist denkbar, dass extrinsische Faktoren dafür verantwortlich waren: Die fehlenden B- und T-Zellen in der RAG1 ${ }^{-/}$-Maus können zu einer kompensatorischen und übermäßigen Aktivierung der ILC2 im Haut-Kompartiment geführt haben. Dies könnte aufgrund eines übermäßigen Vorhandenseins von aktivierenden Zytokinen wie IL-7 oder auch IL-2 begründet werden. Wahrscheinlicher erscheinen jedoch intrinsische Effekte, die auf das Fehlen des RAG1-Proteins in den dILC2 selbst zurückzuführen sind. Karo et al. (2014) haben gezeigt, dass der RAG1-Defekt in NK-Zellen zu einer „fragilen“ Hyperaktivität der betroffenen Zellen führt, die zwar mit einer erhöhten Aktivierung verbunden ist, aber auch zu einer gesenkten „Stressresistenz“ führt (Karo et al. 2014). Die vorliegenden Daten weisen nun darauf hin, dass dies nicht nur für NK-Zellen zutreffen könnte, sondern auch dILC2 einen hyperaktiven Zustand durch eine erhöhte Expression inflammatorischer Zytokine entwickeln können. Da sich diese Schlussfolgerung aber auf die eigenen Sequenzierungs-Daten bezieht, müssen diese Daten weiter verifiziert werden: So wären etwa eine bestätigende PCR zu den o. g. Genen oder aber ein Nachweis auf Protein-Ebene mittels FACS denkbar. Außerdem könnte man funktionelle Untersuchungen durchführen, um unmittelbar die Funktion der jeweiligen Zytokine im Kontext zu klären. Ein etwas unspezifischer und breiterer Ansatz bestünde darin, die Haut der RAG1/--Mäuse in ihrem Mikromilieu genauer zu analysieren: So könnten vollständige Haut-Biopsate aufgearbeitet und die Gesamtmenge an IL-1 $\beta$ bzw. IL-25 gemessen werden, die die dILC2 in eine bestimmte Richtung lenken würden. Dies ist Gegenstand aktueller Untersuchungen.

\subsubsection{Schwierigkeiten mit der Definition und Nomenklatur von ILC2 in der Haut}

Aufgrund des Fehlens eines geeigneten Positiv-Markers besteht kein wissenschaftlicher Konsens darüber, wie sich dILC2 klar identifizieren lassen. Mit der von Roediger et al. (2013) vorgeschlagenen und auch hier angewandten gating-Strategie gelang dies für murine dILC2 in nachvollziehbarer und reproduzierbarer Weise. In der Literatur existieren jedoch verschiedene weitere Vorschläge zur Identifikation von Haut-ILC2. Oft kommt es zur Verwendung eines sogenannten Lineage-Markers, der eine Reihe von Antikörpern enthält, die die meisten anderen Immunzellen exprimieren und dann binden sollten. Die ILC2 würden sich dann durch das NichtAnsprechen auf einen solchen Marker als „Lineage-Marker negativ“ (kurz: Lin”) definieren lassen (Kim et al. 2013; 2014; Spits 2013). Die von Roediger et al. (2013) verwendete gating-Strategie 
war leicht modifiziert. Bei Roediger et al. (2013) und auch in den vorliegenden Untersuchungen wurden ILC2 als CD $45^{+} \mathrm{CD} 90^{\text {hi }} \mathrm{CD} 11 \mathrm{~b}$ CD 3 CD2-Zellen beschrieben, die GATA3 und ICOS exprimieren. Interessanterweise waren diese ILC2, die in beiden Untersuchungen auch in die der Haut identifiziert wurden, auch stark CD103 positiv, was für die ILC2 anderer Organe nicht gilt (Roediger et al. 2013). Kleinere Zahlen dieser ILC2 waren neben der Haut auch im gastrointestinalen Trakt sowie in der Lunge zu finden. Andere Arbeitsgruppen, die sich mit murinen Haut-ILC2 beschäftigt haben, verwendeten die o. g. „Lin-gating-Strategie“.

An dieser Stelle ist zu klären, ob die unterschiedlichen Identifikations-Strategien dieselbe ILC2Zellpopulation messen. Sowohl die von Roediger et al. (2013) definierte dILC2-Zellpopulation als auch die Lin-ILC2-Zellpopulation waren in der RAG1 ${ }^{-/}$-Maus zu finden, weshalb sie zum angeborenen Immunsystem gehören. Außerdem haben beide Zellpopulationen eine Produktion typischer $\mathrm{T}_{\mathrm{H}} 2-$ Zytokine wie IL-5 und IL-13 sowie in kleinen Mengen IL-4 gezeigt. Beide haben den Transkriptionsfaktor GATA3 und den Aktivierungsfaktor ICOS exprimiert. Weiterhin hat man bei beiden Zellpopulationen eine Interaktion mit Mastzellen und basophilen Granulozyten beobachtet. Roediger et al. (2013) haben dies in der in vivo-Mikroskopie untersucht und Kim et al. (2014) haben verschiedene in vitro und in vivo Assays eingesetzt. Letztlich wurde bei beiden Zellpopulationen eine hohe Expression von CD103 nachgewiesen, weshalb es sehr wahrscheinlich ist, dass es sich bei beiden um eine ILC2-Zellpopulation handelt.

Demgegenüber gab es jedoch verschiedene Hinweise, dass die unterschiedlich nachgewiesenen ILC2-Zellpopulationen auch unterschiedliche Eigenschaften haben: Die Lin- ILC2 wiesen eine insgesamt etwas höhere Expression von GATA3, ICOS und CD25 auf als die ILC2 von Roediger et al. (2013). Außerdem ließen sich die von Roediger et al. (2013) identifizierten ILC2 nicht durch einen anti-CD90-Antikörper depletieren, wie es bei den Lin-ILC2 von Kim et al. (2013) der Fall war. Es sind weitere Untersuchungen notwendig, um die präzisen Unterschiede zwischen den verschiedenen ILC2-Zellpopulationen in der Haut weiter zu klären. Es ist denkbar, dass es sich um ILC2 mit unterschiedlicher Differenzierung und Aktivierung handelt. Ob und wie sich diese verschiedenen ILC2-Zellpopulationen auch funktionell voneinander unterschieden, bleibt zum aktuellen Zeitpunkt unklar. In der vorliegenden Arbeit habe ich mich bewusst für die von Roediger et al. (2013) etablierte gating-Strategie entschieden, da diese zu einer konzentrierteren und klarer definierten Zellpopulation führt als die von Kim et al. (2013) (Abb. 3.1). Inwieweit sich die Ergebnisse auch auf die anderen Varianten oder Subtypen der Haut-ILC2 übertragen lassen, kann hier nicht abschließend geklärt werden. Dies bedürfe einer weiteren detaillierten Gegenüberstellung dieser beiden Zellpopulationen. 
$\overline{\text { Generell bestehen weiterhin Probleme mit der genauen Nomenklatur und Charakterisierung }}$ dieser immer noch sehr neuen Zellpopulationen. Verschiedene Autoren versuchten sich im letzten Jahrzehnt an einer einheitlichen Charakterisierung, die teilweise auch gelungen und nachvollziehbar war (Spits et al. 2013). Dennoch bestehen Schwierigkeiten bei der Übertragung dieser Untersuchungen auf die speziellen ILC2 einzelner Organe. Es wurden bereits ausführliche genomische Analysen zu den ILC2 der Maus und des Menschen durchgeführt und miteinander verglichen (Bjorklund et al. 2016; Seillet et al. 2016). Jedoch stammten diese isolierten ILC2 aus dem GI-Trakt sowie der Lunge, weshalb die Ergebnisse nicht einfach auf ILC2 der Haut übertragen werden können. Da die Haut-ILC2 zahlenmäßig noch seltener als die ILC2 anderer Organe sind, ist die Haut ein besonders schwierigeres Organ für die ILC2-Forschung. Dementsprechend existieren auch weniger Arbeiten zu den Haut-ILC2 als zu den ILC2 anderer Organe, was mit Sicherheit auch die weiterhin bestehenden Unstimmigkeiten in der Nomenklatur von hautspezifischen ILC2 bedingt. Zukünftige Forschungsarbeiten werden daher die molekularen Details für die Unterschiede zwischen den Haut-ILC2 und anderen ILC2 untersuchen müssen.

\subsection{Die unterschiedliche Dynamik der dILC2 im DNFB- Kontaktallergie-Modell in WT- und RAG1 ${ }^{-/-}$-Mäusen}

Die DNFB-CHS verursachte bei den WT-Mäusen eine stärkere Ohrschwellung als bei den $\mathrm{RAG}^{-/}$-Mäusen. Weiterhin kommt es im DNFB-behandelten Ohr zum Anstieg der Zellzahlen der dILC2 bei den W'T-Mäusen, aber zu einem Abfall bei den RAG1\%-Mäusen, was einer reziproken Dynamik entspricht. Dieser Abfall ließ sich durch adoptiven Transfer von WT-Lymphozyten nicht revidieren, sondern nur in seinem Ausmaß etwas abschwächen. Es sind nun also zwei Effekte gesondert zu diskutieren:

Zum einen zeigten RAG1/--Mäuse eine signifikant niedrigere Ohrschwellung nach der DNFBchallenge als WT-Mäuse. In der Literatur gibt es unterschiedliche Hinweise, die einerseits niedrigere und andererseits nicht-signifikant unterschiedliche Ohrschwellungen bei RAG1 ${ }^{/-}$-Mäusen beschreiben (Bonneville et al. 2007; O'Leary et al. 2006). Die CHS stellt nach aktuellem Verständnis eine T-Zell-vermittelte Allergie dar. Daher erscheint unsere Beobachtung schlüssig, dass die RAG1 ${ }^{1 /}$-Mäuse eine geringere Ohrschwellung aufwiesen, weil sie keine T-Zellen besitzen, die eine solche Reaktion induzieren und amplifizieren könnten. Es wird postuliert, dass $\mathrm{RAG}^{-/}$-Mäuse trotzdem eine CHS entwickeln können. Diese soll von NK-Zellen initiiert und getragen werden, wonach sich ein spezifisches NK-Zell-Gedächtnis bildet (O'Leary et al. 2006). Dieser Prozess scheint trotz eines acht Jahre später gezeigten Befundes in NK-Zellen möglich 
zu sein: NK-Zellen in RAG1/-Mäusen weisen durch den RAG1-knockout eine geringere „Stressresistenz“ und eine zelluläre Dysregulation auf, was sich an der erniedrigten Expression von anti-apoptotischen Genen (Ku80, Chk2, Atm) und einer verminderten Zytotoxizität gegenüber viralen Erregern zeigt. Dieser Effekt ließ sich spezifisch auf das Fehlen von RAG1 zurückführen (Karo et al. 2014). Darauf bezieht sich die Schlussfolgerung, dass NK-Zellen zwar durch die RAG1-Defizienz eine gestörte Biologie und „Stresslabilität“ aufweisen, ihre Funktionen in der CHS bei der RAG1 ${ }^{--}$-Maus jedoch weiter ausführen können. Wir können überlegen, diesen Effekt auch auf RAG1-exprimierende dILC2 zu erweitern: Ein Grund für die geringere Ohrschwellung bei RAG1 ${ }^{-/}$-Mäusen könnte dann ein vermehrtes Vorhandensein von dILC2 sein. Die Arbeiten von Rafei-Shambasadi et al. (2018) haben gezeigt, dass ILC2 eine entzündungsregulierende (auch: supprimierende) Wirkung in der TNCB-vermittelten CHS aufweisen. Mehr dILC2 in Ruhe könnten also zu einer geringeren Ohrschwellung durch eine stärkere Entzündungs-Suppression nach der DNFB-CHS beigetragen haben. Neben den erhöhten Zellzahlen zeigten die dILC2 auch eine stärkere Aktivierung durch die Bildung ihrer relevanten Zytokine IL-5 und IL-13: Dies könnte bedeuten, dass RAG1-defiziente dILC2 trotz erhöhter ApoptoseNeigung ihre regulatorischen Wirkungen bei einer CHS zumindest noch teilweise ausüben können. Sicherlich von Bedeutung ist auch die Tatsache, dass in den von Karo et al. (2014) durchgeführten Arbeiten nur 30-40 \% aller ILC2 eine RAG1-Expression gezeigt haben. Deshalb ist davon auszugehen, dass nicht alle dILC2 in RAG1/--Mäusen die von beobachteten Defizite zeigen und es eine mehrheitliche Anzahl an dILC2 gibt, die physiologisch funktionieren könnten. Eine ausführlichere Zeitdynamik der Ohrschwellung sowie eine genauere Untersuchung, wie dILC2 ihre regulatorischen Funktionen ausüben, stehen jedoch aus. dILC2 stehen über MHC-II-Molekülkomplexe auch mit den Zellen des adaptiven Immunsystems (v. a. T-Zellen) in einem engen Kontakt (Oliphant et al. 2014). Wie diese Zusammenhänge das allergische Kontaktekzem und die T-Zell-Funktion in WT-Mäusen beeinflussen, ist jedoch noch Gegenstand aktueller Forschung.

Zum anderen ist der Abfall der Zellzahl nach der DNFB-Behandlung zu diskutieren: Grundlegende Ursachen für den Abfall der Zellzahl sind erstens Migration, zweitens der Zelltod durch Apoptose oder Nekrose. Mögliche apoptotische Vorgänge wurden bereits in RAG1-defizienten NK-Zellen beschrieben (Karo et al. 2014). Weil der adoptive Transfer von WT-Lymphozyten den Abfall nicht wesentlich beeinflusste, können die fehlenden B- und T-Zellen in den $\mathrm{RAG1}^{-/}$-Mäusen zumindest nicht der einzige Grund für diese beobachtete Dynamik sein. Man kann also davon ausgehen, dass eher intrinsische Effekte dafür verantwortlich sind. Dieser Aspekt wird näher in Kap. 4.3.1 diskutiert. 
Angesichts der zentralen Fragestellung wurde eine mögliche Auswirkung der Migration nicht weiter untersucht. Rafei-Shamsabadi et al. (2018) konnten ILC2 nach TNCB-CHS in den Hautdrainierenden Lymphknoten nachweisen. Da die Zellzahlen in WT-Mäusen steigen, in $\mathrm{RAG}^{-/}$-Mäusen aber selektiv sinken, ist eine Migration jedoch allenfalls gering ausgeprägt und sicherlich nicht als hauptverantwortlich für die sinkenden dILC2-Zellzahlen zu betrachten.

\subsection{RNA-Sequenzierung zeigt ein stark verändertes Gen- Expressionsprofil in RAG1-defizienten dILC2}

Die NK-Zellen der RAG1 ${ }^{-/}$-Maus waren überaktiviert und regulierten Proteine herunter, die für die DNA-Reparatur verantwortlich sind, wodurch sie nicht mehr suffizient funktionell aktiv waren (Karo et al. 2014). In der eigenen RNA-Sequenzierung von WT- und RAG1-defizienten dILC2 zeigte sich, dass über 2000 Gene unterschiedlich reguliert wurden.

Methodisch gestaltete sich die Sequenzierung aufgrund der sehr geringen Zellzahlen von dILC2 in der Haut schwierig (0,1-0,5 \% aller Zellen der Haut). Es mussten zahlreiche Versuchstiere verwendet werden (16 bzw. 30 Mäuse), um genügend Zellen für die RNA-Sequenzierung zu gewinnen. Die Qualitätskontrollen haben jedoch gezeigt, dass für beide Zellpopulationen ausreichend viel und qualitativ hochwertige RNA isoliert werden konnte, sodass die Aussagekraft der Ergebnisse aktuellen wissenschaftlichen Standards entspricht. Im vorliegenden Fall kam außerdem ein sog. Single-Cell-Sequencing (Einzelzell-Sequenzierung) infrage, das mit sehr viel geringeren Zellzahlen funktioniert hätte, was allerdings mit einem noch höheren methodischen und ökonomischen Aufwand verbunden gewesen wäre. Außerdem handelt es sich dabei um eine neuere Methode, die zwar in dem beauftragten NIG-Labor schon etabliert war, aber zum damaligen Zeitpunkt gab es noch zu wenige Daten, um eine genaue Interpretation zu gewährleisten. Deshalb wurde die gesamte Population sequenziert, um ein vollständigeres Bild zu erhalten.

Da dILC2 keinen TCR besitzen und somit nicht auf RAG1 angewiesen sind, konnte man zunächst von nur geringen Unterschieden zwischen den Zellpopulationen ausgehen. Überraschenderweise zeigten RAG1-defiziente dILC2 jedoch ein stark verändertes Transkriptionsprofil im Vergleich mit den WT-dILC2. Die meisten Gene waren in den Signalwegen der ZytokinZytokin-Rezeptor-Interaktion, der NK-Zell-Zytotoxizität und der Differenzierung von T-Zellen verändert. Die betroffenen Signalwege waren insbesondere der Jak-STAT- und der PI3KSignalweg, die auch eine wichtige Rolle downstream der Signalwege diverser Zytokin-Rezeptoren, wie des IL-7R, spielen. Weiterhin zeigten sich auch Veränderungen in Genen, die mit Autoimmun-Prozessen sowie viraler und parasitärer Abwehr assoziiert sind. 
Zuerst einmal war es interessant, dass sich überhaupt ein so dramatisch verändertes Transkriptionsprofil ergeben hat. Ob die Unterschiede durch die RAG1-Defizienz der dILC2 selbst (intrinsisch) oder durch sekundäre Veränderungen in der RAG1//-Maus entstanden sind (extrinsisch), kann nicht hinreichend beantwortet werden (Abb. 4.1).

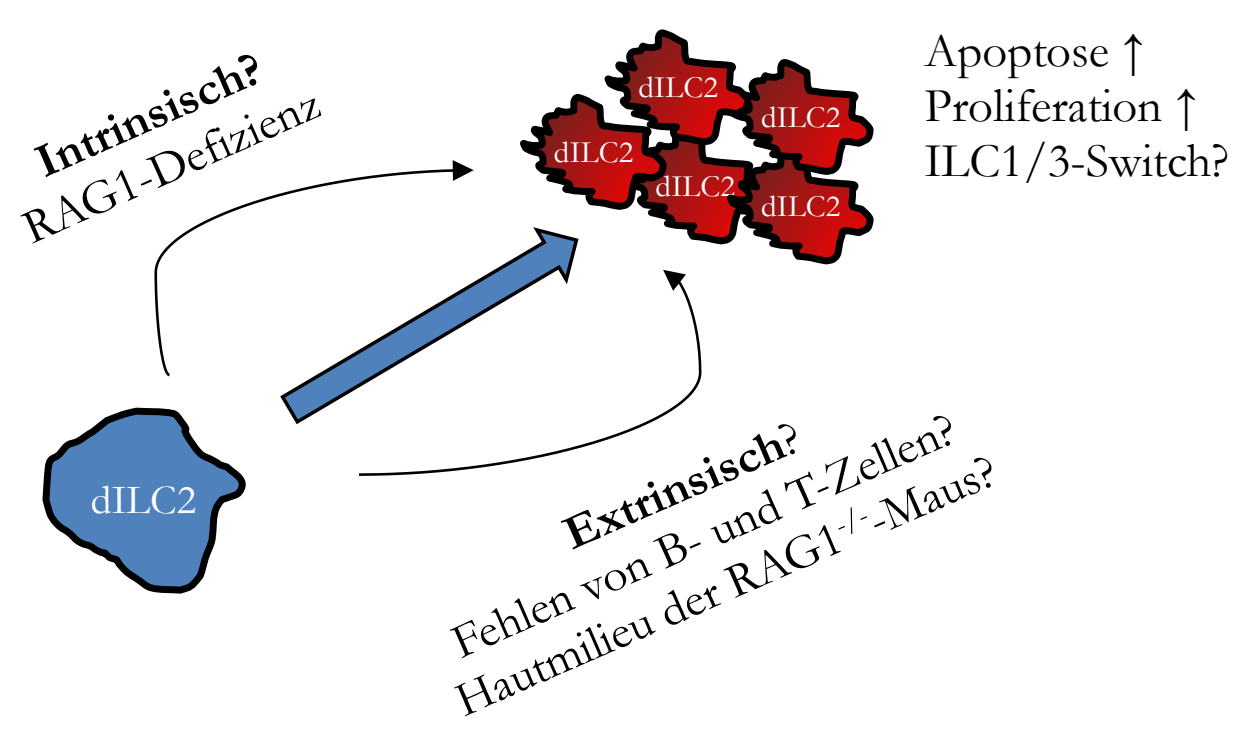

Abb. 4.1 dILC2 zeigen in RAG1/--Mäusen ein stark verändertes Gen-Expressionsprofil, wobei sowohl die Apoptose und die Proliferation als auch das allgemeine Zytokinprofil beeinflusst werden. Ob und inwieweit extrinsische oder intrinsische Faktoren die entscheidende Rolle dabei spielen, kann nicht abschließend beantwortet werden.

Für intrinsische Effekte existieren zahlreiche Hinweise: Es wird beschrieben, dass RAG1 in der Entwicklung von allen ILC eine vitale Rolle übernimmt. In NK-Zellen, die zu den ILC2 zählen, führte das Nicht-Vorhandensein von RAG1 zu einer zellulären Labilität, die spezifisch auf das Fehlen des RAG1-Proteins zurückzuführen ist (Karo et al. 2014). Weiter zeigten die vorliegenden Ergebnisse, dass ein adoptiver Transfer von WT-Lymphozyten die reziproke Dynamik im DNFB-CHS-Modell zumindest nicht wesentlich zu beeinflussen scheint. Letztlich existieren keine Untersuchungen und Hinweise dafür, dass B- und T-Zellen während der ILC-Entwicklung mit der ILC-Vorläuferzelle kommunizieren und ihr genomisches Profil in dieser Hinsicht beeinflussen könnten. Haut-ständige ILC2 kommunizieren zwar über MHC-Komplexe mit residenten T-Zellen, was jedoch in Ruhe eine untergeordnete Rolle zu spielen scheint (Oliphant et al. 2014). Sowohl Kim et al. (2014) als auch Roediger et al. (2013) haben mittels in vivo Mikroskopie gezeigt, dass dILC2 hauptsächlich mit Mastzellen und basophilen Granulozyten kommunizieren, die sowohl in der WT- als auch der RAG1/- - Maus vorkommen. 
Auch bei der Analyse spezifisch veränderter KEGG-pathways ergaben sich interessante Ergebnisse: Hauptsächlich von den Veränderungen betroffen scheinen Signalwege zu sein, die mit der Immunantwort, der Immunzelldifferenzierung und der Proliferation assoziiert sind. Interessanterweise konnte auch eine Beteiligung an Prozessen der viralen und parasitären Abwehr und an Autoimmun-Prozessen nachgewiesen werden. Für ILC2 ist bekannt, dass sie die Rolle der $\mathrm{T}_{\mathrm{H}} 2-$ Immunantwort auf der angeborenen Seite des Immunsystems übernehmen können, wobei die virale und parasitäre Immunantwort insbesondere mit den $\mathrm{T}_{\mathrm{H}} 2$-Zellen assoziiert ist. Die angezeigte Veränderung in den KEGG-pathways weist also darauf hin, dass die grundlegende Funktion der ILC2 bei den Immunantworten der viralen und parasitären Abwehr verändert zu sein scheint (Fallon et al. 2006). Wie genau sich die genannten Veränderungen auf die virale und parasitäre Abwehr auswirken (also den „klassischen ILC2-Funktionen“), ist nicht Gegenstand dieser Arbeit und bedarf weiterer Klärung.

Wie sich die Beteiligung von ILC2 an Autoimmun-Prozessen in diesem Kontext erklären lässt, ist weniger offensichtlich. In vorliegenden Fall waren spezifisch Signalwege verändert, die mit chronisch-entzündlichen Darmerkrankungen assoziiert sind. Es wird vermutet, dass es sich bei chronisch-entzündlichen Darmerkrankungen um eine autoimmune Entzündung der Darmschleimhaut handelt, weshalb eine Beteiligung der ILC an dieser autoimmunen Entzündung zumindest nachvollziehbar erscheint. Frühere Forschungsarbeiten haben gezeigt, dass besonders IL23 oder IL-17 produzierende ILC3 eine Rolle bei der Pathogenese chronisch-entzündlicher Darmerkrankungen spielen (Buonocore et al. 2010). Da die untersuchte RAG1-defiziente dILC2-Zellpopulation ein ILC3-typisches bzw. iILC2-typisches Profil aufwies, ist es nicht verwunderlich, dass gewisse Signalwege im Rahmen dieser Erkrankung in den KEGG-pathways als verändert angezeigt wurden.

Die Daten der RNA-Sequenzierung liefern also viele Kandidaten, anhand derer sich die Biologie der ILC weiter erforschen lassen könnte. Zum einen sollte man die molekularen Mechanismen untersuchen, die für eine verstärkte Regulation der Proliferation und der Apoptose verantwortlich sind. Zum anderen ist hier das Zytokinprofil von besonderem Interesse, um die molekularen Ursachen für den Switch bzw. eine mögliche Plastizität hinsichtlich einer Veränderung in die Richtung der ILC1 oder ILC3 zu untersuchen und dies mit den W'T-dILC2 zu vergleichen. Außerdem bleibt momentan unklar, weshalb der knockout von RAG1 und RAG1-defiziente dILC2 überhaupt mit einem veränderten Zytokinprofil verbunden sind.

Der Fokus dieser Dissertation lag jedoch aus qualitativen und quantitativen Gründen weniger in der wissenschaftlichen Untersuchung einzelner spezifischer Signalwege. Im Wesentlichen 
ging es vielmehr um eine Identifizierung und Untersuchung der allgemeinen funktionellen Auswirkungen der gemessenen genetischen Veränderungen in RAG1-defizienten dILC2. Zukünftige Arbeiten und Experimente werden sich gezielt auf die in den Sequenzierungs-Analysen herausgearbeiteten Unterschiede konzentrieren.

\subsubsection{RAG1-defiziente dILC2 neigen zur Apoptose}

Die vorliegenden Sequenzierungs-Daten, die sinkenden Zahlen nach der DNFB-challenge und frühere Arbeiten zu ILC2 in RAG1 ${ }^{/-}$Tieren bilden den Hintergrund für eine nähere Untersuchung der Apoptose der RAG1-defizienten dILC2 im Vergleich mit der Apoptose der WTMäuse. Zunächst zeigte sich bei den RAG1-defizienten dILC2 in Ruhe eine erhöhte AnnexinV-Expression, die allerdings nach der DNFB-challenge ähnlich hoch war wie bei den WT-dILC2. Die Annexin-V-Färbung wurde zum qualitativen und quantitativen Nachweis von Phosphatidylserin eingesetzt, einem Membran-Phospholipid, das nach dem Eintritt der Zelle in die Apoptose vom intrazellulären zum extrazellulären Bereich ,geflippt“ wird (Naito et al. 1997). Außerdem konnten erhöhte Mengen von Caspase-3/7-Spaltprodukten gemessen werden, was auf eine Beteiligung des klassischen Apoptose-Signalweges hinwies. Die Sequenzierungs-Daten zeigten, dass sowohl der extrinsische als auch der intrinsische Apoptose-Weg betroffen waren. So zeigte sich zum einen eine Hochregulierung von Bax, Bak1 sowie Apaf1, die über bestimmte Signalkaskaden zu einer Aktivierung von Caspase 3 führen (intrinsischer Weg). Zum anderen zeigte sich jedoch auch eine Hochregulierung von Fasl, das essentiell für den alternativen extrinsischen Weg der Apoptose ist (Daten nicht gezeigt) (Ow et al. 2008). Insgesamt lässt sich also zusammenfassen, dass RAG1 ${ }^{-1}$-dILC2 eine stärkere Apoptose-Neigung in Ruhe hatten, die auf eine Kombination von intrinsischen und extrinsischen Apoptose-Signalwegen zurückgeführt werden kann. Die erhöhte Apoptose-Neigung in Ruhe könnte auch ein Grund für die sinkenden dILC2-Zahlen nach der DNFB-challenge sein. Obwohl es bei der Annexin-V-Expression der dILC2 nach der DNFB-challenge keine Unterschiede zu der der WT-dILC2 gab, könnte die anfängliche „Apoptose-Suszeptibilität“ für die sinkende Zellzahl nach der DNFB-challenge in den

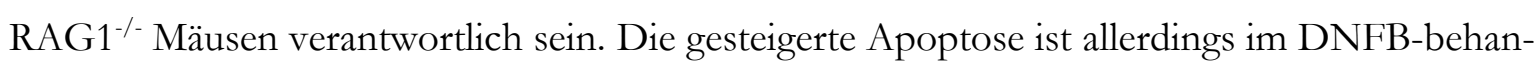
delten Ohr nicht mehr zu erkennen, was man evtl. auf eine Maskierung durch die starke und durch DNFB ausgelöste Entzündungsreaktion erklären kann.

Diese Ergebnisse sind deswegen interessant, weil sich frühere Arbeiten mit NK-Zellen beschäftigt haben und die eigenen Daten nun erste Hinweise liefern, dass sich der knockout von RAG1 auch auf andere ILC-Gruppen in ihrer Funktion auszuwirken scheint. Wie und warum beeinflusst RAG1 nun aber die Apoptose einer Zelle? Diese Frage haben Karo et al. (2014) in ihren 
Arbeiten an NK-Zellen untersucht. Nach ihren Untersuchungen kam es in NK-Zellen zu einer Herunterregulation von DNA-Reparatur-Proteinen (Atm, Ku80 und Chk2), was zu einer gesteigerten „Stresslabilität“ führte (Karo et al. 2014). Der eigentliche Mechanismus dahinter ist erst kürzlich aufgedeckt worden: Verantwortlich scheinen die durch den RAG-Komplex induzierten DSB zu sein. Wie bereits erwähnt wurde, finden die RAG-induzierten DSB wie heute angenommen nicht mehr nur an VDJ-Gensegmenten, sondern über das gesamte Genom verstreut statt (Ji et al. 2010; Teng et al. 2015). Ob die Zelle dies überlebt oder der Apoptose unterliegt, hängt von einer Vielzahl bisher teilweise noch unbekannter Faktoren ab. So werden bei der Induktion eines Doppelstrangbruches entweder Proteine aktiviert, die die DNA-Reparatur fördern oder aber die Apoptose einleiten und den Zellzyklus inhibieren. Es ist denkbar, dass der RAG-Komplex bei dieser Funktion eine entscheidende und das Genom stabilisierende Rolle einnimmt und für die Integrität der DNA verantwortlich ist bzw. dazu beiträgt. Beim Fehlen des RAG-Komplexes ist es möglich, dass es zu einer Dysregulation in diesem Prozess kommt und die Zelle durch eine Akkumulation von Doppelstrangbrüchen ihre Physiologie verliert und damit in die Apoptose übergeht. Es ist noch zu wenig über die Details und über die exakte Funktion des RAG-Komplexes in ILC bekannt, weswegen dies aktuell unklar bleibt. Arbeiten in der Zukunft werden dabei helfen, die Rolle von RAG in ILC besser verstehen zu können.

\subsubsection{Der IL-7-Rezeptor ist in RAG1-defizienten dILC2 höher exprimiert}

Eine weitere wichtige Beobachtung bestand darin, dass RAG1-defiziente dILC2 den IL-7R höher exprimierten als WT-dILC2. Außerdem zeigten RAG1-defiziente dILC2 eine erhöhte Proliferationsrate, was durch eine gesteigerte BrdU-Inkorporation in Ruhe nachgewiesen wurde. Die Sequenzierungs-Daten haben den Verdacht auf eine gesteigerte Proliferation bestätigt, da eine Überexpression von Genen u. a. der Jak-STAT- und PI3K-Signalwege gezeigt werden konnte, die auch downstream des IL-7R relevant sind (Mackall et al. 2011).

Es ist bekannt, dass der IL-7R eine vitale Rolle für das Überleben der ILC2 spielt (Vonarbourg und Diefenbach 2012). IL-7R $\mathrm{R}^{-/}$-Mäuse haben keine bis sehr wenig messbare ILC gezeigt, sie sind aber in der Entwicklung nahezu unabdingbar (Robinette et al. 2015; Yagi et al. 2014). Man kann vermuten, dass die gesteigerte Expression des IL-7R für die gesteigerte Proliferation verantwortlich ist. Der Signalweg downstream des IL-7R setzt sich aus Proteinen des Jak-STATSignalweges unter Beteiligung von JAK3 und STAT1 zusammen, die nach den SequenzierungsDaten beide eine Hochregulation aufwiesen (Mackall et al. 2011). Frühere Arbeiten haben interessanterweise gezeigt, dass lymphopene Mäuse, zu denen neben den RAG1 ${ }^{-/}$Mäusen auch SCID-Mäuse gehören, höhere IL-7-Konzentrationen als WT-Mäuse in vivo zeigen (Guimond et 
al. 2009). Es wäre zu erwarten, dass RAG1-defiziente dILC2 deswegen einen niedriger exprimierten IL-7R aufweisen, weil hohe IL-7-Konzentrationen zu einer Herunterregulation des IL-7R führen (Vranjkovic et al. 2007). Sie wiesen allerdings eine erhöhte IL-7R-Expression auf. Dieses Resultat verweist auf zwei Aspekte: Einerseits entfliehen RAG1-defiziente dILC2 der IL-7R-Regulation durch frei verfügbares IL-7. Andererseits könnte diese gesteigerte Rezeptivität sicherlich auch die erhöhten dILC2-Zellzahlen erklären. Wodurch wird nun aber der IL-7R reguliert, wenn nicht durch freies IL-7? Es ist bekannt, dass die IL-7R-Expression in einer reziproken Dynamik zur RAG-Expression steht (Johnson et al. 2012). Deshalb scheint es denkbar, dass das fehlende RAG1-Protein in der Entwicklung der dILC2 zu einer fehlenden negativen Regulation der IL-7R-Expression führt, die zu einer Überexpression des Rezeptors geführt hat. Der Rezeptor hat folglich zu einer höheren Rezeptivität von IL-7 geführt, wodurch die Zellzahlen und die Proliferationsaktivität gesteigert werden konnten. In dieser Hinsicht ist nun aber wichtig, dass es sich hierbei um einen RAG1-spezifischen Effekt handelt. Nicht die Tatsache des erhöhten IL-7 in den lymphopenen Mäusen, sondern die gesteigerte Expression des Rezeptors dafür hat wohlmöglich diesen Effekt herbeigeführt. Wichtig zu erwähnen ist weiterhin, dass mit dem verwendeten Antikörper nur die $\alpha$-Kette des Heterodimers IL-7R nachgewiesen werden konnte. Der IL-7R $\alpha$ ist jedoch ebenfalls eine Rezeptorunterkette für einen weiteren und viel klassischeren starken Stimulator von ILC2, nämlich das TSLP (Park et al. 2000). In den Sequenzierungs-Daten zeigte sich jedoch keine höhere Expression von Tshpr, der zweiten Unterkette des TSLP-R, wodurch weitgehend ausgeschlossen wird, dass es sich um einen Effekt von TSLP anstelle von IL-7 handeln könnte.

Insgesamt konnte gezeigt werden, dass RAG1-defiziente dILC2 keinen „stabilen“ Proliferationsstatus aufweisen, da zusätzlich zur Proliferation auch die Apoptose verstärkt wurde. Somit besteht ein Nebeneinander zwischen erhöhter Apoptose und erhöhter Proliferation. Weitere Untersuchungen sollten sich auf die molekularen Mechanismen dieses Nebeneianders spezialisieren und insbesondere auch betrachten, wie die erhöhte Aktivierung der RAG1-defizienten dILC2 sich in diesen Zusammenhang integrieren lässt. Ein spekulatives Modell sähe folgendermaßen aus: Die RAG1-Defizienz führt zur gesteigerten Proliferation durch IL-7R-Signale. Diese „Hyperaktivität“ der dILC2 führt als „Kollateralschaden“ zu einer durch diese Aktivierung-induzierten-Apoptose (AICD; activation induced cell death), die der gesteigerten Proliferation entgegenwirkt (Arakaki et al. 2014). Durch eine gesteigerte Expression des IL-2R kommt es parallel zu einer erhöhten Proliferation auch zu einer Aktivierung der dILC2, die dann durch weitestgehend unbekannte Mechanismen zu einer ILC1/ILC3-Polarisaton führt. 
Die zukünftige Forschung an dILC2 sollte nicht leichtfertig an $\mathrm{RAG}^{-/-}$-Mäusen durchgeführt werden, weil sie eine grundsätzlich andere Biologie aufweisen als WT-dILC2. Die dILC2 kommen zwar zahlenmäßig häufiger vor und es gibt keine B- und T-Zellen, die als „Störfaktoren“ wirken könnten, wodurch eine isolierte Analyse von dILC2 möglich ist. Die Zellen sind aber auch so verändert, dass die Ergebnisse an RAG1-defizienten dILC2 nicht ohne Weiteres auf W'T-dILC2 übertragen werden können. Bisherige Forschungen, die mit RAG1-defizienten dILC2 durchgeführt wurden, sind daher vorsichtig zu evaluieren.

\subsection{Implikationen unserer Daten auf den Menschen}

Die vorliegenden Ergebnisse sind in vielerlei Hinsicht für den Menschen interessant. Einerseits konnten Erkenntnisse über das Verhalten von dILC2 bei einer CHS gesammelt werden. Im Einklang mit der Literatur scheinen hohe dILC2-Zahlen das Ausmaß und die Entzündung einer CHS zu regulieren und zu beschränken (Rafei-Shamsabadi et al. 2018), wie es bei den $\mathrm{RAG}^{-/-}$-Mäusen zu beobachten ist. Deshalb ist meine Arbeit die zweite überhaupt, die dILC2 als einen wichtigen und neuen Effektor bei der CHS der Haut beschreibt. Es bleibt unklar, welche genauen Mechanismen für die beobachteten Effekte verantwortlich sind, und ob sich die Ergebnisse auf die menschliche Haut übertragen lassen. Bisher existieren keine Daten bezüglich dILC2 und der CHS beim Menschen. Es ist bekannt, dass ILC2 in einer engen Verbindung mit den T-Zellen stehen, die als Haupteffektor des allergischen Kontaktekzems betrachtet werden (Bour et al. 1995; Oliphant et al. 2014). Andere entzündliche Hauterkrankungen wie das atopische Ekzem bzw. die Psoriasis sind mit einer vermehrten Aktivität und höheren Zahlen von ILC2 in der läsionierten Haut verbunden (Pantelyushin et al. 2012; Salimi et al. 2013). Eine regulatorische oder aktivierende Wirkung auf diese T-Zellen ist daher denkbar und sollte in der Zukunft weiter erforscht werden.

Die zweite Erkenntnis bezieht sich auf die fehl-regulierte Biologie von RAG1-defizienten dILC2. Beim Menschen werden Erkrankungen beschrieben, die ebenfalls einen knockout in den RAG-Genen als verursachenden Auslöser haben, dazu gehören das Omenn-Syndrom und das kombinierte Immunschwäche-Syndrom (severe combined immunodeficiency; SCID) (Marrella et al. 2011). Die Haut dieser Patienten fällt durch unspezifische Hautrötungen und Exantheme auf. Aufgrund der Seltenheit der Erkrankung existieren weder Daten zu den gestörten immunologischen Hautkompartimenten dieser Patienten noch Daten zu den sehr seltenen ILC2. Es ist denkbar, dass ILC2 bei den pathologischen Prozessen der Haut eine entscheidende Rolle spielen, angesichts der Tatsache, dass ILC2 in der Haut der RAG1/--Mäuse fehlreguliert sind und 
ILC2 bei diversen Hautentzündungen einen maßgeblich Einfluss haben (Kim 2015). Diese Resultate bieten zukünftige Angriffspunkte zur Verstärkung oder Hemmung in der Immuntherapie für Patienten mit diesen seltenen Immundefekten. 


\section{$5 \quad$ Zusammenfassung}

Dermale innate-like lymphoid cells type 2 (dILC2) sind erst in den letzten 10 Jahren zum Gegenstand intensiver Forschung geworden. Zur Funktion von dILC2 liegen bislang nur wenige Erkenntnisse vor. In der vorliegenden Arbeit wurde gezeigt, dass RAG1 ${ }^{-}$-Mäuse signifikant höheren dILC2-Zahlen als WT-Mäuse aufweisen. Eine durchgeführte RNA-Sequenzierung von WTdILC2 und RAG1-defizienten dILC2 konnte starke genomische Veränderungen in Prozessen nachweisen, die mit der Zytokin-Zytokin-Rezeptor-Interaktion, der Proliferation, der Immunantwort sowie mit Autoimmun-Prozessen assoziiert sind. Interessant war eine vermeintliche Aktivierung in die Richtung eines ILC1/ILC3-Phänotyps.

Im 1-Fluor-2,4-dinitrobenzol-Kontaktallergie-Modell zeigten die dILC2 der RAG1 ${ }^{-/}$-Mäuse eine reziproke Dynamik gegenüber den WT-dILC2: Während die dILC2 in WT-Mäusen zahlenmäßig anstiegen, sanken sie bei den $\mathrm{RAG}^{-/}{ }^{-}$-Mäusen ab. Dieser Effekt ließ sich durch einen adoptiven Transfer von WT-Lymphozyten nicht rückgängig machen.

RAG1-defiziente dILC2 weisen eine erhöhte Apoptose-Neigung in Ruhe sowie eine erhöhte Produktion von Caspase-3/7-Spaltprodukten auf. Außerdem zeigten sie eine erhöhte Expression des IL-7-Rezeptors. Letztlich wiesen RAG1-defiziente dILC2 auch eine erhöhte BrdUInkorporation auf, welches eine erhöhte Proliferationsaktivität in Ruhe zeigt.

Insgesamt konnte gezeigt werden, dass RAG1-defiziente dILC2 ein signifikant verändertes Gen-Expressionsprofil aufweisen, das mit einem funktionellen Defekt, einer Überaktivierung und letztlich auch veränderten Proliferations- und Apoptose-Signalwegen verbunden ist. Da in der Forschung zu murinen dILC2 sehr oft RAG1 ${ }^{-/}$-Mäuse zum Einsatz kommen, müssen die so gewonnenen Ergebnisse mit Vorsicht interpretiert werden. 


\section{$6 \quad$ Literaturverzeichnis}

Aiba S, Terunuma A, Manome H, Tagami H (1997): Dendritic cells differently respond to haptens and irritants by their production of cytokines and expression of co-stimulatory molecules. Eur J Immunol 27, 3031-3038

Arakaki R, Yamada A, Kudo Y, Hayashi Y, Ishimaru N (2014): Mechanism of activationinduced cell death of $T$ cells and regulation of FasL expression. Crit Rev Immunol $\underline{34}$, 301-14

Artis D, Spits H (2015): The biology of innate lymphoid cells. Nature $\underline{517}$, 293-301

Bernink JH, Germar K, Spits H (2014): The role of ILC2 in pathology of type 2 inflammatory diseases. Curr Opin Immunol $\underline{31}, 115-120$

Bieber T (2008): Atopic dermatitis. N Engl J Med $\underline{358}, 1483-1494$

Bjorklund AK, Forkel M, Picelli S, Konya V, Theorell J, Friberg D, Sandberg R, Mjosberg J (2016): The heterogeneity of human CD127(+) innate lymphoid cells revealed by single-cell RNA sequencing. Nat Immunol 17, 451-460

Bonneville M, Chavagnac C, Vocanson M, Rozieres A, Benetiere J, Pernet I, Denis A, Nicolas JF, Hennino A (2007): Skin contact irritation conditions the development and severity of allergic contact dermatitis. J Invest Dermatol 127, 1430-1435

Bour H, Peyron E, Gaucherand M, Garrigue JL, Desvignes C, Kaiserlian D, Revillard JP, Nicolas JF (1995): Major histocompatibility complex class I-restricted CD8+ T cells and class II-restricted CD4+ $\mathrm{T}$ cells, respectively, mediate and regulate contact sensitivity to dinitrofluorobenzene. Eur J Immunol 25, 3006-3010

Buonocore S, Ahern PP, Uhlig HH, Ivanov, II, Littman DR, Maloy KJ, Powrie F (2010): Innate lymphoid cells drive interleukin-23-dependent innate intestinal pathology. Nature $\underline{464}, 1371-$ 1375

Cavani A, Nasorri F, Ottaviani C, Sebastiani S, de Pita O, Girolomoni G (2003): Human CD25+ regulatory $\mathrm{T}$ cells maintain immune tolerance to nickel in healthy, nonallergic individuals. $\mathrm{J}$ Immunol 171, 5760-5768 
Ciccia A, Elledge SJ (2010): The DNA damage response: making it safe to play with knives. Mol Cell $\underline{40}, 179-204$

Daussy C, Faure F, Mayol K, Viel S, Gasteiger G, Charrier E, Bienvenu J, Henry T, Debien E, Hasan UA et al. (2014): T-bet and Eomes instruct the development of two distinct natural killer cell lineages in the liver and in the bone marrow. J Exp Med 211, 563-577

Divkovic M, Pease CK, Gerberick GF, Basketter DA (2005): Hapten-protein binding: from theory to practical application in the in vitro prediction of skin sensitization. Contact Dermatitis $\underline{53}, 189-200$

Dobin A, Davis CA, Schlesinger F, Drenkow J, Zaleski C, Jha S, Batut P, Chaisson M, Gingeras TR (2013): STAR: ultrafast universal RNA-seq aligner. Bioinformatics 29 , 15-21

Early P, Huang H, Davis M, Calame K, Hood L (1980): An immunoglobulin heavy chain variable region gene is generated from three segments of DNA: VH, D and JH. Cell $\underline{19}$, 981992

Eberl G, Marmon S, Sunshine MJ, Rennert PD, Choi Y, Littman DR (2004): An essential function for the nuclear receptor RORgamma(t) in the generation of fetal lymphoid tissue inducer cells. Nat Immunol $\underline{5}, 64-73$

Eden E, Navon R, Steinfeld I, Lipson D, Yakhini Z (2009): GOrilla: a tool for discovery and visualization of enriched GO terms in ranked gene lists BMC. Bioinformatics $\underline{10}, 48$

Fallon PG, Ballantyne SJ, Mangan NE, Barlow JL, Dasvarma A, Hewett DR, McIlgorm A, Jolin HE, McKenzie AN (2006): Identification of an interleukin (IL)-25-dependent cell population that provides IL-4, IL-5, and IL-13 at the onset of helminth expulsion. J Exp Med 203, 11051116

Fort MM, Cheung J, Yen D, Li J, Zurawski SM, Lo S, Menon S, Clifford T, Hunte B, Lesley R et al. (2001): IL-25 induces IL-4, IL-5, and IL-13 and Th2-associated pathologies in vivo. Immunity $\underline{15}$, 985-995

Gellert M (2002): V(D)J recombination: RAG proteins, repair factors, and regulation. Annu Rev Biochem 1ㅡ, 101-132 
Gordon SM, Chaix J, Rupp LJ, Wu J, Madera S, Sun JC, Lindsten T, Reiner SL (2012): The transcription factors T-bet and Eomes control key checkpoints of natural killer cell maturation. Immunity $\underline{36}, 55-67$

Gratzner HG (1982): Monoclonal antibody to 5-bromo- and 5-iododeoxyuridine: A new reagent for detection of DNA replication. Science $\underline{218}, 474-475$

Guimond M, Veenstra RG, Grindler DJ, Zhang H, Cui Y, Murphy RD, Kim SY, Na R, Hennighausen L, Kurtulus S et al. (2009): Interleukin 7 signaling in dendritic cells regulates the homeostatic proliferation and niche size of CD4+ T cells. Nat Immunol $\underline{10}, 149-157$

Hadley GA, Bartlett ST, Via CS, Rostapshova EA, Moainie S (1997): The epithelial cell-specific integrin, CD103 (alpha E integrin), defines a novel subset of alloreactive CD8+ CTL. J Immunol $\underline{159}, 3748-3756$

Halim TY, Krauss RH, Sun AC, Takei F (2012): Lung natural helper cells are a critical source of Th2 cell-type cytokines in protease allergen-induced airway inflammation. Immunity $\underline{36}, 451-$ 463

Hazenberg MD, Spits H (2014): Human innate lymphoid cells. Blood 124, 700-709

Honda T, Egawa G, Grabbe S, Kabashima K (2013): Update of immune events in the murine contact hypersensitivity model: toward the understanding of allergic contact dermatitis. J Invest Dermatol $\underline{133}, 303-315$

Huang D, Sherman BT, Lempicki RA (2009): Systematic and integrative analysis of large gene lists using DAVID bioinformatics resources. Nat Protoc $\underline{4}, 44-57$

Huang Y, Guo L, Qiu J, Chen X, Hu-Li J, Siebenlist U, Williamson PR, Urban JF, Jr., Paul WE (2015): IL-25-responsive, lineage-negative KLRG1(hi) cells are multipotential 'inflammatory' type 2 innate lymphoid cells. Nat Immunol 16, 161-169

Hurst SD, Muchamuel T, Gorman DM, Gilbert JM, Clifford T, Kwan S, Menon S, Seymour B, Jackson C, Kung TT et al. (2002): New IL-17 family members promote Th1 or Th2 responses in the lung: in vivo function of the novel cytokine IL-25. J Immunol $\underline{169}$, 443-453 
Iwasaki A, Medzhitov R (2010): Regulation of adaptive immunity by the innate immune system. Science $\underline{327}, 291-295$

Janeway CA, Jr. (1989): Approaching the asymptote? Evolution and revolution in immunology.

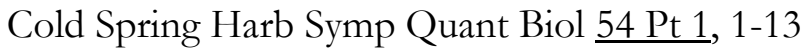

Ji Y, Resch W, Corbett E, Yamane A, Casellas R, Schatz DG (2010): The in vivo pattern of binding of RAG1 and RAG2 to antigen receptor loci. Cell 141, 419-431

Johnson K, Chaumeil J, Micsinai M, Wang JMH, Ramsey LB, Baracho GV, Rickert RC, Strino F, Kluger Y, Farrar MA, Skok JA (2012): IL-7 functionally segregates the pro-B cell stage by regulating transcription of recombination mediators across cell cycle. J Immunol $\underline{188}$, 60846092

Karo JM, Schatz DG, Sun JC (2014): The RAG recombinase dictates functional heterogeneity and cellular fitness in natural killer cells. Cell $\underline{159}, 94-107$

Karo JM, Sun JC (2015): Novel molecular mechanism for generating NK-cell fitness and memory. Eur J Immunol 45, 1906-1915

Kiessling R, Klein E, Wigzell H (1975): "Natural" killer cells in the mouse. I. Cytotoxic cells with specificity for mouse Moloney leukemia cells. Specificity and distribution according to genotype. Eur J Immunol $\underline{5}, 112-117$

Kim BS (2015): Innate lymphoid cells in the skin. J Invest Dermatol 135, 673-678

Kim BS, Siracusa MC, Saenz SA, Noti M, Monticelli LA, Sonnenberg GF, Hepworth MR, Van Voorhees AS, Comeau MR, Artis D (2013): TSLP elicits IL-33-independent innate lymphoid cell responses to promote skin inflammation. Sci Transl Med $\underline{5}$, 170ra116

Kim BS, Wang K, Siracusa MC, Saenz SA, Brestoff JR, Monticelli LA, Noti M, Tait Wojno ED, Fung TC, Kubo M et al. (2014): Basophils promote innate lymphoid cell responses in inflamed skin. J Immunol $\underline{193}, 3717-3725$

Kim DR, Dai Y, Mundy CL, Yang W, Oettinger MA (1999): Mutations of acidic residues in RAG1 define the active site of the V(D)J recombinase. Genes Dev 13, 3070-3080 
Lai L, Alaverdi N, Maltais L, Morse HC 3rd (1998): Mouse Cell Surface Antigens: Nomenclature and Immunophenotyping. J Immunol 160, 3861-3868

Landree MA, Wibbenmeyer JA, Roth DB (1999): Mutational analysis of RAG1 and RAG2 identifies three catalytic amino acids in RAG1 critical for both cleavage steps of V(D)J recombination. Genes Dev 13, 3059-3069

Larsen JM, Bonefeld CM, Poulsen SS, Geisler C, Skov L (2009): IL-23 and T(H)17-mediated inflammation in human allergic contact dermatitis. J Allergy Clin Immunol $\underline{123}$, 486-492

Lee MW, Odegaard JI, Mukundan L, Qiu Y, Molofsky AB, Nussbaum JC, Yun K, Locksley RM, Chawla A (2015): Activated type 2 innate lymphoid cells regulate beige fat biogenesis. Cell $\underline{160}, 74-87$

Li M, Hener P, Zhang Z, Kato S, Metzger D, Chambon P (2006): Topical vitamin D3 and lowcalcemic analogs induce thymic stromal lymphopoietin in mouse keratinocytes and trigger an atopic dermatitis. Proc Natl Acad Sci U S A $\underline{103}, 11736-11741$

Liao Y, Smyth GK, Shi W (2014): featureCounts: an efficient general purpose program for assigning sequence reads to genomic features. Bioinformatics $\underline{30}$, 923-930

Maazi H, Patel N, Sankaranarayanan I, Suzuki Y, Rigas D, Soroosh P, Freeman GJ, Sharpe AH, Akbari O (2015): ICOS:ICOS-ligand interaction is required for type 2 innate lymphoid cell function, homeostasis, and induction of airway hyperreactivity. Immunity $\underline{42}, 538-551$

Mackall C, Fry T, Gress R (2011): Harnessing the biology of IL-7 for therapeutic application. Nat Rev Immunol 11, 330-342

Maggi L, Montaini G, Mazzoni A, Rossettini B, Capone M, Rossi MC, Santarlasci V, Liotta F, Rossi O, Gallo O et al. (2017): Human circulating group 2 innate lymphoid cells can express CD154 and promote IgE production. J Allergy Clin Immunol 139, 964-976

Marrella V, Maina V, Villa A (2011): Omenn syndrome does not live by V(D)J recombination alone. Curr Opin Allergy Clin Immunol 11, 525-531 
Martin SF (2011): Immunology of contact allergy. Hautarzt 62, 739-743

Martin SF (2012): Allergic contact dermatitis: xenoinflammation of the skin. Curr Opin Immunol 24, 720-729

Matthews AG, Kuo AJ, Ramon-Maiques S, Han S, Champagne KS, Ivanov D, Gallardo M, Carney D, Cheung P, Ciccone DN et al. (2007): RAG2 PHD finger couples histone H3 lysine 4 trimethylation with $\mathrm{V}(\mathrm{D}) \mathrm{J}$ recombination. Nature $\underline{450}, 1106-1110$

Mebius RE, Rennert P, Weissman IL (1997): Developing lymph nodes collect CD4+CD3LTbeta+ cells that can differentiate to APC, NK cells, and follicular cells but not T or B cells. Immunity $\underline{7}, 493-504$

Mjosberg JM, Trifari S, Crellin NK, Peters CP, van Drunen CM, Piet B, Fokkens WJ, Cupedo T, Spits H (2011): Human IL-25- and IL-33-responsive type 2 innate lymphoid cells are defined by expression of CRTH2 and CD161. Nat Immunol 12, 1055-1062

Mombaerts P, Iacomini J, Johnson RS, Herrup K, Tonegawa S, Papaioannou VE (1992): RAG1-deficient mice have no mature B and T lymphocytes. Cell $\underline{68}, 869-877$

Moodycliffe AM, Shreedhar V, Ullrich SE, Walterscheid J, Bucana C, Kripke ML, Flores-Romo L (2000): CD40-CD40 ligand interactions in vivo regulate migration of antigen-bearing dendritic cells from the skin to draining lymph nodes. J Exp Med 191, 2011-2020

Moro K, Yamada T, Tanabe M, Takeuchi T, Ikawa T, Kawamoto H, Furusawa J, Ohtani M, Fujii H, Koyasu S (2010): Innate production of T(H)2 cytokines by adipose tissue-associated cKit(+)Sca-1(+) lymphoid cells. Nature $\underline{463}, 540-544$

Naito M, Nagashima K, Mashima T, Tsuruo T (1997): Phosphatidylserine externalization is a downstream event of interleukin-1 beta-converting enzyme family protease activation during apoptosis. Blood $\underline{89}$, 2060-2066

Neill DR, Wong SH, Bellosi A, Flynn RJ, Daly M, Langford TK, Bucks C, Kane CM, Fallon PG, Pannell R et al. (2010): Nuocytes represent a new innate effector leukocyte that mediates type-2 immunity. Nature $\underline{464}, 1367-1370$ 
Nishana M, Raghavan SC (2012): Role of recombination activating genes in the generation of antigen receptor diversity and beyond. Immunology 137, 271-281

Nuriya S, Yagita H, Okumura K, Azuma M (1996): The differential role of CD86 and CD80 co-stimulatory molecules in the induction and the effector phases of contact hypersensitivity. Int Immunol $\underline{8}, 917-926$

Nussbaum J, Van Dyken S, von Moltke J, Cheng LE, Mohapatra A, Molofsky AB, Thornton EE, Krummel MF, Chawla A, Liang H, Locksley RM (2013): Type 2 innate lymphoid cells control eosinophil homeostasis. Nature $\underline{502}, 245-248$

Oettinger MA, Schatz DG, Gorka C, Baltimore D (1990): RAG-1 and RAG-2, adjacent genes that synergistically activate V(D)J recombination. Science 248, 1517-1523

Ohne Y, Silver JS, Thompson-Snipes L, Collet MA, Blanck JP, Cantarel BL, Copenhaver AM, Humbles AA, Liu YJ (2016): IL-1 is a critical regulator of group 2 innate lymphoid cell function and plasticity. Nat Immunol 17, 646-655

O'Leary J, Goodarzi M, Drayton D, von Andrian UH (2006): T cell- and B cell-independent adaptive immunity mediated by natural killer cells. Nat Immunol $\underline{7}, 507-516$

Oliphant CJ, Hwang YY, Walker JA, Salimi M, Wong SH, Brewer JM, Englezakis A, Barlow JL, Hams E, Scanlon ST et al. (2014): MHCII-mediated dialog between group 2 innate lymphoid cells and CD4(+) $\mathrm{T}$ cells potentiates type 2 immunity and promotes parasitic helminth expulsion. Immunity $\underline{41}, 283-295$

Ow YP, Green DR, Hao Z, Mak TW (2008): Cytochrome c: functions beyond respiration. Nat Rev Mol Cell Biol 2, 532-542

Paclik D, Stehle C, Lahmann A, Hutloff A, Romagnani C (2015): ICOS regulates the pool of group 2 innate lymphoid cells under homeostatic and inflammatory conditions in mice. Eur J Immunol 45, 2766-2772

Pantelyushin S, Haak S, Ingold B, Kulig P, Heppner FL, Navarini AA, Becher B (2012): Rorgammat+ innate lymphocytes and gammadelta $\mathrm{T}$ cells initiate psoriasiform plaque formation in mice. J Clin Invest 122, 2252-2256 
Park LS, Martin U, Garka K, Gliniak B, Di Santo JP, Muller W, Largaespada DA, Copeland NG, Jenkins NA, Farr AG et al. (2000): Cloning of the Murine Thymic Stromal Lymphopoietin (Tslp) Receptor: Formation of a Functional Heteromeric Complex Requires Interleukin 7 Receptor. J Exp Med 192, 659-670

Park JH, Yu Q, Erman B, Appelbaum JS, Montoya-Durango D, Grimes HL, Singer A (2004): Suppression of IL7Ralpha transcription by IL-7 and other prosurvival cytokines: a novel mechanism for maximizing IL-7-dependent T cell survival. Immunity $\underline{21}, 289-302$

Peiser M, Tralau T, Heidler J, Api AM, Arts JH, Basketter DA, English J, Diepgen TL, Fuhlbrigge RC, Gaspari AA et al. (2012): Allergic contact dermatitis: epidemiology, molecular mechanisms, in vitro methods and regulatory aspects. Current knowledge assembled at an international workshop at BfR, Germany. Cell Mol Life Sci 69, 763-781

Price AE, Liang HE, Sullivan BM, Reinhardt RL, Eisley CJ, Erle DJ, Locksley RM (2010): Systemically dispersed innate IL-13-expressing cells in type 2 immunity. Proc Natl Acad Sci U S A $\underline{107}, 11489-11494$

Rafei-Shamsabadi DA, van de Poel S, Dorn B, Kunz S, Martin SF, Klose CSN, Arnold SJ, Tanriver Y, Ebert K, Diefenbach A et al. (2018): Lack of Type 2 Innate Lymphoid Cells Promote a Type I Driven Enhanced Immune Response in Contact Hypersensitivity. J Invest Dermatol 138, 1962-1972

Reduta T, Stasiak-Barmuta A, Laudanska H (2011): CD4+CD25+ and CD4+CD2+high regulatory $\mathrm{T}$ cells in disseminated and localized forms of allergic contact dermatitis: relation to specific cytokines. Folia Histochem Cytobiol 49, 255-262

Ring S, Schafer SC, Mahnke K, Lehr HA, Enk AH (2006): CD4+ CD25+ regulatory T cells suppress contact hypersensitivity reactions by blocking influx of effector $\mathrm{T}$ cells into inflamed tissue. Eur J Immunol 36, 2981-2992

Robinette ML, Bando JK, Song W, Ulland TK, Gilfillan S, Colonna M (2017): IL-15 sustains IL-7R-independent ILC2 and ILC3 development. Nat Commun $\underline{8}, 14601$

Robinette ML, Cella M, Telliez JB, Ulland TK, Barrow AD, Capuder K, Gilfillan S, Lin LL, Notarangelo LD, Colonna M (2018): Jak3 deficiency blocks innate lymphoid cell development. Mucosal Immunol 11, 50-60 
Robinette ML, Fuchs A, Cortez VS, Lee JS, Wang Y, Durum SK, Gilfillan S, Colonna M, Immunological Genome Consortium (2015): Transcriptional programs define molecular characteristics of innate lymphoid cell classes and subsets. Nat Immunol $\underline{16}$, 306-317

Roediger B, Kyle R, Le Gros G, Weninger W (2014): Dermal group 2 innate lymphoid cells in atopic dermatitis and allergy. Curr Opin Immunol $\underline{31}, 108-114$

Roediger B, Kyle R, Yip KH, Sumaria N, Guy TV, Kim BS, Mitchell AJ, Tay SS, Jain R, ForbesBlom E et al. (2013): Cutaneous immunosurveillance and regulation of inflammation by group 2 innate lymphoid cells. Nat Immunol $\underline{14}, 564-573$

Sakano H, Huppi K, Heinrich G, Tonegawa S (1979): Sequences at the somatic recombination sites of immunoglobulin light-chain genes. Nature 280, 288-294

Salimi M, Barlow JL, Saunders SP, Xue L, Gutowska-Owsiak D, Wang X, Huang LC, Johnson D, Scanlon ST, McKenzie AN et al. (2013): A role for IL-25 and IL-33-driven type-2 innate lymphoid cells in atopic dermatitis. J Exp Med 210, 2939-2950

Sandilands A, Sutherland C, Irvine AD, McLean WH (2009): Filaggrin in the frontline: role in skin barrier function and disease. J Cell Sci 122, 1285-1294

Schatz DG, Ji Y (2011): Recombination centres and the orchestration of V(D)J recombination. Nat Rev Immunol 11, 251-263

Schatz DG, Spanopoulou E (2005): Biochemistry of V(D)J recombination. Curr Top Microbiol Immunol $\underline{290}, 49-85$

Schlickum S, Sennefelder H, Friedrich M, Harms G, Lohse MJ, Kilshaw P, Schon MP (2008): Integrin alpha $\mathrm{E}(\mathrm{CD} 103)$ beta 7 influences cellular shape and motility in a ligand-dependent fashion. Blood 112, 619-625

Segawa K, Nagata S (2015): An Apoptotic 'Eat Me' Signal: Phosphatidylserine Exposure. Trends Cell Biol 25, 639-650

Seillet C, Mielke LA, Amann-Zalcenstein DB, Su S, Gao J, Almeida FF, Shi W, Ritchie ME, Naik SH, Huntington ND et al. (2016): Deciphering the Innate Lymphoid Cell Transcriptional Program. Cell Rep 17, 436-447 
Simoni Y, Fehlings M, Kloverpris HN, McGovern N, Koo SL, Loh CY, Lim S, Kurioka A, Fergusson JR, Tang CL et al. (2017): Human Innate Lymphoid Cell Subsets Possess TissueType Based Heterogeneity in Phenotype and Frequency. Immunity $\underline{46}, 148-161$

Sonnenberg GF, Mjosberg J, Spits H, Artis D (2013): SnapShot: innate lymphoid cells. Immunity $\underline{39}, 622$

Spits H (2013): Group 2 innate lymphoid cells show up in the skin. Immunol Cell Biol 91, 390392

Spits H, Artis D, Colonna M, Diefenbach A, Di Santo JP, Eberl G, Koyasu S, Locksley RM, McKenzie AN, Mebius RE et al. (2013): Innate lymphoid cells--a proposal for uniform nomenclature. Nat Rev Immunol 13, 145-149

Teng G, Maman Y, Resch W, Kim M, Yamane A, Qian J, Kieffer-Kwon KR, Mandal M, Ji Y, Meffre E et al. (2015): RAG Represents a Widespread Threat to the Lymphocyte Genome. Cell $\underline{162}, 751-765$

Verykokakis M, Zook EC, Kee BL (2014): ID'ing innate and innate-like lymphoid cells. Immunol Rev 261, 177-197

Visser MJ, Landeck L, Campbell LE, McLean WHI, Weidinger S, Calkoen F, John SM, Kezic S (2013): Impact of atopic dermatitis and loss-of-function mutations in the filaggrin gene on the development of occupational irritant contact dermatitis. Br J Dermatol $\underline{168}$, 326-332

Vocanson M, Hennino A, Cluzel-Tailhardat M, Saint-Mezard P, Benetiere J, Chavagnac C, Berard F, Kaiserlian D, Nicolas JF (2006): CD8+ T cells are effector cells of contact dermatitis to common skin allergens in mice. J Invest Dermatol $\underline{126}, 815-820$

Vonarbourg C, Diefenbach A (2012): Multifaceted roles of interleukin-7 signaling for the development and function of innate lymphoid cells. Semin Immunol 24, 165-174

Vranjkovic A, Crawley AM, Gee K, Kumar A, Angel JB (2007): IL-7 decreases IL-7 receptor alpha (CD127) expression and induces the shedding of CD127 by human CD8+ T cells. Int Immunol $\underline{19}$, 1329-1339 
Wong SH, Walker JA, Jolin HE, Drynan LF, Hams E, Camelo A, Barlow JL, Neill DR, Panova V, Koch U et al. (2012): Transcription factor RORalpha is critical for nuocyte development. Nat Immunol 13, 229-236

Yagi R, Zhong C, Northrup DL, Yu F, Bouladoux N, Spencer S, Hu G, Barron L, Sharma S, Nakayama T et al. (2014): The transcription factor GATA3 is critical for the development of all IL-7Ralpha-expressing innate lymphoid cells. Immunity $\underline{40}$, 378-388

Zhang K, Xu X, Pasha MA, Siebel CW, Costello A, Haczku A, MacNamara K, Liang T, Zhu J, Bhandoola A et al. (2017): Cutting Edge: Notch Signaling Promotes the Plasticity of Group-2 Innate Lymphoid Cells. J Immunol 198, 1798-1803

Zhong H, Fan XL, Yu QN, Qin ZL, Chen D, Xu R, Chen DH, Lin ZB, Wen W, Fu QL (2017): Increased innate type 2 immune response in house dust mite-allergic patients with allergic rhinitis. Clin Immunol 183, 293-299

Zhou BB, Elledge SJ (2000): The DNA damage response: putting checkpoints in perspective. Nature $\underline{408}, 433-439$

Zhou LJ, Tedder TF (1995): A distinct pattern of cytokine gene expression by human CD83+ blood dendritic cells. Blood $\underline{86}, 3295-3301$ 


\section{Danksagung}

Besonderen Dank möchte ich richten an:

Prof. Dr. med. T. Buhl für die Betreuung meines Projektes und die exzellente Unterstützung bei sämtlichen projektbezogenen Fragen, für die stete Erreichbarkeit, außerdem für seine maßgebliche Beteiligung beim Überlegen der Fragestellungen, Planen der Experimente sowie bei der Interpretation der Daten.

Prof. Dr. med. M. P. Schön für die interessanten und klugen Anregungen zur Verbesserung des Projektes sowie der ideellen und finanziellen Förderung meines Freisemesters.

Sämtlichen Labormitarbeitern, die direkt und indirekt Hilfestellungen zur Fertigstellung dieser Arbeit geleistet haben. Besonders hervorheben möchte ich Jutta Schulz, die mir großzügig und mit exzellenter Kompetenz und Sorgfalt sowohl bei der Planung des experimentellen Designs als auch bei der Durchführung der Experimente geholfen hat.

Letztlich den Mitarbeitern des Transkriptom-Labors der Universitätsmedizin Göttingen für die Durchführung unserer RNA-Sequenzierung und der Hilfestellung bei der darauffolgenden Auswertung unserer Daten. Hierbei ist insbesondere Dr. O. Shomroni hervorzuheben. 


\section{Lebenslauf}

Mein Name ist Mohamed Mahde Saleh und ich wurde am 17.10.1992 als drittes Kind meiner Eltern Wafa Amen und Mahde Farhan in Bagdad geboren. In Hannover besuchte ich die Grundschule sowie das Gymnasium, für die Oberstufe wechselte ich vom Kurt-Schwitters Gymnasium Misburg an die Sophienschule Hannover, wo ich im Mai 2011 mein Abitur erwarb. Mein Medizinstudium begann ich im Oktober 2011 an der Georg-August-Universität Göttingen, wo ich 2013 mein Physikum ablegte. Es folgten Famulaturen, unter anderem in den Fachbereichen der Inneren Medizin, Pathologie und Dermatologie. Im Herbst 2017 absolvierte ich das Zweite Staatsexamen. Im anschließenden Praktischen Jahr (PJ) verbrachte ich das erste Tertial am Hawkes Bay Hospital in Hastings/Neuseeland, das zweite Tertial in der Abteilung Dermatologie der Universität Göttingen sowie das dritte Tertial an der Universitätsklinik Köln in der Abteilung für Chirurgie. Im Winter 2018 schloss ich mein Medizinstudium mit dem Dritten Staatsexamen erfolgreich ab.

Seit April 2019 arbeite ich als Assistenzarzt in der Abteilung für Pathologie an der Universitätsklinik Köln.

Im Rahmen meiner Promotion wurde ich vom April bis Oktober 2014 in meinem Freisemester finanziell von der Abteilung Dermatologie gefördert. Experimentelle Arbeiten erfolgten bis einschließlich Juli 2018. Im September 2015 erfolgte die Aufnahme in die Studienstiftung des deutschen Volkes durch Professorenvorschlag des Direktors der Abteilung Dermatologie, Prof. Dr. Michael Schön.

\section{Publikationen:}

Saleh MM, Forkel S, Schön MP, Fuchs T, Buhl T (2019): Profile Shift in Latex Sensitization over the last 20 Years. Int Arch Allergy and Immunol 178, 83-88

Buhl T, Saleh MM, Schön MP (2017): More tolerance for dendritic cells in psoriasis. Exp Dermatol 26, 335-337 